AUTARQUIA ASSOCIADA À UNIVERSIDADE DE SÃO PAULO

Estudo da influência de impurezas e da qualidade das superfícies em cristais de brometo de tálio para aplicação como um detector de radiação

Robinson Alves dos Santos

Tese apresentada como parte dos requisitos para obtenção do Grau de Doutor em Ciências na Área de Tecnologia Nuclear - Aplicações

Orientadora:

Profa. Dra. Margarida Mizue Hamada

Coorientador:

Prof. Dr. Carlos Henrique de Mesquita 


\section{INSTITUTO DE PESQUISAS ENERGÉTICAS E NUCLEARES}

Autarquia associada à Universidade de São Paulo

Estudo da influência de impurezas e da qualidade das superfícies em cristais de brometo de tálio para aplicação como um detector de radiação

Robinson Alves dos Santos

Tese apresentada como parte dos
requisitos para obtenção do Grau de
$\begin{aligned} & \text { Doutor em Ciências na Área } \\ & \text { de Tecnologia Nuclear - Aplicações }\end{aligned}$

Orientadora:

Profa. Dra. Margarida Mizue Hamada

Coorientador:

Prof. Dr. Carlos Henrique de Mesquita

Versão Corrigida

Versão Original disponível no IPEN

São Paulo

2016 
A S.S. Jayapataka Svami e a memória de

Francisco Alves dos Santos Filho 


\section{AGRADECIMENTOS}

À Dra. Margarida Mizue Hamada pelo grande apoio, amizade e orientação constantes e muito valiosas, bem como pelo exemplo de pessoa e de profissional da ciência.

Ao Dr. Carlos Henrique de Mesquita pelo auxilio com a análise compartimental, pelo grande apoio, incentivo e ótimas discussões.

Ao Dr. Fábio Eduardo da Costa pelas discussões, pelo auxílio nas montagens eletrônicas, caracterização dos cristais e ótimas explicações.

A Dra. Roseli F. Gennari, do Laboratório de Cristais Iônicos, Filmes e Datação do Instituto de Física da Universidade de São Paulo.

Ao Dr. Nelson Batista de Lima, do Centro de Ciências e Tecnologia dos Materiais do Instituto de Pesquisas Energéticas e Nucleares (CCTM / IPEN - SP).

Ao Centro de Tecnologia das Radiações do Instituto de Pesquisas Energéticas e Nucleares pela infra-estrutura cedida, fundamental para a realização deste trabalho.

A Comissão Nacional de Energia Nuclear pela projeção e intercâmbio acadêmico e científico que me foram proporcionados e pelo apoio financeiro.

A Neusa de Melo Santos, Keile Alves dos Santos, Ariane Alves dos Santos, Suniti Devi Dasi, Lucy Rigonato e Dorival Francisco Adame pelo apoio e ensinamentos.

Aos meus amigos Fabio Paiva, João Santana, João Trencher, Diego Vergaças, Felipe Felix, Andre Luiz Silva, Prema Avatara Das, Adbhuta-Nrsimha Hari Das, Keshava Kasmiri Das, Douglas Aceiro, Marcos Carmelo, Ailton Silva, Marcelo Cleto, Renan Francisco, Alicio Francisco, José Carlos dos Santos e todos meus colegas do IPEN pela amizade inspiradora. 
"Conhecimento verdadeiro significa conhecer a matéria, o espírito e o controlador de ambos".

A.C.B.S. Prabhupada

"Pense como um homem de ação e aja como um homem de pensamento". Henri Poincaré 


\title{
ESTUDO DA INFLUÊNCIA DE IMPUREZAS E DA QUALIDADE DAS SUPERFÍCIES EM CRISTAIS DE BROMETO DE TÁLIO PARA APLICAÇÃO COMO UM DETECTOR DE RADIAÇÃO
}

\author{
Robinson Alves dos Santos
}

\begin{abstract}
RESUMO
Neste trabalho, cristais de $\mathrm{TIBr}$ foram crescidos e purificados pelo método de Bridgman Repetido, a partir de sais comerciais de $\mathrm{TIBr}$, e caracterizados para serem usados como detectores de radiação à temperatura ambiente. Para avaliar a eficiência de purificação, estudos da diminuição da concentração de impurezas foram feitos após cada crescimento, analisando as impurezas traço por Espectrometria de Massas com Plasma (ICP-MS). Um decréscimo significativo da concentração de impurezas em função do número de purificações foi observado. Os cristais crescidos apresentaram boa qualidade cristalina de acordo com os resultados de análise por Difração de Raios $X(D R X)$, boa qualidade morfológica e estequiometria adequada de acordo com os resultados de análise por MEV(SE) e MEV(EDS). Um modelo matemático definido por equações diferenciais foi desenvolvido para avaliar as concentrações de impurezas no cristal de $\mathrm{TIBr}$ e suas segregações em função do número de crescimentos pelo método de Bridgman. Este modelo pode ser usado para calcular o coeficiente de migração das impurezas e mostrou ser útil para prever o número necessário de repetições de crescimento Bridgman para atingir nível de pureza adequado para assegurar a qualidade do cristal como detector de radiação. Os coeficientes se segregação obtidos são parâmetros importantes para análise microestrutural e análise de transporte de cargas nos cristais detectores. Para avaliar os cristais a serem usados como detectores de radiação, medidas de suas resistividades e resposta à incidência de radiação gama das fontes de ${ }^{241} \mathrm{Am}(59,5 \mathrm{keV})$ e ${ }^{133} \mathrm{Ba}(81 \mathrm{keV})$ foram realizadas. Essa resposta foi dependente da pureza do cristal. Os detectores apresentaram um avanço significativo na eficiência de coleta de cargas em função da pureza.
\end{abstract}




\title{
STUDY ON IMPURITIES INFLUENCE AND QUALITY OF SURFACES OF THALLIUM BROMIDE CRYSTALS FOR USE AS A RADIATION DETECTOR
}

\author{
Robinson Alves dos Santos
}

\begin{abstract}
In this work, $\mathrm{TIBr}$ crystals have been purified and grown by the Repeated Bridgman method from commercial $\mathrm{TIBr}$ materials and characterized to be used as radiation detectors, at room temperature. To evaluate the purification efficiency, studies on the impurity concentration decrease were performed after each growth, analysing the trace impurities by inductively coupled plasma mass.A mathematical model defined by differential equations was developed to evaluate the concentrations of impurities in $\mathrm{TIBr}$ crystal and their segregations along this crystalin function of the purification number.This model may be used to calculate the coefficient of impurities migration and it showed to be useful for predicting the number of purification stagesnecessary to achieve the suitable level for ensuring the crystal quality as a radiation detector.The segregation coefficients obtained are important parameters for the analysis of the microstructure and charge transport in detector semiconductor crystals. The grown crystals presented good crystalline quality according to the results of the x-ray diffraction analysis (XRD), good morphological quality and proper stoichiometry, in accordance with the results of SEM (SE) and SEM (EDS) analyses. To evaluate the crystals to be used as radiation detectors, measurements of resistivity and their response to the incidence of ${ }^{241} \mathrm{Am}(59.5 \mathrm{keV})$ and ${ }^{133} \mathrm{Ba}(81 \mathrm{keV})$ gamma radiation sources were performed. The quality of the response was dependent on the purity of the crystal. A significant improvement in the charge collection efficiency, in function of the crystal purity, was found.
\end{abstract}




\section{SUMÁRIO}

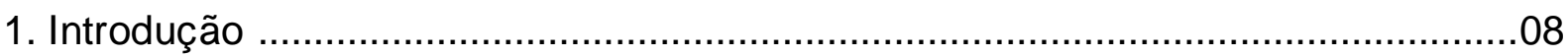

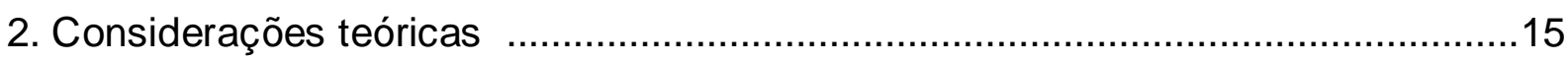

2.1. Interações da radiação eletromagnética com a matéria ....................................15

2.1.1. Efeito fotoelétrico .............................................................................. 16

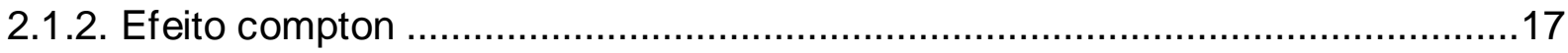

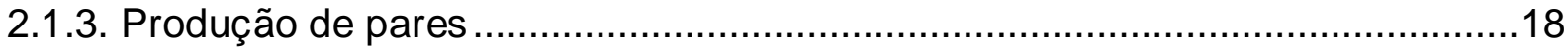

2.2. Propriedades de detectores semicondutores ..............................................19

2.3. Cristais utilizados como detectores semicondutores de radiação ......................22

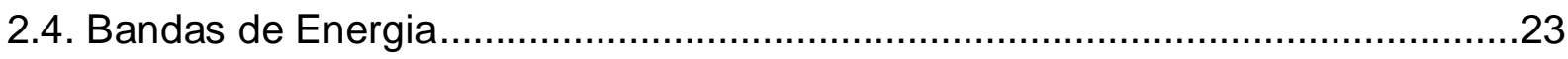

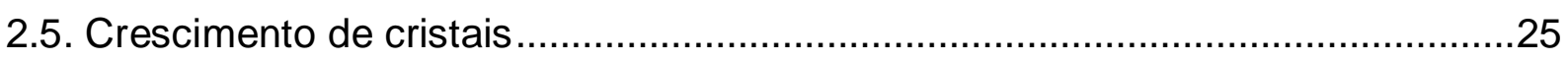

2.6. Purificação e crescimento de cristais pelo método de Bridgman .........................26

2.7. Métodos de caracterização física e química de materiais cristalinos ..................28

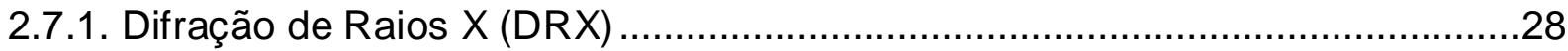

2.7.2. Espectrometria de massas com plasma (ICP-MS) .......................................30

2.7.3. Microscopia eletrônica de varredura (MEV) ...............................................32

2.8. Formulação de modelos matemáticos e análise compartimental ......................33

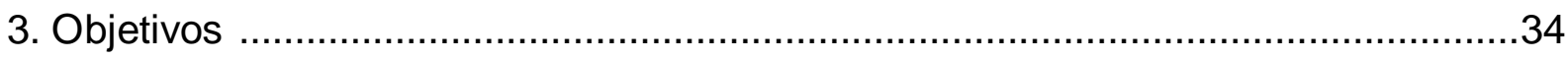

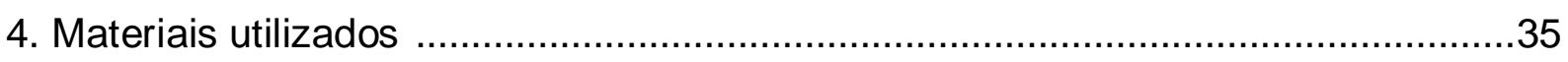

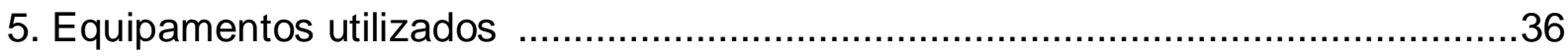

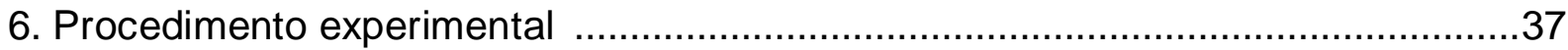

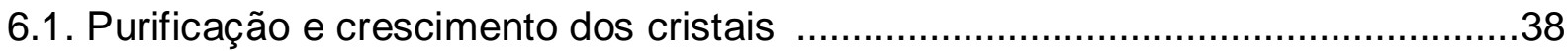

6.1.1. Levantamento do perfil térmico do forno utilizado no método de Bridgman ...38

6.1.2. Confecção dos cadinhos utilizados para o crescimento dos cristais a partir de

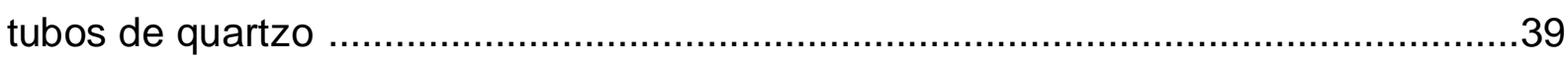

6.1.3.Tratamento químico e desgaseificação dos cadinhos de quartzo e do sal de $\mathrm{TIBr}$

6.1.4. Crescimento de cristais de TIBr pelo método de Bridgman e purificação por

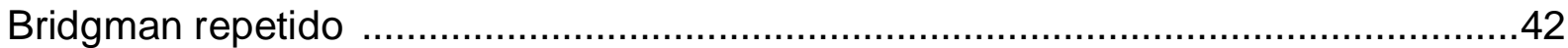

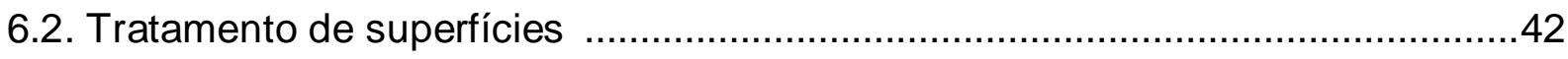

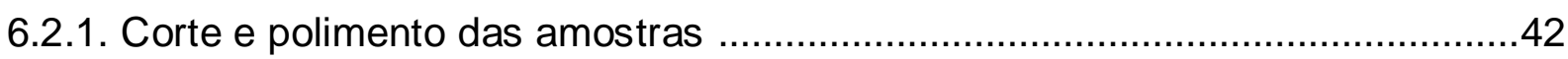

6.2.2. Deposição de recobrimento metálico e aplicação dos contatos elétricos ......43 
6.3. Caracterização física e química e de detecção à radiação dos cristais de $\mathrm{TIBr} 44$ 6.3.1. Análise da estrutura cristalina: difração de Raios X (DRX) ............................44

6.3.2. Análise morfológica e verificação estequiométrica: MEV-SE e MEV-EDS .....45

6.3.3. Preparação das amostras de TIBr para análise química das impurezas e do modelo compartimental .............................................................................. 48

6.3.4. Análise quantitativa das impurezas presentes por ICP-MS …………….....49

6.3.5. Análise de segregação de impurezas presentes (modelo compartimental) ....50

6.3.6. Caracterização do cristal semicondutor de $\mathrm{TIBr}$ como detector de radiação a

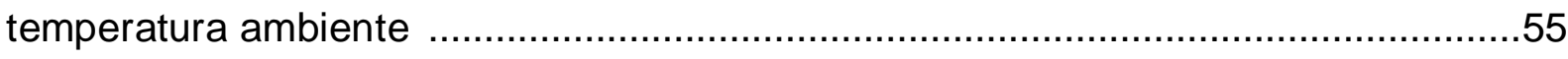

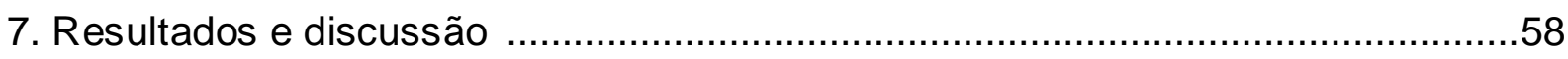

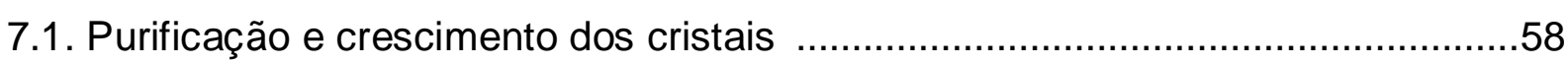

7.1.1. Levantamento do perfil térmico do forno utilizado no método de Bridgman ....58

7.1.2. Tratamento químico e desgaseificação dos cadinhos e do sal de $\mathrm{TIBr}$..........59

7.1.3. Crescimento de cristais de $\mathrm{TIBr}$ pelo método de Bridgman repetidas vezes

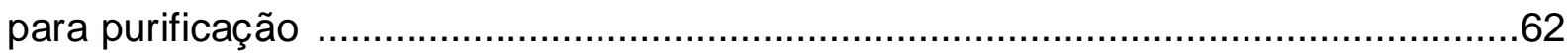

7.2. Tratamento de superfícies .....................................................................63

7.2.1. Corte dos cristais de $\mathrm{TIBr}$ e polimento das amostras ....................................63

7.3. Caracterização física e química e de detecção à radiação dos cristais .............64

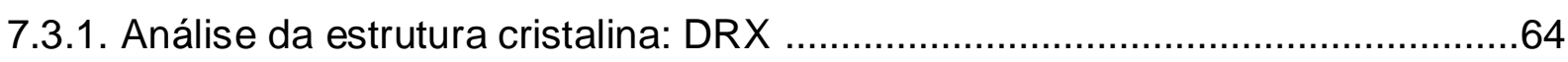

7.3.2. Análise morfológica e verificação estequiométrica: MEV(SE) e MEV(EDS) ...67

7.3.3. Análise quantitativa das impurezas presentes por ICP-MS ..........................71

7.3.4. Análise de segregação das impurezas presentes (modelo compartimental) ..72

7.3.5. Caracterização do cristal semicondutor de $\mathrm{TIBr}$ como detector de radiação à

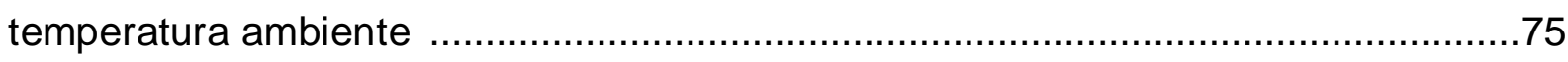

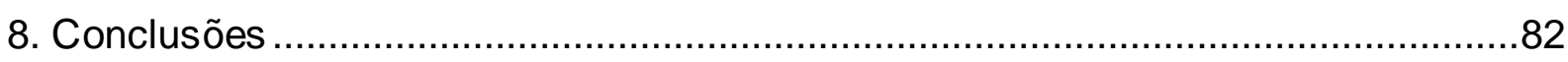

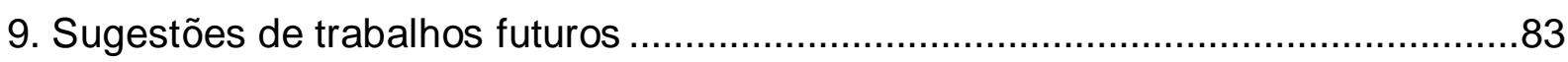

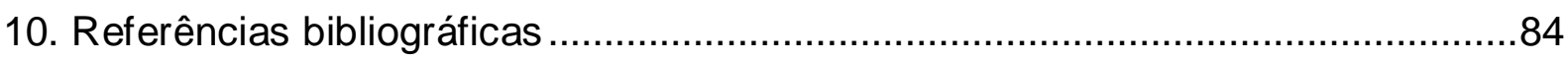




\section{INTRODUÇÃO}

A grande maioria dos detectores semicondutores de radiação em frequente uso é fabricada a partir de matrizes de silício (Si) e germânio (Ge). A popularidade destes materiais é atribuída à excelente propriedade de transporte de carga, a qual permite o uso de cristais com espessuras de até $10 \mathrm{~mm}$, sem excessiva perda de portadores de carga devido ao armadilhamento ou recombinação das cargas produzidas [1,2]. Na última década, além do $\mathrm{Si}$ e $\mathrm{Ge}$, foi disponibilizado comercialmente o cristal de telureto de cádmio (CdTe) como detector de radiação. Destes materiais somente o $\mathrm{Si}$ e $\mathrm{CdT}$ e podem ser usados à temperatura ambiente. O Si é um material semicondutor frequentemente usado para medidas de raios- $X$ de baixa energia e partículas ionizantes. No entanto, quando são necessárias medidas espectrométricas de alta resolução, o material adequado é o Ge, mas este apresenta o inconveniente de requerer refrigeração para reduzir a corrente de fuga gerada termicamente $[1,2]$. Normalmente $\circ$ nitrogênio líquido é utilizado para essa finalidade. Em aplicações de baixo ruído, como espectroscopia de raios- $\mathrm{X}$, o detector de Si também deve ser refrigerado pela mesma razão. Atualmente, para aplicações onde é desejada operação à temperatura ambiente e reduzidas dimensões (até $5 \mathrm{~mm}^{3}$ ) é utilizado o CdTe. No entanto, o efeito de polarização é observado neste detector, no decorrer do tempo. Apesar das excelentes propriedades do Si e Ge, é observado na literatura um considerável interesse no desenvolvimento de outros materiais que apresentem a vantagem de não operar sob refrigeração, tais como: arseneto de gálio (GaAs), iodeto de mercúrio $\left(\mathrm{Hgl}_{2}\right)$, iodeto de chumbo $\left(\mathrm{Pbl}_{2}\right)$, telureto de cádmio e zinco ( $\mathrm{CdZnTe})$, lodeto de bismuto $\left(\mathrm{Bil}_{3}\right)$ e brometo de tálio $(\mathrm{TIBr})$, para utilização como detectores de radiação[1,3-8].

Em princípio, um material semicondutor com larga energia de banda proibida (acima de 1,35 eV) apresenta um valor de corrente de fuga baixo, suficiente para operar à temperatura ambiente [1], que somada a outras características pode viabilizar o material como um detector de radiação semicondutor à temperatura ambiente. O conjunto de propriedades requerido para atuar como um detector semicondutor para raios-X e gama e operar à temperatura ambiente é composto de: (a) elevado número atômico [Z], (b) larga energia de banda proibida [Eg]: entre 1,35 
e 2,7eV e (c) alto produto de mobilidade dos portadores por tempo de vida [ $\mu$ T], com o intuito de obter uma completa coleção de cargas, indispensável para boa resolução energética [1-4].

O fator comum aos materiais semicondutores, que operam à temperatura ambiente, é a dificuldade em crescer cristais com alta perfeição cristalográfica, tendo alta pureza química e estequiometria adequadas. Estes requisitos básicos devem ser satisfeitos em vários estágios na fabricação do detector. Esse processo envolve a escolha e confecção adequada dos cadinhos, purificação dos materiais de partida, crescimento do cristal, fabricação do detector, deposição dos eletrodos, montagem sobre um substrato rígido, possível encapsulamento e seu acoplamento a uma eletrônica associada. Cada uma dessas etapas podem introduzir defeitos diversos que podem deteriorar a resposta do detector à radiação incidente [1-4,6].

Os compostos semicondutores com alto número atômico e larga energia de banda proibida, como $\mathrm{CdTe}, \mathrm{CdZnTe}, \mathrm{Hgl}_{2}, \mathrm{Pbl}_{2}$ e $\mathrm{TIBr}$ vêm sendo pesquisados como detectores de radiação gama, encontrando-se em diferentes estágios de desenvolvimento para alcançar boas resoluções em energia à temperatura ambiente. Destes, o brometo de tálio ( $\mathrm{TIBr}$ ) vem sendo estudado, em particular, por apresentar características superiores ou comparáveis a esses semicondutores, apresentando potencialidade para confecção de detectores de radiação ionizante $[1,3-9]$.

$\mathrm{O} \mathrm{TIBr}$ tem um número atômico médio alto $(\mathrm{ZTI}=81$ e $\mathrm{ZBr}=35)$, densidade alta $\left(7,5 \mathrm{~g} / \mathrm{cm}^{3}\right)$, resistividade alta $\left(10^{12} \Omega \mathrm{cm}\right)$ e energia de banda proibida de 2,7 eV. Cristaliza em uma estrutura cúbica simples, apresentando parâmetro de rede de $3,97 \AA$, microdureza Knoop de $1,18.10^{-4} \mathrm{kgf} . \mathrm{m}^{-4}$ e funde à $480^{\circ} \mathrm{C}$. A larga energia da banda proibida tem permitido que detectores de $\mathrm{TIBr}$ operem em temperatura ambiente com baixa corrente de fuga [7,9] e baixo ruído eletrônico [4,6,7,9] apresentando considerável resolução para Raios -X e gama.

Uma das desvantagens do $\mathrm{TIBr}$ é a baixa mobilidade de seus portadores de carga, $6 \mathrm{~cm}^{2} / \mathrm{Vs}$ para elétrons e $2 \mathrm{~cm}^{2} / \mathrm{Vs}$ para lacunas [4,6,9]. Entretanto, o 
transporte de cargas é regido pelo produto da mobilidade pelo tempo de armadilhamento $(\mu \mathrm{T})$, podendo ser suficientemente grande para materiais de alta pureza e perfeição cristalina $[4,7,9,11,12]$. Isto pode ser alcançado com prévia purificação dos sais por refinamento zonal antes do crescimento dos cristais, bem como pelo método de Bridgman repetido para os cristais já crescidos $[5,7,9,10,13,18$ 20].

O desempenho e a utilização de compostos semicondutores para aplicação como detectores de radiação são geralmente limitados pela qualidade do material usado para a fabricação destes detectores. Em particular, a alta concentração de níveis profundos de armadilhas dos portadores de carga é a mais frequente causa da baixa eficiência em materiais semicondutores com energia de banda proibida larga. As armadilhas para elétrons e lacunas provêm de duas origens: impurezas extrínsecas e defeitos na estrutura cristalina [3,4,6,12,23,24].

$\mathrm{Na}$ literatura observa-se um crescente interesse no desenvolvimento de detectores de radiação de $\operatorname{TIBr}[1,2,3,7,9,13-23]$. As dificuldades relacionadas com a purificação, o crescimento e a caracterização destes cristais são ainda objeto de estudo em diversos centros de pesquisa.

Uma apresentação sucinta sobre os trabalhos realizados até a atualidade sobre os cristais de $\mathrm{TIBr}$ referente à sua purificação, crescimento, caracterização e sua aplicação na área nuclear é descrita a seguir.

O $\mathrm{TIBr}$ foi citado pela primeira vez, como um promissor material para ser aplicado como detector de radiação, por Hofstadter [25] em 1947. Nesse trabalho, a pureza do material foi apontada como um possível fator limitante para o desempenho do detector. No entanto, desde esta descoberta até o final de década de 1980, os trabalhos encontrados na literatura sobre $\mathrm{TIBr}$ eram referentes às suas características físico-químicas, térmicas e cristalinas. Nenhum trabalho prioritariamente focado sobre sua aplicação e desempenho como detector radiação foi encontrado até esta data. 
Em 1965 Lefkowitz e col. [26] fizeram um estudo comparativo dos espectros de absorção do $\mathrm{TIBr}$ e do $\mathrm{TICl}$ (cloreto de tálio) a temperaturas de $-196^{\circ} \mathrm{C}$ e -269º $\mathrm{C}$. Foram atingidos avanços significativos, sobretudo no estudo das propriedades físicas dos cristais, especialmente quanto a estrutura e orientação dos planos cristalinos. Estudos sobre a dependência entre pressão e dilatação térmica do $\mathrm{TIBr}$ entre as temperaturas de $-195^{\circ} \mathrm{C}$ e $400^{\circ} \mathrm{C}$ foram realizados por Garth e col., em 1967 [27]. Overhof e Treusch[28], em 1971, calcularam relativisticamente as bandas de energia do $\mathrm{TIBr}$ ao longo dos planos cristalinos com as orientações (100), (110) e (111). Estes trabalhos foram muito significativos para a caracterização dos cristais de TIBr. Análises feitas por meio de espectrometria de massas possibilitaram o conhecimento de diversos íons formados a partir do $\mathrm{TIBr}$ [29], da energia livre de Gibbs e da pressão de vapor do $\operatorname{TIBr}[30]$.

Somente a partir do final da década de 80 , com o interesse por detectores semicondutores de radiação que operam à temperatura ambiente, foram apresentados estudos sobre preparação e caracterização de cristais de $\mathrm{TIBr}$ aplicados como detector de radiação. Em 1987, Rahman e col. [31] analisaram os espectros de altura de pulso do $\mathrm{TIBr}$ obtidos com partículas alfa do ${ }^{241} \mathrm{Am}$ à temperatura de $-80^{\circ} \mathrm{C}$ e com radiação gama do ${ }^{60} \mathrm{Co}$, do ${ }^{207} \mathrm{Bi}$ e do ${ }^{137} \mathrm{Cs}$, nas temperaturas de $-29^{\circ} \mathrm{C}$ e $0^{\circ} \mathrm{C}$, respectivamente. Os autores apresentaram conclusões referentes apenas aos experimentos realizados a baixa temperatura e é mencionado apenas o valor de resolução FWHM de 20\% (Full Width at Half Maximum - largura à meia altura) obtido a partir das partículas alfa. Os valores obtidos para radiação gama não foram expostos.

Luca e col. [32] pesquisaram os espectros de emissão e absorção de $\mathrm{TIBr}$ em solução alcoólica para diferentes concentrações de sal. Os autores fizeram ensaios para diferentes temperaturas e concluíram que diferentes estequiometrias de $\mathrm{TIBr}$ apresentam solubilidades similares e maiores em álcool, quando comparadas com a água.

Em 1990 K.S. Shah e col. [7] fabricaram cristais de $\mathrm{TIBr}$ por meio da purificação do material de partida por refino zonal em um forno de duas zonas e crescimento do 
cristal pelo método de Bridgman. O número de passos e maiores detalhes do processo de purificação e crescimento não foram revelados neste trabalho. Os cristais detectores obtidos foram irradiados com fontes de ${ }^{55} \mathrm{Fe}$, operando a $60 \mathrm{~V}$, e ${ }^{241} \mathrm{Am}$, operando a $110 \mathrm{~V}$, ambos à temperatura ambiente. $\mathrm{O}$ trabalho sugere que $\mathrm{O}$ melhor desempenho do detector de $\mathrm{TIBr}$ pode ser obtido com maior purificação do mesmo, além de apontar o cristal de $\mathrm{TIBr}$ como um material promissor para a construção de detectores de raios $\mathrm{X}$ e radiação gama.

A partir de 1990, um aumento significativo de estudos sobre diferentes aspectos e características dos cristais de $\mathrm{TIBr}$ para atingir a qualidade requerida para sua atuação como detectores de radiação que operam à temperatura ambiente são encontrados na literatura $[3,4,5-7,10,11,13-15,18,19]$. Dentre eles, podemos destacar alguns trabalhos, como o do Hitomi e col. [33] que utilizaram o método de refino zonal para crescer cristais de $\mathrm{TIBr}$ e conseguiram resolução energética de 29,8 keV (5,8\%) FWHM para fontes de raios gama de $511 \mathrm{keV}$. Sellin [13] destacou o $\mathrm{TIBr}$ como um dos mais promissores materiais a serem pesquisados e utilizados como semicondutores detectores de radiação à temperatura ambiente. Gostilo e col. [34] $\mathrm{ZHOU}$ e col. [35] realizaram um estudo comparativo entre o desempenho de cristais de $\mathrm{TIBr}$ crescidos pelo método de Bridgman e pelo método de refino zonal. Mais recentemente, têm-se observado, na literatura, um aumento significativo de estudos para obtenção de cristais de $\mathrm{TIBr}$ com melhor desempenho como detector de radiação, aprimorando diferentes parâmetros, tais como: eletrônica associada e processamento de sinais, características físico-químicas do cristal [36,37,38], síntese de $\mathrm{TIBr}$ a partir de nitrato de tálio $\left(\mathrm{TINO}_{3}\right)$ e ácido bromídrico $(\mathrm{HBr})$, introdução de dopantes em cristais de $\mathrm{TIBr}$, análise sob refrigeração, técnicas de crescimento, recozimento, distância intermolecular, estresse estrutural, propriedades elétricas [38,39], análise de impurezas [19,40-42]. Adicionalmente, pesquisas sobre a degradação do sinal no decorrer do tempo (polarização), inerente a cristais semicondutores que operam à temperatura ambiente, também, tem aumentado [4347]. Embora tenham sido obtidos resultados expressivos para todos os casos, não foram expostos maiores detalhes sobre como realizar de forma mais eficiente cada uma das etapas de desenvolvimento de detectores semicondutores de $\mathrm{TIBr}$. Estes exemplos destacam a relevância e empenho no desenvolvimento dos detectores de 
$\mathrm{TIBr}$, tanto no Brasil, quanto num panorama internacional. A Figura 1 mostra a quantidade de artigos sobre $\mathrm{TIBr}$ publicados ao longo dos anos [4-7,9-11,13-15,1820,23,24,26-70,82-111].

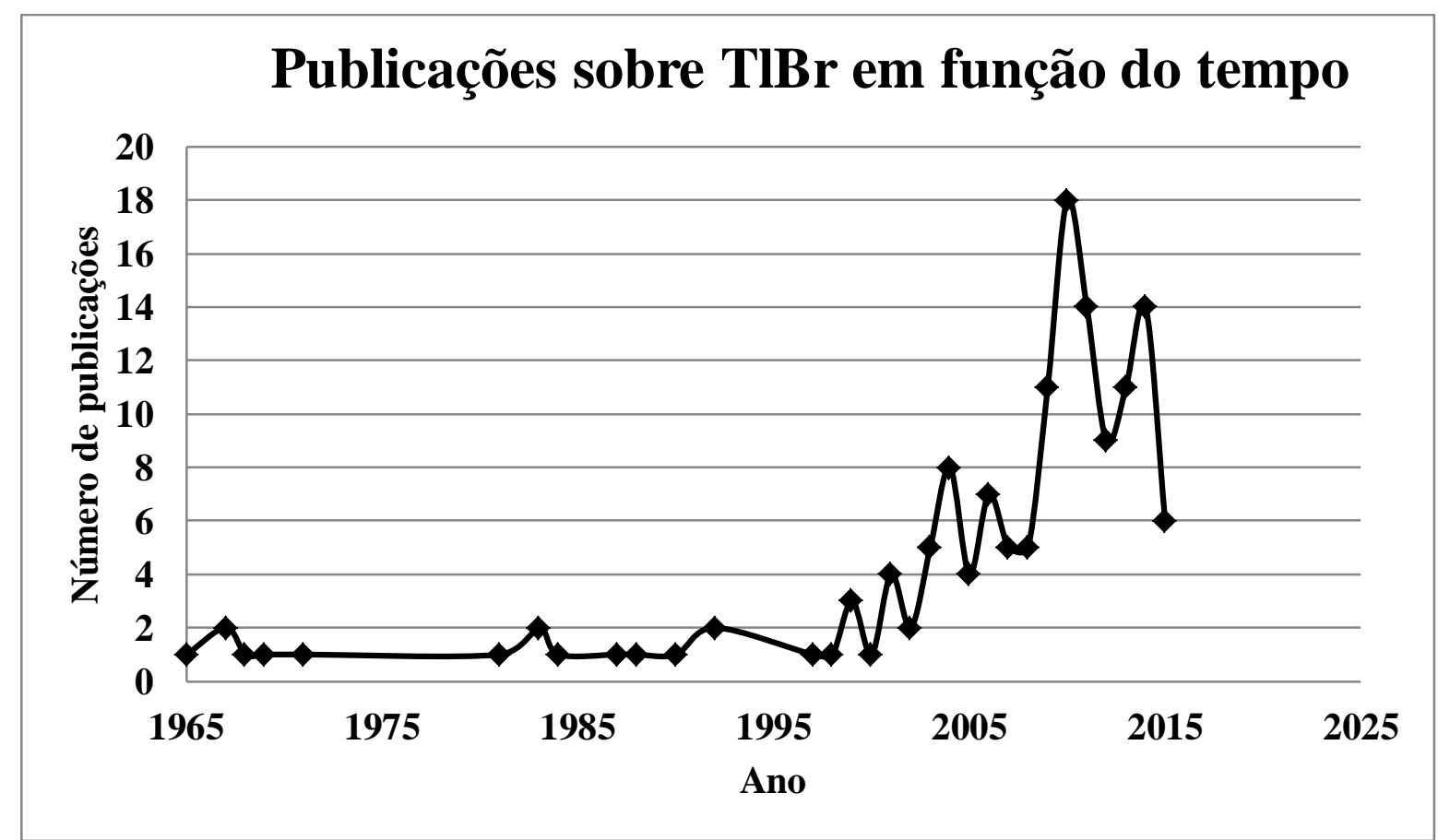

Figura 1: Publicações sobre TIBr em função do tempo.

Apesar das pesquisas com os cristais semicondutores de $\mathrm{TIBr}$ para detecção de radiação à temperatura ambiente ter avançado progressivamente nos últimos anos, a busca pela melhoria na coleção de carga e na estabilidade de longo prazo, ainda deve ser prosseguida. Dessa forma, em 2006 foi realizada uma tese de doutoramento [4] no IPEN/CNEN - CTR cujo objetivo foi desenvolver e caracterizar cristais de $\mathrm{TIBr}$ como detectores de radiação à temperatura ambiente. $\mathrm{O}$ trabalho apresentou uma metodologia detalhada de purificação e crescimento dos cristais por meio da combinação das técnicas de refino zonal e de Bridgman. Os resultados obtidos com a purificação prévia do material pela técnica de refino zonal foram bastante satisfatórios e os cristais crescidos por Bridgman apresentaram boa qualidade cristalina e resposta à radiação. Estes cristais foram utilizados para o desenvolvimento de uma sonda cirúrgica para operações radioguiadas, também chamado de mapeamento linfático intra-operatório com linfadenectomia seletiva, possibilitando a retirada do tumor cancerígeno com mais acurácia e menor morbidade [18,49]. No entanto, embora os cristais de $\mathrm{TIBr}$ desenvolvidos 
apresentassem características adequadas para aplicações onde não requerem o uso contínuo de operação do detector como a sonda cirúrgica, uma progressiva degradação dos detectores foi observada devido ao efeito de polarização [4] ao longo do tempo. O efeito é uma redução na eficiência de coleta de cargas devido ao armadilhamento de cargas na estrutura interna do cristal que produzem um campo elétrico contrário ao sentido desejado de coleta das cargas. É observado na literatura um grande esforço para compreensão deste efeito com o intuito de alcançar estabilidade a longo prazo para os detectores que operam à temperatura ambiente [18,46-49,54,58,60]. Contudo, o efeito de polarização em detectores que operam à temperatura ambiente e consequente falta de estabilidade continua sendo um grande desafio. No presente trabalho a metodologia de preparação e análise dos cristais semicondutores de $\mathrm{TIBr}$ foi otimizada para melhorar a estabilidade do cristal detector de $\mathrm{TIBr}$. Nesse sentido, os processos de purificação e análise de segregação de impurezas dos cristais têm sido fundamentais para avaliar os parâmetros que influenciam suas qualidades como detectores de radiação que operam à temperatura ambiente e sua estabilidade ao longo do tempo. 


\section{CONSIDERAÇÕES TEÓRICAS}

\subsection{INTERAÇÕES DA RADIAÇÃO ELETROMAGNÉTICA COM A MATÉRIA}

As radiações eletromagnéticas podem penetrar grandes espessuras de determinados materiais, antes de perderem parte de sua energia pelas interações com os átomos de tais materiais. A capacidade de penetração da radiação em determinado meio depende de sua energia inicial de incidência, bem como da probabilidade de interação, associada à seção de choque (área, em barn, b, sendo $1 b=10^{-28} \mathrm{~m}^{2}$ ) que $\mathrm{o}$ meio oferece para espalhamento ou absorção da radiação incidente $[2,6,71]$.

As três principais formas de interação da radiação eletromagnética com um meio material são: efeito fotoelétrico, efeito Compton e produção de pares. A Figura 2 apresenta as regiões de predominância de ocorrência dos efeitos de interação da radiação em função da energia do fóton incidente (hv) e do número atômico (Z) do material absorvedor.

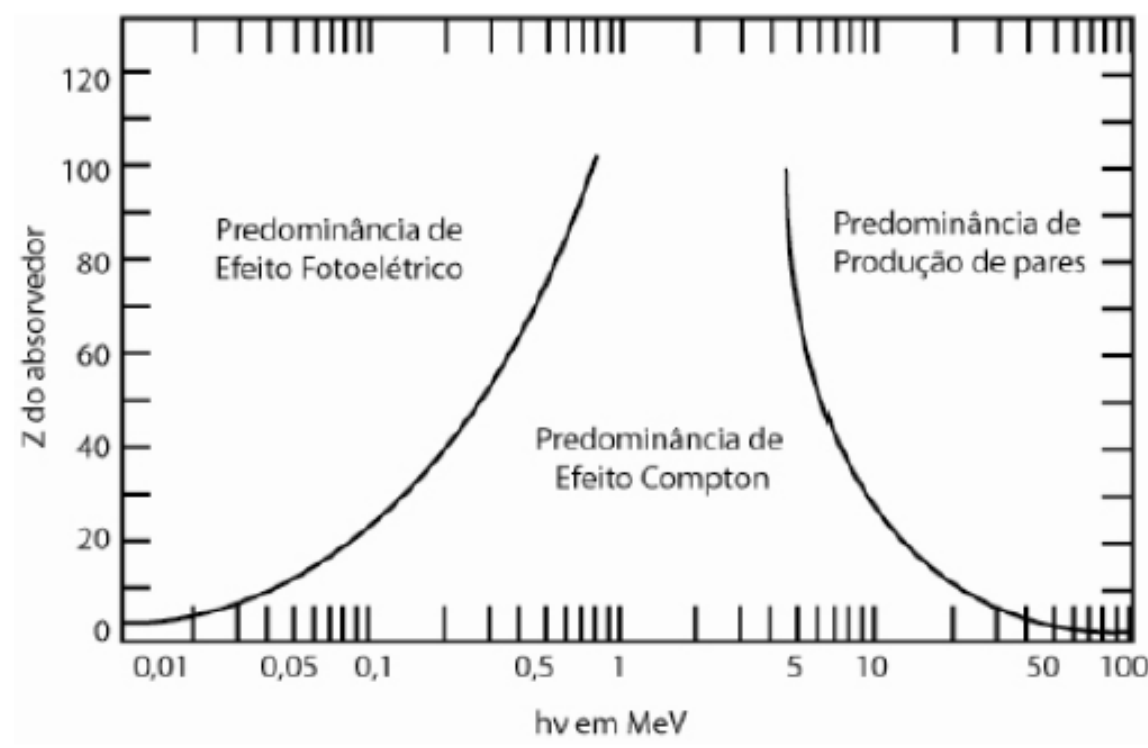

Figura 2: Regiões de predominância de ocorrência dos efeitos de interação da radiação em função da energia do fóton incidente (hv) e do número atômico (Z) do material absorvedor [2]. 
A probabilidade de interação da radiação eletromagnética (fótons de raios- $X$ ou gama) com um determinado material detector, é função do número atômico $Z$ em suas respectivas faixas de energias, com as seguintes dependências aproximadas [2]:

a) $Z^{\mathrm{n}}(4<\mathrm{n}<5)$ para ocorrer efeito fotoelétrico;

b) Z para ocorrer espalhamento Compton;

c) $Z^{2}$ para produção de pares

\subsubsection{EFEITO FOTOELÉTRICO}

Efeito Fotoelétrico consiste no fenômeno em que um fóton de energia igual a h.v (produto entre a constante de Planck e a frequência da radiação) interage com um átomo de determinado material, transferindo toda sua energia a um dos elétrons das órbitas mais internas do mesmo, como mostrado na Figura 3. Se a energia do fóton incidente for maior que a energia de ligação $E l$ dos elétrons da camada mais interna do átomo, o fóton desaparece e o átomo emite um fotoelétron (na maior parte das vezes da camada $\mathrm{K}$ ) com energia cinética $E_{c}$, que é a diferença entre a energia do fóton incidente (h.v) e a energia de ligação do elétron a sua órbita de origem (El):

$$
E_{c}(e V)=h . v-E l(1)
$$

As lacunas criadas pela emissão do fotoelétron fazem com que as camadas eletrônicas do átomo se recomponham, causando emissão de raios- $X$ característicos. O fotoelétron emitido, por apresentar baixa energia, é rapidamente reabsorvido, causando emissão de raios- $X$ característicos, que originam outro efeito fotoelétrico em outro átomo. Tem-se, assim, uma cadeia de criação de pares elétron - lacuna que é diretamente proporcional a energia do fóton incidente [2,6,72,73]. 


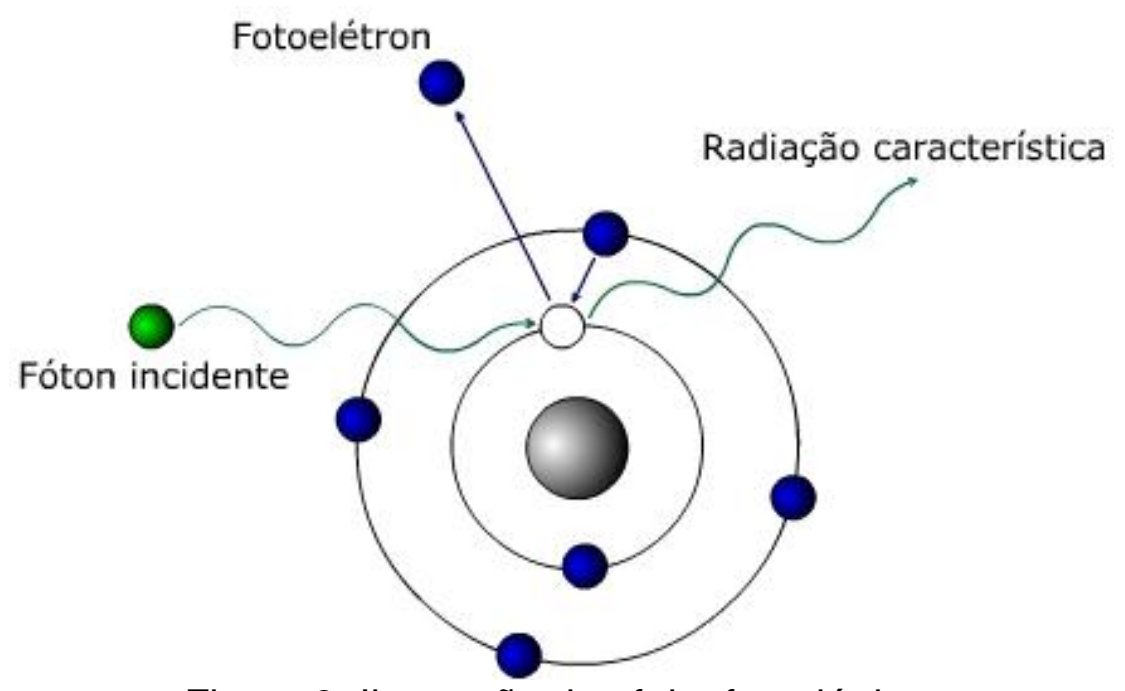

Figura 3: llustração do efeito fotoelétrico.

\subsubsection{EFEITO COMPTON}

Efeito Compton consiste na interação de um fóton com um elétron da camada mais externa dos átomos de determinado material na qual ocorre colisão entre um fóton e um destes elétrons. Em tal colisão, o elétron absorve parte da energia do fóton, que passa a ter uma frequência menor em relação à anterior e, assim, um comprimento de onda maior em relação ao anterior. O elétron é arrancado da estrutura atômica sob um ângulo $\theta$ e o fóton incidente é espalhado em uma direção distinta da direção de incidência, como mostrado na Figura 4 [2,6,72].

Partindo-se das conservações da quantidade de movimento e de energia, chega-se a equação do espalhamento de Compton ${ }^{(2,6)}$.

$$
\begin{aligned}
\lambda_{2} & =\frac{h}{m_{e} c}(1-\cos \theta)+\lambda_{1} \\
h v_{2} & =\frac{h v_{1}}{1+\frac{h v_{1}}{m_{e} c^{2}}(1-\cos \theta)}
\end{aligned}
$$


onde:

$\lambda_{1}$ é o comprimento de onda do fóton antes do espalhamento;

$\lambda_{2}$ é o comprimento de onda do fóton depois do espalhamento;

$m_{e}$ é a massa de repouso do elétron;

$h /\left(m_{e} . c\right)$ é o comprimento de onda de Compton;

$\Theta$ é o ângulo de saída do fóton;

h é a constante de Planck;

c é a velocidade da luz no vácuo;

$h v_{2}$ é a energia do fóton espalhado;

$h v_{1}$ é a energia do fóton incidente;

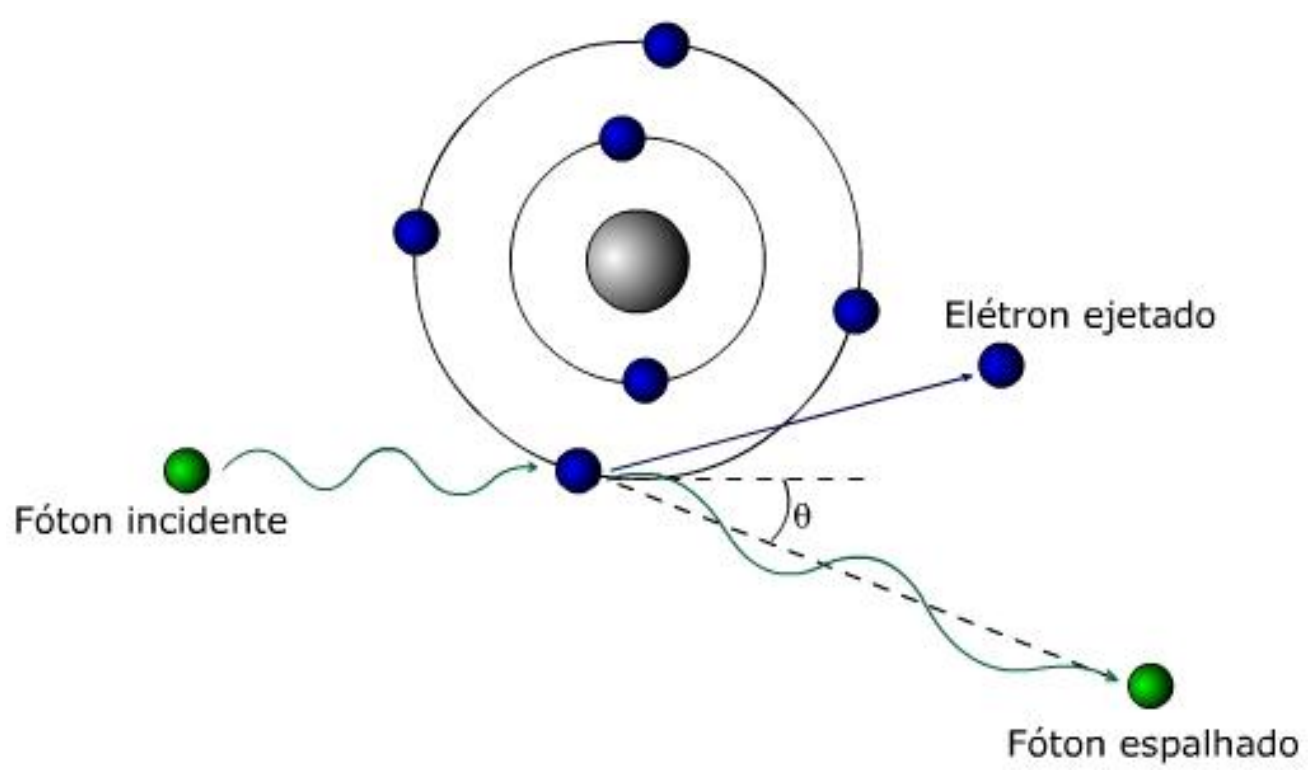

Figura 4: Ilustração do efeito Compton.

\subsubsection{PRODUÇÃO DE PARES}

Produção de pares consiste no fenômeno em que um fóton (radiação eletromagnética) interage com o campo coulombiano próximo do núcleo atômico e desaparece, dando origem a um par elétron-pósitron. A energia mínima necessária para se produzir um elétron (e-) e um pósitron (e+) é fornecida conforme a relação relativística entre massa e energia dada pela seguinte equação [2,6,72]:

$$
E=2 \cdot m_{0} \cdot c^{2}(4)
$$


na qual $m_{o}$ é a massa de repouso do elétron e $c$ é a velocidade da luz no vácuo.

Isso corresponde a um fóton incidente com energia mínima de 1,02MeV [2,6].

O pósitron transmite sua energia cinética aos átomos do meio e em seguida volta a se combinar com um elétron, originando dois fótons, cada um com energia de 0,511MeV. A Figura 5 ilustra o processo de produção de pares.

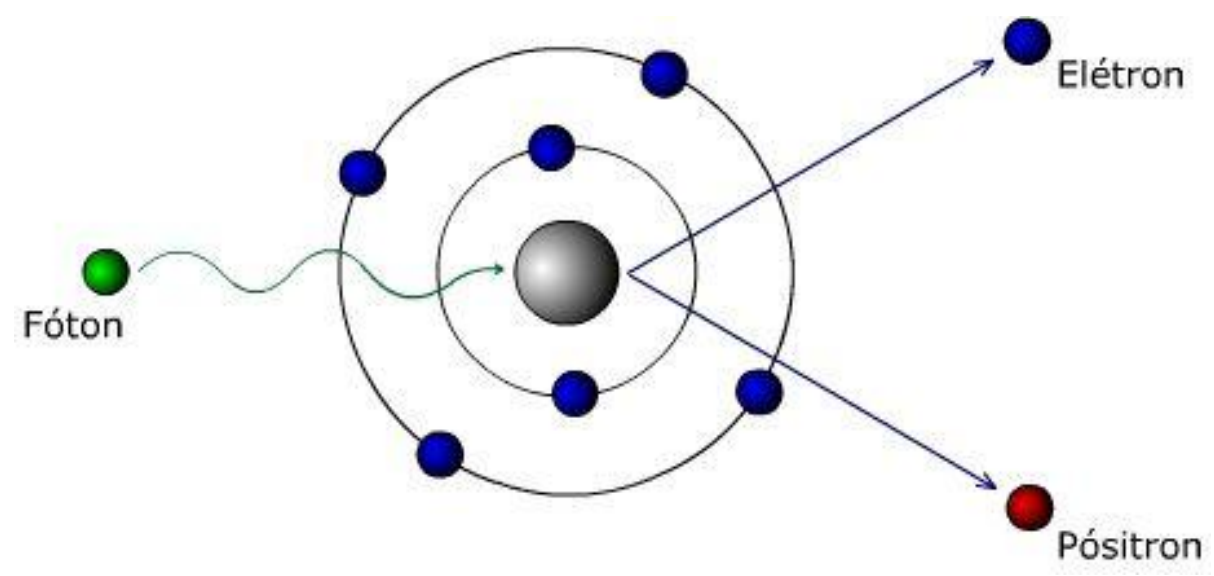

Figura 5: Ilustração do processo de produção de pares

\subsection{PROPRIEDADES DE DETECTORES SEMICONDUTORES}

Detectores de radiação são materiais capazes de indicar a presença de determinada radiação quando expostos a ela [2,6]. A partir de tal evento, têm-se diversos processos que podem evidenciar a radiação incidente, tais como produção de luz, produção de cargas elétricas, geração de calor, geração de traços no material, entre outros. Um detector é constituído de um material sensível à radiação e um sistema associado que transforme determinadas grandezas da radiação incidente em valores mensuráveis a serem analisados para diversas finalidades $[2,6,72]$. 
O funcionamento de materiais detectores semicondutores é regido pelo princípio de excitação dos elétrons, que passam da banda de valência para a banda de condução de tais materiais. Isso permite a coleção destes elétrons e a realização de análises quantitativas relacionadas a radiação incidente causadora da excitação $[2,4,6,19]$.

O grande interesse no uso de detectores semicondutores deve-se a propriedades superiores em comparação aos detectores cintiladores e gasosos, tais como:

a) elevado número atômico [Z], o que possibilita um aumento da probabilidade de interação da radiação, contribuindo para uma melhor resolução energética;

b) a quantidade de energia necessária para produzir um par elétron-lacuna nos semicondutores é de aproximadamente 3,5 eV; nos detectores gasosos é de $30 \mathrm{eV}$ e nos cintiladores é de $350 \mathrm{eV}$. Portanto, o número de portadores de carga gerados em um material semicondutor mediante perda da radiação incidente é muito superior. Isso contribui para uma melhor resolução energética $[2,4,6,19]$;

c) o pulso de saída nos detectores semicondutores é diretamente proporcional à quantidade de pares elétron - lacuna produzidos. Assim, esses detectores fornecem um pulso proporcional à energia do fóton incidente. Dessa forma, é possível identificar a energia da radiação incidente $[2,4,6,19]$.

O conjunto de propriedades requerido para atuar como um detector semicondutor para raios- $\mathrm{X}$ e gama e operar à temperatura ambiente é composto de:

(a) elevado número atômico (Z) para aumentar a probabilidade de interação;

(b) alto produto de mobilidade dos portadores por tempo de vida $[\mu \mathrm{T}]$, com o intuito de obter uma completa coleção de cargas, indispensável para boa resolução energética [1-4,6];

(c) larga energia de banda proibida (Eg - entre 1,35 e 2,7 eV)[1-6,9,12,13], de modo a minimizar a corrente de fuga gerada termicamente [efeito termoiônico] e maximizar o valor da resistividade. Este parâmetro consiste no principal fator para que o material seja utilizado como detector de radiação à temperatura ambiente, 
pois, nessas condições, deseja-se obter apenas medidas de sinais provenientes de determinada radiação incidente, em detrimento de variações de temperatura.

A Tabela 1 apresenta os principais materiais semicondutores e suas características, que são adequadas para sua aplicação como detectores de radiação $[1-6,9,12,13]$.

Tabela 1 - Propriedades de alguns semicondutores que operam à temperatura ambiente.

\begin{tabular}{|c|c|c|c|c|c|c|c|}
\hline Material & $\begin{array}{c}Z \\
\text { Médio }\end{array}$ & $\begin{array}{c}\text { Densidade } \\
\left(\mathrm{g} / \mathrm{cm}^{3}\right)\end{array}$ & $\begin{array}{c}\text { Energia } \\
\text { Banda } \\
\text { Proibida } \\
(\mathrm{e} V)\end{array}$ & $\begin{array}{c}\text { Mobilidade } \\
\text { de elétrons } e \\
\text { lacunas } \\
\left(\mathrm{cm}^{2} / V . s\right)\end{array}$ & $\begin{array}{c}\text { Resistividade } \\
\quad(\Omega c m)\end{array}$ & $\begin{array}{c}\text { Produto } \\
\mu_{i} \tau \\
\left(\mathrm{cm}^{2} / V\right)\end{array}$ & $\begin{array}{c}\text { Melhor \% } \\
\text { FWHM, } \\
\text { Resolução } \\
\text { à Temp. } \\
\text { Ambiente }\end{array}$ \\
\hline $\mathrm{TlBr}$ & 58 & 7,5 & 2,7 & $\begin{array}{l}\text { e: } 6 \\
\text { 1: } 2\end{array}$ & $10^{12}$ & $\begin{array}{l}\text { e: } 1,3 \times 10^{-5} \\
\text { l: } 1,5 \times 10^{-6}\end{array}$ & $\begin{array}{c}60 \mathrm{keV}: \\
13 \%\end{array}$ \\
\hline $\mathrm{HgI}_{2}$ & 62 & 6,4 & 2,2 & $\begin{array}{l}\text { e: } 100 \\
\text { l: } 4\end{array}$ & $10^{14}$ & $\begin{array}{l}\text { e: } 1 \times 10^{-3} \\
\text { l: } 8 \times 10^{-5}\end{array}$ & $\begin{array}{c}5,9 \mathrm{keV}: \\
5,9 \% \\
60 \mathrm{keV}: \\
2,7 \%\end{array}$ \\
\hline $\mathrm{PbI}_{2}$ & 67 & 6,2 & 2,3 & $\begin{array}{l}\mathrm{e}: 8 \\
\mathrm{l}: 2\end{array}$ & $10^{12}$ & $\begin{array}{l}\text { e: } 8 \times 10^{-6} \\
\text { 1: } 9 \times 10^{-1}\end{array}$ & $\begin{array}{c}5,9 \mathrm{keV}: \\
16 \%\end{array}$ \\
\hline $\mathrm{CdTe}$ & 50 & 6,2 & 1,5 & $\begin{array}{l}\text { e: } 1050 \\
\text { l: } 100\end{array}$ & $10^{9}$ & $\begin{array}{l}\text { e: } 8 \times 10^{-4} \\
\text { 1: } 2 \times 10^{-4}\end{array}$ & $\begin{array}{c}5,9 \mathrm{keV}: \\
19 \% \\
60 \mathrm{keV}: \\
2,9 \%\end{array}$ \\
\hline $\begin{array}{l}\mathrm{Cd}_{1-\mathrm{x}} \\
\mathrm{Zn}_{\mathrm{x}} \mathrm{Te}\end{array}$ & $41-50$ & $5,7-6,2$ & $1,6-2,4$ & $\begin{array}{l}\text { e: } 1120 \\
\text { l: } 200\end{array}$ & $10^{11}$ & $\begin{array}{l}\text { e: } 1 \times 10^{-5} \\
\text { 1: } 1 \times 10^{-6}\end{array}$ & $\begin{array}{c}30 \mathrm{keV}: \\
8,4 \% \\
122 \mathrm{keV}: \\
7 \%\end{array}$ \\
\hline GaAs & 32 & 5,3 & 1,4 & $\begin{array}{l}\text { e:8500 } \\
\text { 1: } 400\end{array}$ & $10^{8}$ & - & $\begin{array}{c}60 \mathrm{keV}: \\
37 \% \\
122 \mathrm{keV}: \\
33 \%\end{array}$ \\
\hline $\mathrm{CdSe}$ & 41 & 5,8 & 1,7 & $\begin{array}{l}\text { e:720 } \\
\text { l: } 75\end{array}$ & $10^{12}$ & $\begin{array}{l}\text { e: } 2 \times 10^{-5} \\
\text { 1: } 1 \times 10^{-6}\end{array}$ & $\begin{array}{c}60 \mathrm{keV}: \\
14 \%\end{array}$ \\
\hline $\mathrm{CdS}$ & 32 & 4,9 & 2,4 & $\begin{array}{l}\text { e: } 240 \\
\text { 1: } 50\end{array}$ & $10^{13}$ & - & $\begin{array}{c}122 \mathrm{keV}: \\
6,6 \%\end{array}$ \\
\hline
\end{tabular}




\subsection{CRISTAIS UTILIZADOS COMO DETECTORES SEMICONDUTORES DE RADIAÇÃO}

Um cristal consiste em um conjunto de átomos ou moléculas, constituído por uma repetição regular em três dimensões de uma determinada unidade fundamental chamada de célula unitária do cristal [71,73-75]. A estrutura cristalina é composta de uma rede (estrutura geométrica, ou arranjo, regular) e uma base (distribuição dos átomos do material em cada ponto da rede). A menor célula cristalina capaz de gerar a rede é chamada de célula primitiva. Com isso, uma célula primitiva que é transladada múltiplas vezes nas direções $x, y$ e $z$ gera a rede cristalina inteira $[71,73$ 75].

A formação de núcleos sólidos de determinado material a partir de uma fase líquida ocorre pelo processo de nucleação. Este processo pode ser definido como a formação de uma nova fase a partir de outra em posição específica. A nucleação é caracterizada por contornos bem definidos que a separam do meio que a gerou. No caso da solidificação, a nucleação envolve a formação de partículas de sólido envolvidas pelo material líquido. As condições que favorecem a ocorrência de nucleação dependem dos aspectos termodinâmicos e das condições cinéticas da transformação. Quando o sólido é formado dentro do próprio líquido sem o auxílio de nenhum tipo de estimulante energético externo, diz-se que a nucleação é homogênea. Todavia, o processo pode sofrer uma ação catalisadora por meio da presença de partículas sólidas em suspensão no líquido, elementos/compostos inseridos propositalmente, superfícies e geometrias que servem de molde, dentre outros fatores. Sob tais condições, o processo de nucleação é iniciado exatamente sobre esses parâmetros citados, que são diferentes do sistema em foco, e é denominado de nucleação heterogênea [74,75]. Devido as suas características, o processo de crescimento dos cristais de $\mathrm{TIBr}$ apresenta nucleação heterogênea.

Os átomos que formam um determinado cristal são unidos por ligações covalentes entre os elétrons de suas camadas mais externas [2,12,71,73-75]. Nestas ligações, tais elétrons são compartilhados entre os átomos dos elementos que formam o cristal, conforme Figura 6. 


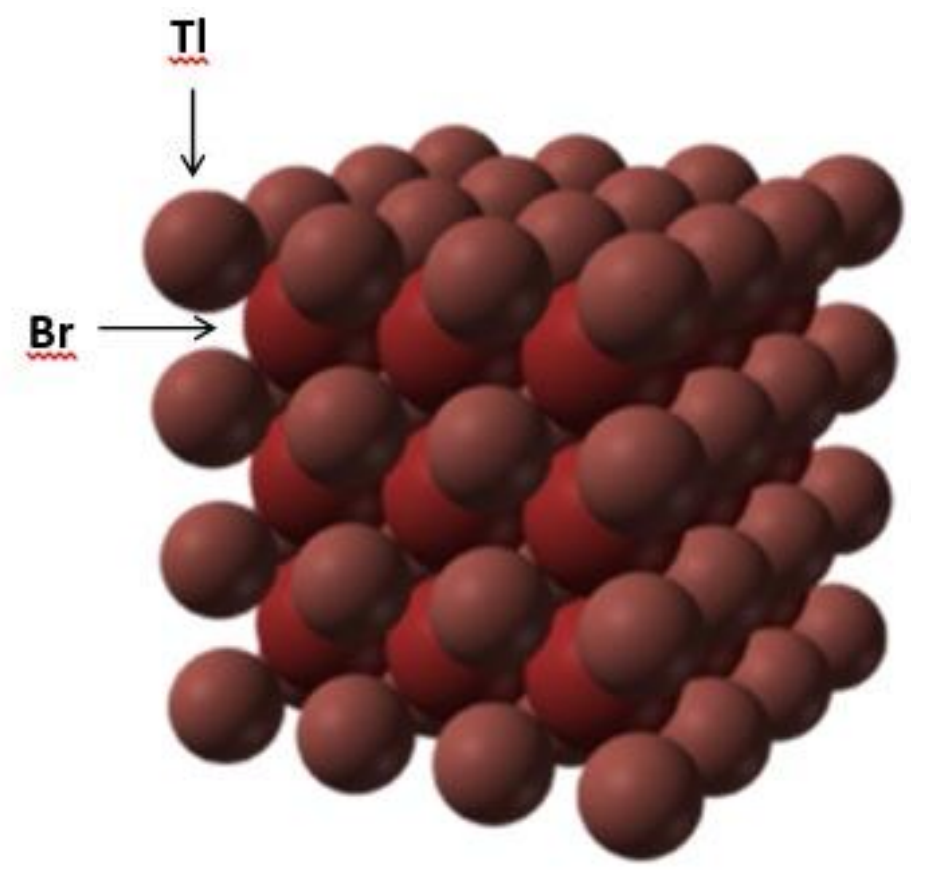

Figura 6: Estrutura cúbica simples do cristal semicondutor de $\mathrm{TIBr}$ [75].

Devido ao processo de quantização de energia, somente determinadas dimensões de órbitas (níveis de energia) são permitidas aos elétrons dos átomos. Quanto maior for a órbita do elétron, maior será seu nível de energia potencial em relação ao núcleo. Se um determinado átomo sofre incidência de energia externa, na forma de radiação, por exemplo, um de seus elétrons pode ser elevado a um nível mais energético em relação ao inicial, constituindo o chamado estado excitado do átomo [71-73].

\subsection{BANDAS DE ENERGIA}

Os níveis energéticos de elétrons de camadas mais internas dos átomos não sofrem influência significativa de átomos vizinhos, mas os níveis energéticos de elétrons da camada mais externa são influenciados, uma vez que tais elétrons são compartilhados por mais um átomo na estrutura cristalina devido a ligações covalentes. Segundo a Mecânica Quântica tais compartilhamentos geram uma banda de estados de energias muito próximos, níveis discretos de energia, em vez de níveis de energia separados presentes no átomo isolado [2,71,72]. 
Uma representação ilustrativa das bandas de energia é mostrada na Figura 7. A banda mais baixa, representada pelo nível de energia inferior, consiste na banda de valência, que corresponde aos elétrons que estão ligados a níveis específicos na estrutura cristalina. A banda mais alta, representada pelo nível de energia superior, consiste na banda de condução e corresponde aos elétrons que estão livres para migrar pelo cristal. Assim, os elétrons que estão na banda de condução contribuem para a condutividade elétrica de determinado material.

Uma das principais diferenças entre os materiais sólidos é a chamada banda proibida, isto é, a energia necessária para um elétron migrar da banda de valência para a banda de condução. Ela define se o material é isolante, condutor ou semicondutor. Os condutores possuem as bandas parcialmente preenchidas, fazendo com que haja uma intersecção entre estas bandas que acaba permitindo que um elétron migre de uma a outra. Com a aplicação de um campo elétrico, estes elétrons adquirem uma energia adicional e vão para estados de maior energia constituindo a corrente [71,72]. Quanto menor a banda proibida, maior é a possibilidade de um elétron migrar de uma banda para a outra e, assim, aumentar a condução do material [2,71,72]. Já os semicondutores, possuem uma banda proibida grande em relação aos metais, de forma que a condução nesses materiais fica condicionada à energia de excitação dos elétrons, isto é, quanto maior a temperatura maior será a energia térmica dos elétrons e com isso mais elétrons serão transferidos à banda de condução, aumentando assim a condutividade do material. Cada um dos tipos conhecidos de semicondutores possui uma energia de banda proibida específica, como mostrado na Figura 7.

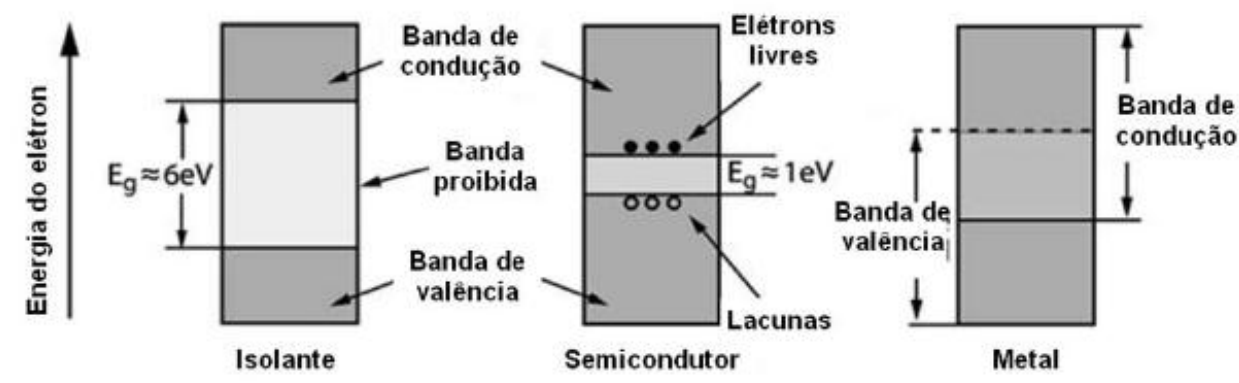

Figura 7: llustração dos níveis de energia para materiais isolantes, condutores e semicondutores [72]. 
Quando elétrons migram de uma banda para outra, deixam um espaço de carga positiva, uma lacuna. Estas lacunas referem-se a estados da banda de valência vazios, não preenchidos por elétrons. Na realidade a lacuna não existe como partícula ou como entidade isolada, mas ela é uma consequência do movimento de elétrons. Com isso, tem-se um movimento de cargas negativas associadas aos elétrons e um movimento de cargas positivas associadas às lacunas [71-73].

Quando um feixe de radiação externa colide com elétrons dos átomos de determinado material, os elétrons têm suas direções mudadas. A distância média entre tais colisões é denominada de livre percurso médio [72]. Com a aplicação de um campo elétrico constante os elétrons dos átomos do material são acelerados até o instante de sua colisão, na qual perdem energia e atingem um novo valor de velocidade de deriva. Sendo $v$ a velocidade de deriva dos elétrons e $\varepsilon$ a permissividade elétrica, a mobilidade $\mu\left(\mathrm{m}^{2} / \mathrm{V} . \mathrm{s}\right)$ é definida por:

$$
\mu=v / \varepsilon
$$

\subsection{CRESCIMENTO DE CRISTAIS}

Crescimento de cristais consiste na modificação estrutural atômica de um determinado material de partida seguida de sua organização em uma estrutura cristalina com orientação bem definida, sendo um processo diretamente ligado ao fenômeno de nucleação. Para ocorrer, é preciso uma fonte de aquecimento, que fornecerá a energia cinética necessária para que os átomos do material de partida se desprendam, e uma fonte de resfriamento, que diminuirá a energia cinética dos átomos, fornecendo o gradiente de temperatura necessário para a formação cristalina $[74,75]$.

A produção industrial de cristais foi iniciada em 1902, quando Verneuil pioneiramente controlou o processo de nucleação no crescimento de cristais de rubi e safira [75]. 
O crescimento de cristais pode ser realizado por meio das técnicas de fusão, de epitaxia e de solução saturada. O presente trabalho foi focado prioritariamente na técnica de fusão, que foi empregada por meio do método de Bridgman $[4,19,42,82,91]$.

\subsection{PURIFICAÇÃo e CRESCIMENTO de CRISTAIS PELO MÉtOdO DE BRIDGMAN}

Em 1925 P.W. Bridgman [82] desenvolveu o método de crescimento de cristais que leva o seu nome. Este método consiste prioritariamente na fusão completa de um determinado material de partida em um molde que lhe dará a geometria desejada. Posteriormente o material é submetido a um gradiente de temperatura adequado para seu resfriamento e formação da estrutura cristalina $[4,6,7,74,75,82]$.

Para a obtenção de monocristais, sem a utilização de semente necessária para a orientação da estrutura cristalina, pode ser utilizado como mecanismo adicional um molde (tubo) de quartzo afinado/afunilado em sua extremidade inferior onde se inicia o crescimento. Este dispositivo consiste no cadinho a ser utilizado. Com isso, tem-se o preenchimento da secção reta do tubo de quartzo com um pequeno monocristal, que servirá de semente orientadora para o crescimento completo do cristal $[4,6,7,74,75]$. Assim, tem-se a ocorrência do processo de nucleação do cristal.

O gradiente de temperatura da região de crescimento deve ser alto o suficiente de modo que apenas um pequeno volume do material fundido seja super resfriado. Todavia, o gradiente de temperatura na região em que o material já está cristalizado deve ser baixo de modo que tensões térmicas no cristal não sejam introduzidas. A taxa de resfriamento do cristal é fundamental para sua qualidade e estabilidade de modo que não ocorram trincas e deformações. A taxa recomendada para o cristal de $\mathrm{TIBr}$ é de $20^{\circ} \mathrm{C} / \mathrm{h}[4]$.

A purificação do cristal de $\mathrm{TIBr}$ pode ser feita por repetições de processo de crescimento, chamado de método de Bridgman repetido [4,42,74,75,91]. A cada 
crescimento as impurezas tendem a migrar para as extremidades do cristal, dependendo da diferença de solubilidade nas duas fases (sólida e líquida), expressa pelo coeficiente de segregação $k$ de cada impureza: (a) para $k$ menor do que a unidade a região inicial do material solidificado será mais pura, porque o soluto será rejeitado pelo sólido e se acumulará no líquido, (b) para $k$ maior do que a unidade, a região final do material solidificado será mais pura. Para $k$ igual a um, a impureza será distribuída homogeneamente ao longo do cristal $[4,74,82]$.

Além do método de crescimento e purificação de cristais desenvolvido por P.W. Bridgman, há outros diferentes métodos baseados no processo de fusão do material de partida. O processo de Refino Zonal consiste em um de tais métodos, sendo vastamente utilizado principalmente como técnica de purificação para diferentes materiais. Porém, apenas o método de Bridgman foi utilizado como método de crescimento e de purificação dos cristais crescidos no presente trabalho, com o propósito de estudar parâmetros e fatores limitantes e consolidar esse método para escala de rotina.

Um esquema de um forno vertical de Bridgman, modelo LEO110 - JUNG, é mostrado na Figura 8, que apresenta a estrutura interna do forno associada com o seu perfil térmico, obtido na fase inicial deste trabalho.
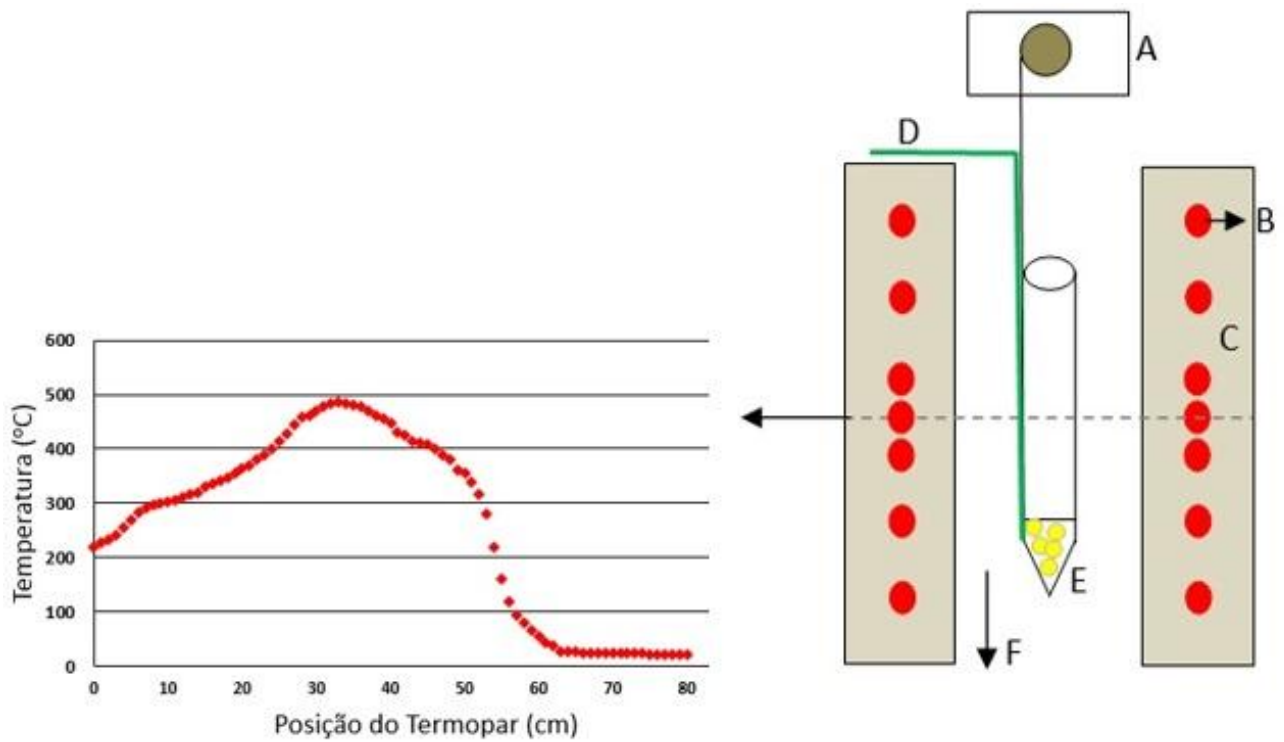

A: Sistema

de abaixamento

B: Aquecedores

C: Asbesto

D: Termopar

E: Cristal de $\mathrm{TIBr}$

F: Velocidade de abaixamento

Figura 8: Perfil térmico interno do forno vertical utilizado no método de Bridgman. 


\subsection{MÉTODOS DE CARACTERIZAÇÃO FÍSICA E QUÍMICA DE MATERIAIS CRISTALINOS}

\subsubsection{DIFRAÇÃO DE RAIOS-X (DRX)}

Uma técnica para se obter as dimensões e a composição da célula cristalina, isto é, fazer uma análise microestrutural, é incidir radiação de comprimentos de onda adequados sobre ocristal. Este é o princípio fundamental da técnica de difração de raios-X. Os primeiros estudos dessa técnica foram feitos em 1912, pelo físico alemão Max Von Laue. Ele considerou que, se os cristais eram compostos de átomos regularmente espaçados que podem atuar como centros de dispersão para raios- $X$, e se os raios- $X$ eram ondas eletromagnéticas de comprimento de onda igual à distância interatômica nos cristais, então seria possível difratar raios-X por meio de cristais $[71,73]$.

Quando o comprimento de onda da radiação incidente é da mesma ordem de grandeza que a distância interatômica da rede cristalina, o feixe é difratado em relação de fase (interação construtiva - formação de picos de difração) pelos átomos do cristal. Com este feixe difratado, pode-se calcular as posições dos átomos no cristal, planos cristalinos, por meio da Lei de Bragg [71,73], como mostrado na Figura 9 e na equação 6:

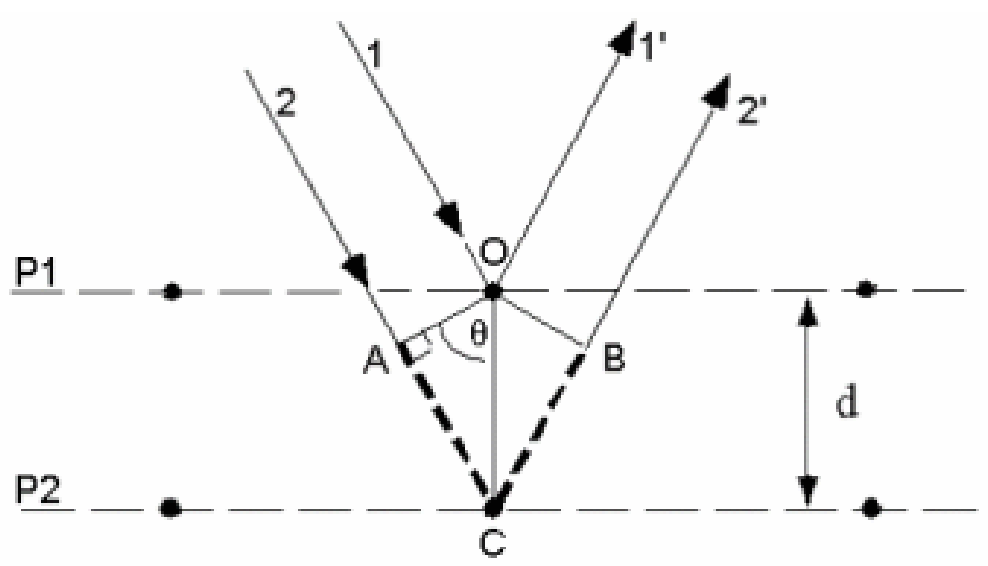

Figura 9: llustração de feixe incidindo em planos cristalinos. 
sendo $\theta$ o ângulo da radiação incidente no plano de átomos em análise, $d$ a distância entre os planos cristalinos, $A B C$ a trajetória extra que a radiação difratada pelo átomo $\mathrm{B}$ tem de percorrer, tem-se:

$$
\begin{gathered}
A B=d \sin \theta \\
\text { como } A B=B C, \\
n \lambda=2 A B, \\
\text { ou seja: } \\
n \lambda=2 d \sin \theta
\end{gathered}
$$

Considerando-se uma estrutura cúbica simples e sendo a = distância interatômica (parâmetro de rede); $h, k, I$ = índices de Miller, que fornecem a orientação do plano cristalino [71,73], tem-se a relação:

$$
d=\frac{a}{\sqrt{h^{2}+k^{2}+l^{2}}}
$$

Dessa forma, variando-se o ângulo de incidência, pode-se obter informações relacionadas a diversas famílias de planos cristalinos, bem como suas orientações em relação ao feixe de radiação incidente. Esta técnica permite, assim, estudar os planos cristalinos, as distâncias interplanares e densidades nos planos específicos e comparação entre padrões difratométricos.

Quando os átomos de um determinado material sofrem empilhamentos dando origem a planos bem definidos no espaço, apresentando uma mesma orientação (índices de Miller), tem-se a formação de monocristais. Uma vez que a obtenção de monocristais é tecnologicamente complexa, o emprego da técnica de DRX faz necessária a pulverização do cristal a ser analisado. Isso possibilita que os planos de difração do material, com orientação específica, sejam distribuídos em todas as direções, aumentando a probabilidade de ocorrer a difração $[71,73]$. 


\subsubsection{ESPECTROMETRIA DE MASSAS COM PLASMA (ICP-MS)}

Um dado composto químico pode ser identificado por meio da técnica de espectrometria de massas com plasma.

Nesta técnica, o espectrômetro de massas bombardeia uma determinada substância com um feixe de plasma, de modo a ionizar seus átomos ou deixá-los eletricamente carregados. Estes íons passam por um campo magnético que curva suas trajetórias de formas diferentes, de acordo com as características intrínsecas de seus espectros de massas. Com isso, tem-se uma relação específica entre massa e carga para os íons de cada material e sua posição no espectro.

Deve-se manter baixas pressões no espectrômetro a fim de evitar colisões entre os íons a serem analisados e outras moléculas no interior do espectrômetro, pois essas possíveis colisões podem causar reações químicas, transformação de energia e alteração na trajetória dos íons de interesse, comprometendo os resultados finais [76].

O espectrômetro de massas é fundamentalmente composto das seguintes partes [76]:

a) Fonte de plasma: converte os átomos dos elementos de determinada amostra em íons gasosos. A saída da fonte é um feixe de íons gasosos que são acelerados para o analisador de massa. Alguns elementos podem ser utilizados na fonte de plasma, dentre eles o argônio, conforme o equipamento e a necessidade de se quantificar uma amostra específica;

b) Analisador de massa/separador de íons: é a parte do equipamento responsável pela discriminação dos íons produzidos, que têm suas trajetórias controladas com o emprego de campos eletromagnéticos e são selecionados de acordo com sua relação m/Z (massa / carga); 
c) Detector e sistema de análise: são responsáveis por detectar os íons e convertê-los em sinais elétricos que são amplificados, processados e analisados.

Portanto, de forma simplificada tem-se o seguinte procedimento:

a) Introdução da amostra / analito a ser analisada no espectrômetro de massas;

b) Elétrons livres oriundos de uma faísca de alta tensão são introduzidos no argônio (Ar);

c) Campos elétricos e magnéticos são produzidos por um gerador de ondas de rádio geradas dentro de uma bobina de carga. Ocorre a aceleração e colisões de elétron de modo a produzir plasma (tocha de plasma). O material da amostra é ionizado por meio do bombardeamento com plasma;

d) Plasma com alto estado de energia: as moléculas injetadas na tocha são quebradas em seus constituintes químicos, que são ionizados. Ocorre a separação e quantificação dos íons conforme sua relação de carga/massa e sua posição no espectro de massas;

e) Coleta de íons através de um orifício diminuto de dois cones metálicos (skimmer-localizados na interface). Esse feixe focalizado de íons é transferido para o separador/analisador de massa (chamado de ion lens-pressão aproximada de 1,33.10 $0^{-3} \mathrm{~Pa}$ );

f) Razão $\mathrm{m} / \mathrm{Z}$ dos íons: os íons seguem trajetória homogênea e conseguem atravessar o quadrupolo magnético, cujos valores de interesse são préselecionados. Com isso, tem-se a formação de pulsos elétricos de curtíssima duração, que são detectados e medidos;

g) Processamento dos sinais e construção da curva de intensidade iônica $x$ relação massa / carga para identificação dos materiais da amostra inicial. 
A configuração de um espectrômetro pode ser vista na Figura 10.

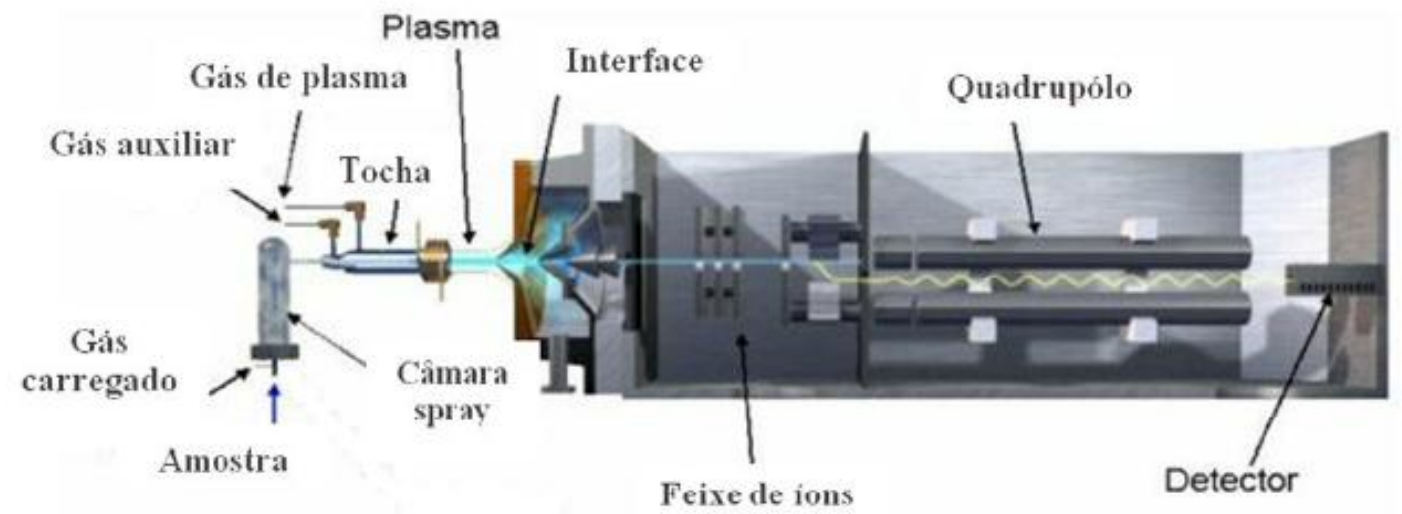

Figura 10: Funcionamento básico de um equipamento de ICP-MS [76].

\subsubsection{MICROSCOPIA ELETRÔNICA DE VARREDURA (MEV)}

A técnica de microscopia eletrônica de varredura permite a obtenção de informações topográficas, morfológicas, químicas e estruturais de amostras de diversos materiais, possibilitando correlacionar sua microestrutura com propriedades químicas, mecânicas e processos de fabricação relacionados. Possui alta resolução $(0,2$ a $5 \mathrm{~nm})$, grande profundidade de foco, imagem com aparência tridimensional e relativa facilidade de preparação das amostras. Essa técnica possibilita que um feixe de elétrons de alta energia incida na superfície de determinada amostra com a probabilidade de ocorrer os seguintes fenômenos: (a) parte do feixe é refletida e coletada por um sistema detector que converte este sinal em uma imagem de elétrons retroespalhados (BSE); (b) parte do feixe incide no material provocando a emissão de elétrons, produzindo a chamada imagem de elétrons secundários (ES) e (c) ocorre a emissão de raios-X que permite conhecer a composição química de um ponto ou região específica da superfície da amostra e identificar os elementos químicos presentes na mesma, sendo essa a técnica denominada de espectrometria de energia dispersiva de Raios X (EDS) [21,77]. 


\subsection{FORMULAÇÃO DE MODELOS MATEMÁTICOS E ANÁLISE COMPARTIMENTAL}

A teoria dos compartimentos é uma ferramenta poderosa para a análise de fenômenos cinéticos, de migração e transporte de moléculas e suas transformações químicas. Esta forma de análise determinista envolve a divisão do sistema a ser analisado em uma série de compartimentos interligados, considerando que um compartimento é definido como qualquer subdivisão estrutural, química, funcional ou física de um sistema [78,79]. A teoria básica é que o analito é uniformemente distribuído em todo o compartimento [78]. A partir de tais definições, pode-se utilizar ferramentas algébricas para realizar ajustes de aproximações, de modo a descrever quantitativamente as grandezas desejadas [79.80].

A teoria dos compartimentos foi usada como modelo matemático para explicar e ajustar os dados da concentração de impurezas como função do número de repetições do crescimento do cristal. A partir da teoria de análise compartimental, pode-se assumir que a variação no conteúdo do i-ésimo compartimento $\mathrm{Ci}$ (onde $\mathrm{Ci}$ é a concentração de impurezas no compartimento i), como função da variável $x$ (onde $\mathrm{x}$ é $\mathrm{o}$ número de repetições do processo de crescimento), pode ser equacionada como:

$$
\frac{d C_{i}(x)}{d x}=-\sum_{i=1 ; i \neq j}^{N} k_{i, j} \cdot C_{i}(x)+\sum_{j=1 ; j \neq i}^{N} k_{j, i} \cdot C_{j}(x)
$$

Onde $k_{i j}$ é o coeficiente de segregação de impureza do compartimento (região do cristal) i para o compartimento j e $\mathrm{N}$ é o número total de compartimentos. Considera-se i diferente de $\mathrm{j}$ devido aos limites geométricos bem definidos para os compartimentos. 


\section{OBJETIVOS}

O objetivo deste trabalho foi estudar a influência das impurezas em cristais de $\mathrm{TIBr}$ e da qualidade morfológica das superfícies no seu desempenho como detectores semicondutores de radiação. Para tanto, foram estudadas as técnicas de purificação e crescimento dos cristais de $\mathrm{TIBr}$, acompanhando a redução das concentrações das impurezas presentes a cada etapa de purificação. Foi desenvolvido um modelo matemático para explicar a segregação das impurezas nos cristais. $\mathrm{O}$ desempenho dos cristais de $\mathrm{TIBr}$ como detectores de radiação à temperatura ambiente foi avaliado utilizando-se radiação gama de fontes de ${ }^{241} \mathrm{Am}$ $(59,5 \mathrm{keV}) \mathrm{e}^{133} \mathrm{Ba}(81 \mathrm{keV})$.

\section{Objetivos específicos}

- Caracterização física e química dos cristais de TIBr;

- Deposição de recobrimento metálico a ser utilizado como contato elétrico dos cristais de $\mathrm{TIBr}$ utilizados como detectores de radiação;

- Destacar e consolidar a técnica de Bridgman como método de crescimento e de purificação de cristais;

- Avaliar a resposta do cristal semicondutor de $\mathrm{TIBr}$ à radiação gama de fontes de baixa energia (da ordem de keV);

- Realizar medida da resistividade elétrica dos cristais de $\mathrm{TIBr}$;

- Avaliar o processo de segregação das impurezas presentes nos cristais de $\mathrm{TIBr}$ utilizando um modelo matemático.

- Prever e analisar a taxa de diminuição de concentração de impurezas em diferentes regiões do Cristal de $\mathrm{TIBr}$ em função do número de repetições do processo de purificação.

- Relacionar as concentrações de impurezas com o desempenho destes cristais aplicados como detectores de radiação à temperatura ambiente. 


\section{Contribuições originais do trabalho.}

Apesar do consenso na literatura que a pureza do cristal é um fator determinante no seu desempenho como detector de radiação, são encontrados poucos trabalhos sobre a purificação do TIBr. Além disso, não existe concordância nos resultados da composição química dos elementos traços presentes no material de partida. A originalidade deste trabalho é acompanhar a redução das impurezas a cada etapa de purificação e propor um modelo matemático relacionado aos coeficientes de segregação das impurezas, a fim de explicar o mecanismo de interação entre as impurezas presentes no cristal com os portadores de cargas produzidas pela excitação do cristal com a radiação. Adicionalmente, para se realizar a análise de impurezas das amostras de cristais de $\mathrm{TIBr}$, foi estabelecido um procedimento para abertura química das amostras.

\section{MATERIAIS USADOS}

* Sal de brometo de tálio (TIBr), 99,99\% de pureza, Alfa-Aeser

* Tubos de quartzo de diâmetro:1,8cm / comprimento: $50 \mathrm{~cm}$ (Hipperquimica e Vidrolex )

* Acetona P.A. (Merck)

* Argônio 6.0 (White Martins)

* Acetileno e oxigênio (White Martins)

* Tecido de algodão (100\%) e papel Sontara

* Abrasivos: lixas de $\mathrm{Al}_{2} \mathrm{O}_{3}$ com granulometria variando de 3 a $30 \mu \mathrm{m}$

* Pinturas de grafite (Electron Microscopy Sciences)

* Ácido nítrico (65\%, Merck) e peróxido de hidrogênio (30\%, Merck)

* Fita condutiva de carbono (modelo: double sided carbon tape, da Eletron Microscopy Sciences) 


\section{EQUIPAMENTOS USADOS}

a) Tratamento químico / térmico dos cadinhos de quartzo e desgaseificação do sal de brometo de tálio

* Bomba mecânica de vácuo, modelo A65401906, motor RV8 1 ph (Edwards)

* Controlador de temperatura com microprocessador, modelo JD13A (Dhacel)

* Termopar cromel-alumel tipo $\mathrm{K}$ revestido com aço inox e isolação mineral $\left(\mathrm{Al}_{2} \mathrm{O}_{3}\right)$ e com condutores de $0,2 \mathrm{~mm}$ de diâmetro cada

* Balança eletrônica (Marte - AD 200)

* Maçarico de solda (Record - MPS super - 201)

\section{b) Crescimento do cristal de brometo de tálio}

* Forno de crescimento de cristal por método de Bridgman, nas dimensões de $250 \mathrm{~mm}$ de largura e altura de $600 \mathrm{~mm}$, modelo LEO110 (Jung)

* Controlador de temperatura com microprocessador, modelo E5T (Omron)

* Controlador de temperatura com microprocessador, modelo N1100 (Novus)

* Termopar cromel-alumel tipo $\mathrm{K}$ com condutores de 0,3 mm de diâmetro cada

c) Corte e polimento do cristal de brometo de tálio

* Serra com disco de corte com borda diamantada Isomet, modelo 11-1180 (Buehler Ltd.)

d) Caracterização de detecção à radiação dos cristais

* Multímetro modelo DM-25 (Beckman Indl.)

* Amperímetro modelo 619 (Keithey)

* Pré-amplificador sensível à carga de baixo ruído, modelo A250F (Amptek )

* Amplificador modelo 450 EG\&G (Ortec) (Ortec)

* Analisador Multicanal 918A EG\&G (Ortec)

* Fonte de tensão modelo 556 EG\&G (Ortec)

* Osciloscópio modelo TDS 3032B (Tektronix)

* Metalizador HHV + modelo etc 


\section{e) Difração de Raios X}

* Difratômetro de Raios X modelo D5005 (Siemens)

\section{f) Microscopia eletrônica de varredura (MEV)}

* Microscópio eletrônico de varredura modelo LX 30, Philips.

* Microscópio eletrônico de varredura com espectroscopia de energia dispersiva (MEV-EDS) modelo TM3000, da Hitachi.

g)Espectrometria de massas com plasma (ICP-MS)

* Espectrômetro de massas com plasma (Elan 6100, Perkin Elmer, USA)

${ }^{*}$ Forno digestor com microondas (modelo DGT 100 Plus, Provecto Analítica).

\section{PROCEDIMENTO EXPERIMENTAL}

O trabalho realizado foi constituído das seguintes etapas experimentais:

1- Purificação e crescimento dos cristais.

a) Levantamento do perfil térmico do forno utilizado no método de Bridgman;

b) Confecção dos cadinhos utilizados para o crescimento dos cristais a partir de tubos de quartzo;

c) Tratamento químico e desgaseificação dos cadinhos de quartzo utilizados e do sal de TIBr para o crescimento do cristal;

d) Crescimento de cristais pelo método de Bridgman repetidas vezes para purificação.

2- Tratamento das superfícies.

a) Corte do cristal usando serra de material diamantado e polimento das amostras;

b) Deposição do recobrimento metálico a ser utilizado como contato elétrico. 
3- Caracterização física e química e de detecção à radiação dos cristais.

a) Análise da estrutura cristalina: difração de raios $X(D R X)$;

b) Análise morfológica e verificação estequiométrica: microscopia eletrônica de varredura com elétrons secundários (MEV- SE) e com espectroscopia de energia dispersiva (MEV-EDS)

c) Preparação das amostras de $\mathrm{TIBr}$ para análises química das impurezas e do modelo compartimental;

d) Análise química das impurezas;

e) Desenvolvimento de uma modelagem matemática utilizando a teoria dos compartimentos;

f) Análise de segregação das impurezas presentes: análise compartimental (modelagem matemática);

g) Aplicação dos contatos elétricos nas amostras dos cristais de $\mathrm{TIBr}$ a serem utilizadas como detectores;

h) Medidas de resistividade nas amostras dos cristais de $\mathrm{TIBr}$ a serem utilizadas como detectores;

i) Análise da resposta do cristal detector semicondutor de $\mathrm{TIBr}$ à radiação gama das fontes de baixas energias de ${ }^{241} \mathrm{Am}$ (energia de $59.5 \mathrm{keV}$ ) e ${ }^{133} \mathrm{Ba}$ (energia de $81 \mathrm{keV}$ ).

\subsection{PURIFICAÇÃO E CRESCIMENTO DOS CRISTAIS}

\subsubsection{LEVANTAMENTO DO PERFIL TÉRMICO DO FORNO UTILIZADO NO MÉTODO DE BRIDGMAN}

O levantamento do perfil térmico do forno utilizado no método de Bridgman, mostrado na Figura 11, consiste em um procedimento fundamental para se mapear o gradiente térmico ao qual o material de partida será submetido no processo de crescimento e purificação do cristal de TIBr. Esse procedimento é necessário para verificar a simetria do gradiente de temperatura antes e depois da região de temperatura máxima do forno, garantido, assim, a melhor estabilidade 
termodinâmica possível durante os processos de crescimento e de purificação dos cristais. É a partir desta região que se inicia o crescimento do cristal. O forno foi programado para atingir a temperatura máxima de $560{ }^{\circ} \mathrm{C}$. Assim, foi obtida uma curva de temperatura em função da posição do termopar no interior do forno vertical utilizado. A posição do termopar foi deslocada de $0,5 \mathrm{em} 0,5 \mathrm{~cm}$ no interior do forno, registrando a sua temperatura a cada $0,5 \mathrm{~cm}$. Foi utilizado um intervalo de tempo de 5 minutos entre cada medida, com o propósito de possibilitar maior estabilidade entre as mesmas.

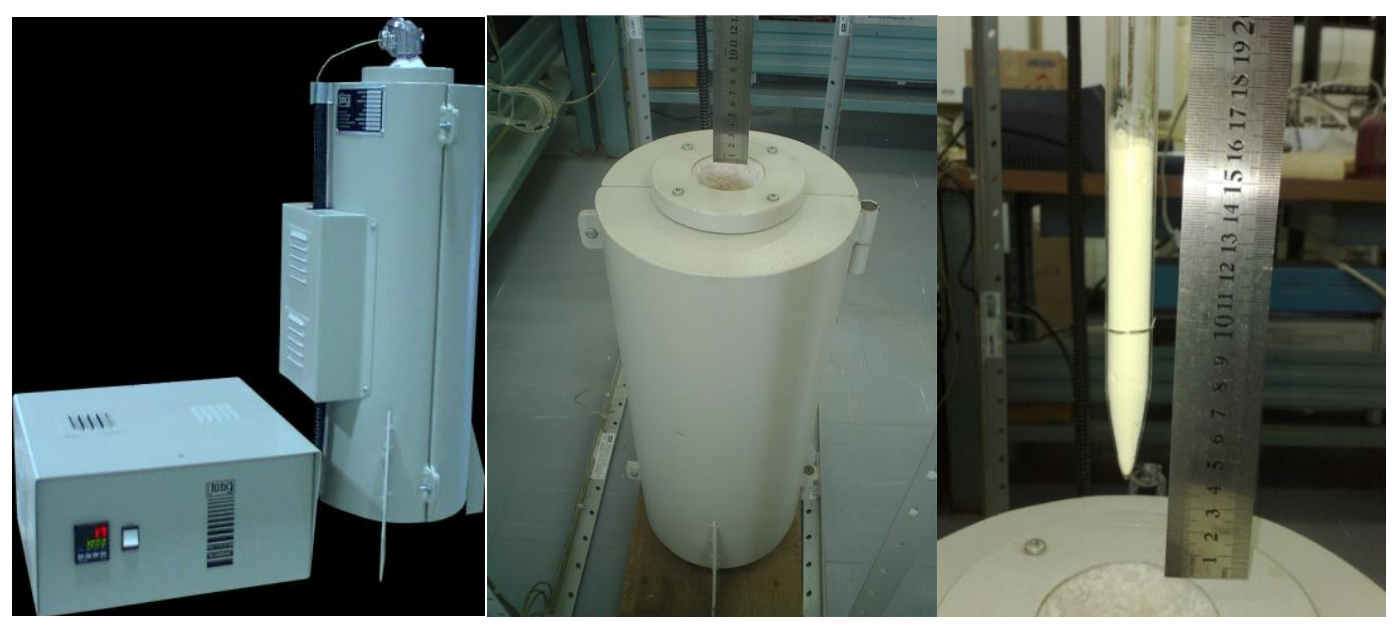

Figura 11: Forno vertical, sob diferentes ângulos, utilizado para crescimento de cristais de $\mathrm{TIBr}$ pelo método de Bridgman.

\subsubsection{CONFECÇÃO DOS CADINHOS UTILIZADOS PARA O CRESCIMENTO DOS CRISTAIS A PARTIR DE TUBOS DE QUARTZO}

Foram utilizados tubos de quartzo para confecção dos cadinhos a serem usados nos processos de crescimento e de purificação dos cristais de $\mathrm{TIBr}$. A obtenção da geometria afunilada adequada constitui um processo bastante complexo, pois o quartzo é um material que apresenta elevada temperatura de fusão $\left(700^{\circ} \mathrm{C}\right)$, fundindo-se pontualmente e bruscamente, quando manipulado com uso de maçarico com gás acetileno. Assim, a definição simétrica da geometria necessária é um processo bastante difícil e que requer muita habilidade do operador para ser realizado. 


\subsubsection{TRATAMENTO QUÍMICO E DESGASEIFICAÇÃO DOS CADINHOS DE QUARTZO E DO SAL DE TIBr}

Os cadinhos de quartzo a serem utilizados foram submetidos a um tratamento químico, previamente, imergindo-os em solução de ácido nítrico $\left(\mathrm{HNO}_{3}-10 \% \mathrm{v} / \mathrm{v}\right)$ durante 20 minutos, com o intuito de se retirar possíveis oleosidades em geral. Em seguida, os cadinhos de quartzo foram lavados com água deionizada repetidas vezes. Após esse processo, os tubos foram armazenados em uma estufa para secagem enquanto o forno de desgaseificação tinha sua temperatura estabilizada a $250 \stackrel{\circ}{\circ}$ (tempo médio de 15 minutos). Posteriormente, $45 \mathrm{~g}$ de sal de $\mathrm{TIBr}$ foi adicionado ao cadinho de quartzo e realizou-se uma nova desgaseificação durante um período de 1 hora sob a temperatura de $160^{\circ} \mathrm{C}$. Essa quantidade de sal de $\mathrm{TIBr}$ foi definida de modo a utilizar a quantidade máxima de sal como material de partida, desde que as dimensões finais do cadinho de quartzo contendo o mesmo não ultrapassassem as dimensões do forno utilizado. $O$ cadinho de quartzo selado a vácuo contendo o sal de $\mathrm{TIBr}$ precisa ter metade de seu volume disponível para a expansão gasosa que ocorre durante o processo de fusão. O comprimento total do cadinho de quartzo utilizado é de $50 \mathrm{~cm}$, com diâmetro de $1,8 \mathrm{~cm}$.

Durante todo o processo um tubo de metal (cobre - $\mathrm{Cu}$ ) com curva em forma de "u" (trapping) foi conectado entre o tubo que sai do registro e o tubo de saída da bomba de vácuo, conforme mostrado na Figura 12, permanecendo mergulhado em um suporte térmico (dewar) contendo nitrogênio líquido. Tal sistema faz com que os possíveis gases e impurezas que saem do material no cadinho, ou da bomba de vácuo, não retornem, ficando retidas no "trapping" imerso em nitrogênio líquido. 


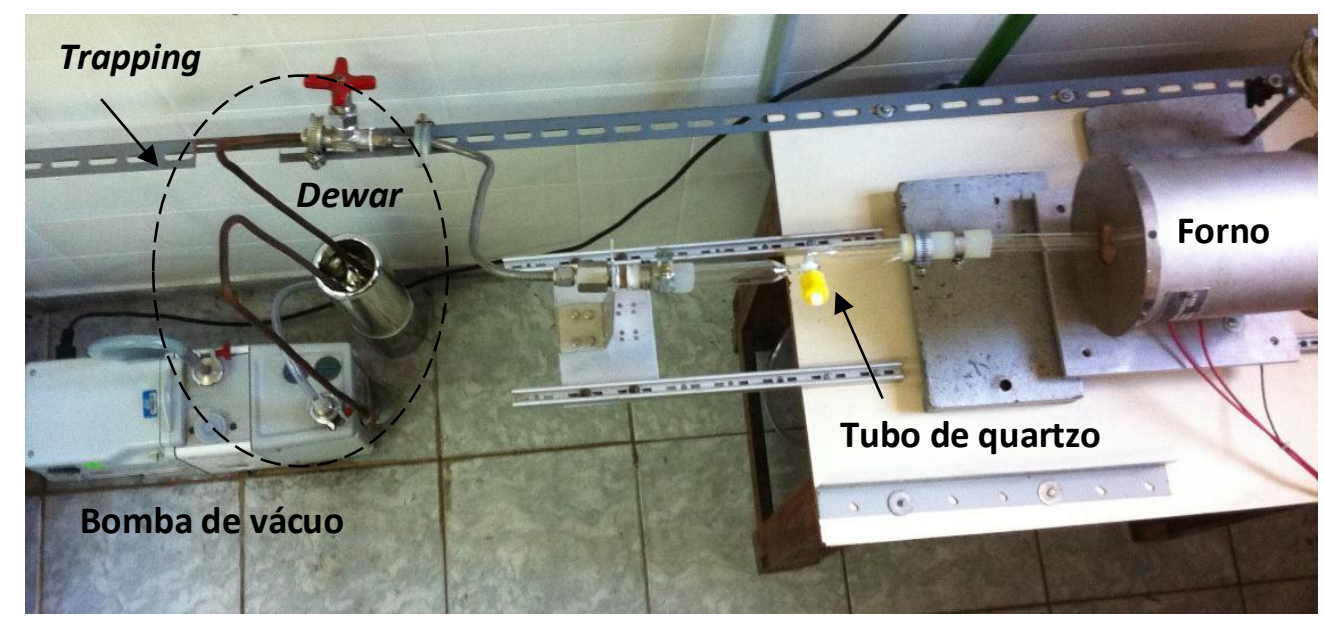

Figura 12: Montagem para tratamento químico e desgaseificação dos tubos de quartzo e do sal de TIBr.

Após a desgaseificação o cadinho de quartzo contendo o sal de $\mathrm{TIBr}$ foi selado a vácuo e utilizado para o crescimento do cristal, como mostrado na Figura 13.

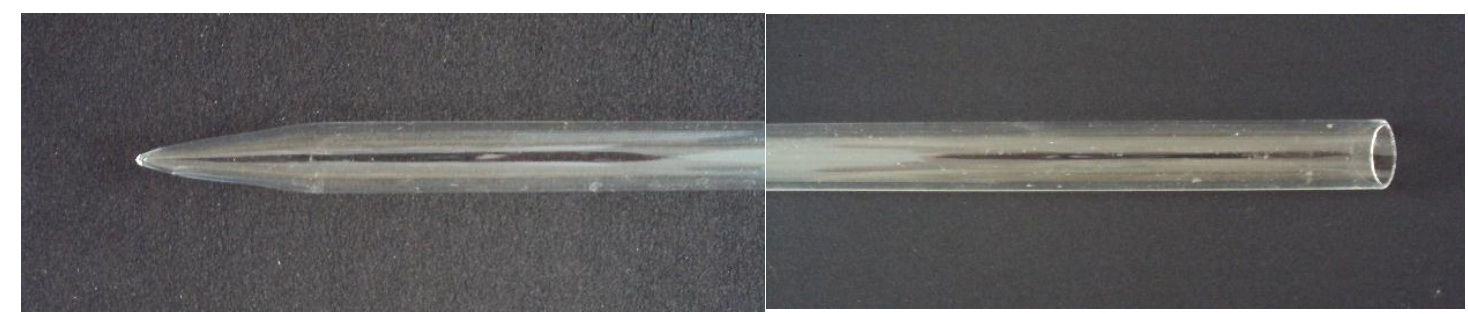

a)

b)

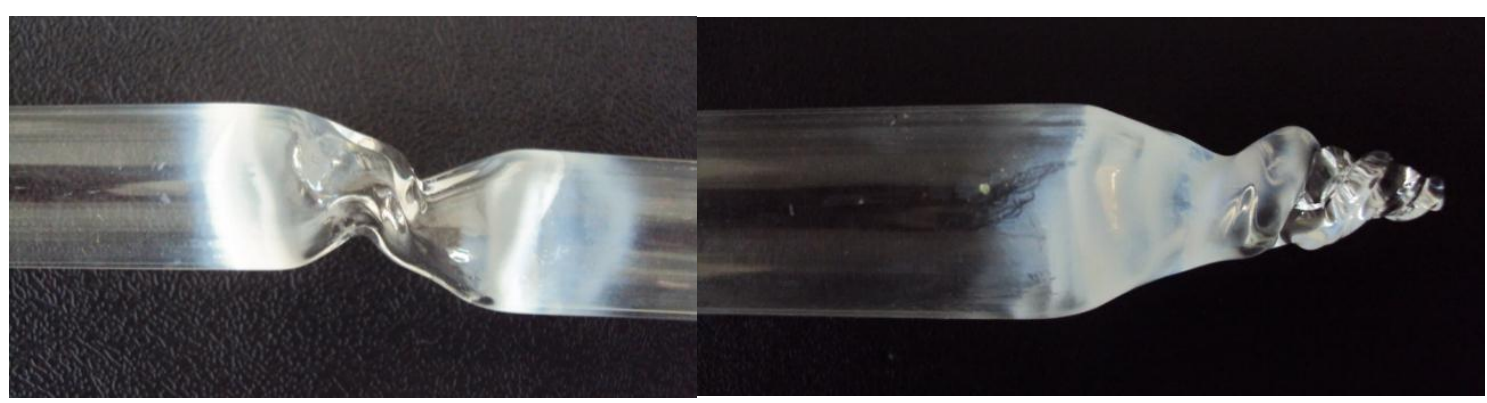

c)

d)

Figura 13: Detalhes do cadinho de quartzo a) e b); detalhes do processo de selamento do cadinho de quartzo c) e d). 


\subsubsection{CRESCIMENTO DE CRISTAIS DE TIBr PELO MÉTODO DE BRIDGAMN E PURIFICAÇÃO POR BRIDGAM REPETIDO.}

Na região de temperatura máxima do forno foi posicionado o tubo de quartzo contendo $45 \mathrm{~g}$ do sal de $\mathrm{TIBr}$ previamente tratado e selado a vácuo. A seguir o sal de $\mathrm{TIBr}$ foi fundido. A partir desse ponto o tubo contendo o sal de $\mathrm{TIBr}$ foi deslocado verticalmente para baixo a uma velocidade de $1 \mathrm{~mm} / \mathrm{h}$. O forno foi programado para atingir a temperatura máxima de $560^{\circ} \mathrm{C}$ a pressão de $1,33.10^{-4} \mathrm{~Pa}$ e manter esta temperatura constante por 50 horas. Após este intervalo de tempo, a temperatura foi programada para resfriar vagarosamente, $20^{\circ} \mathrm{C} / \mathrm{h}$, até a temperatura ambiente. Tais condições permitem 0 crescimento de cristais com menores desordens estruturais/falhas, com baixa tensão térmica [4].

Após cada crescimento, o tubo de quartzo foi aberto e amostras da região superior e do meio do cristal foram retiradas para análise, a partir do procedimento de corte descrito a seguir, no item 6.2.1. A região inferior da amostra foi submetida a um novo processo de crescimento, Bridgman repetido. Este método tem como finalidade a purificação do cristal, onde as impurezas segregam para as extremidades do cristal. Com isso, espera-se encontrar maior pureza na região do meio do cristal.

\subsection{TRATAMENTO DAS SUPERFÍCIES}

\subsubsection{CORTE DOS CRISTAIS DE TIBr E POLIMENTO DAS AMOSTRAS}

A extremidade do cristal crescido (região de maior concentração de impurezas) foi cortada utilizando uma serra contendo com disco de corte com borda diamantada em sua constituição e lubrificada com etileno glicol, como mostrado na Figura 14. O $\mathrm{TIBr}$ consiste em um material de microdureza relativamente baixa (microdureza Knoop de 1,18.10-4 kgf. $\mathrm{m}^{-4}$ ), possibilitando diversos danos estruturais e mecânicos durante a confecção dos detectores. Assim, o processo de corte foi realizado lentamente durante o intervalo de $40 \mathrm{~min}$. Por este procedimento, três fatias de 1,0 $\mathrm{mm}$ de espessura da região central do cristal (região mais pura devido à segregação 
de impurezas para as extremidades) foram cortadas do cristal. Duas amostras foram polidas e preparadas como detectores de radiação. Da terceira amostra, $50 \mathrm{mg}$ foi utilizado para determinação das impurezas presentes pela técnica de ICP-MS e o restante para análise de difração de Raios $X$. O polimento foi realizado utilizando abrasivos de lixas de $\mathrm{Al}_{2} \mathrm{O}_{3}$ com granulometria variando de 3 a $30 \mu \mathrm{m}$.

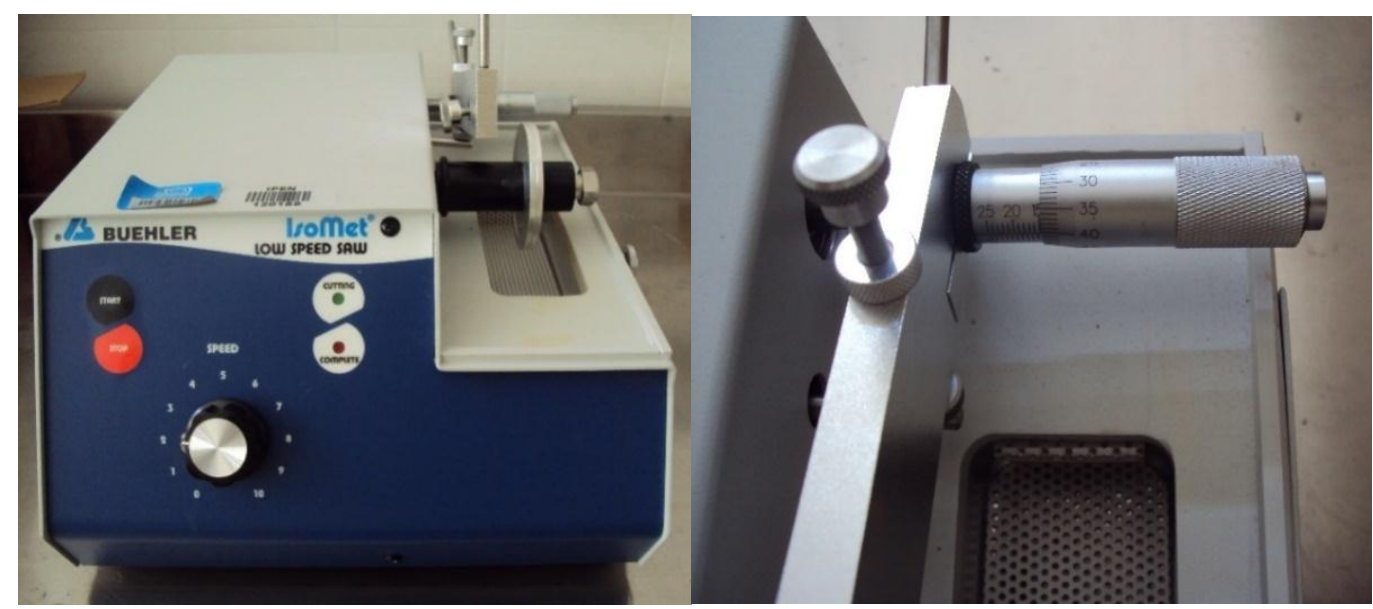

Figura 14: Máquina utilizada no corte do cristal de $\mathrm{TIBr}$.

\subsubsection{DEPOSIÇÃO DE RECOBRIMENTO METÁLICO E APLICAÇÃO DOS CONTATOS ELÉTRICOS}

Para sua aplicação como detectores de radiação, os cristais de $\mathrm{TIBr}$ foram preparados com a aplicação de contatos elétricos nas suas fatias para tornar possível coletar os portadores de carga produzidos pela incidência de radiação. Inicialmente, foi realizada deposição de ouro sobre a superfície das amostras, por meio de transporte físico de vapor.

Posteriormente, fios de cobre foram aplicados em lados opostos das fatias utilizando-se tinta condutiva a base de carbono. A Figura 15 mostra as etapas da aplicação dos contatos eletrônicos. 
Figura 15: Fatias do cristal de TIBr após: tratamento na superfície por meio de polimento (a), aplicação dos contatos com pintura de grafite condutiva (b) e aplicação de fio de cobre (c).

\subsection{CARACTERIZAÇÃo FíSICA E QUÍMICA E DE DETECÇÃO À RADIAÇÃO DOS CRISTAIS DE TIBr}

\subsubsection{ANÁLISE DA ESTRUTURA CRISTALINA: DIFRAÇÃO DE RAIOS X (DRX)}

A avaliação da qualidade cristalina das amostras de $\mathrm{TIBr}$ foi realizada utilizando o Difratômetro de Raio-X modelo D5005 (Siemens), do Laboratório de Difração de Raios-X do CCTM-IPEN/CNEN-SP. Neste processo são identificadas as direções nas quais os planos do cristal crescido são preferencialmente orientados (índices de Miller). Padrões de difração de Raios- $X$ foram obtidos no difratômetro a partir de radiações CuKa $\left(2 \theta\right.$ variando de $20^{\circ}$ a $\left.60^{\circ}\right)$.

As amostras foram pulverizadas, como pode ser visto na Figura 16, de modo a possibilitar que os planos de difração do material, com orientação específica, sejam distribuídos em todas as direções, aumentando a probabilidade de ocorrer a difração. 


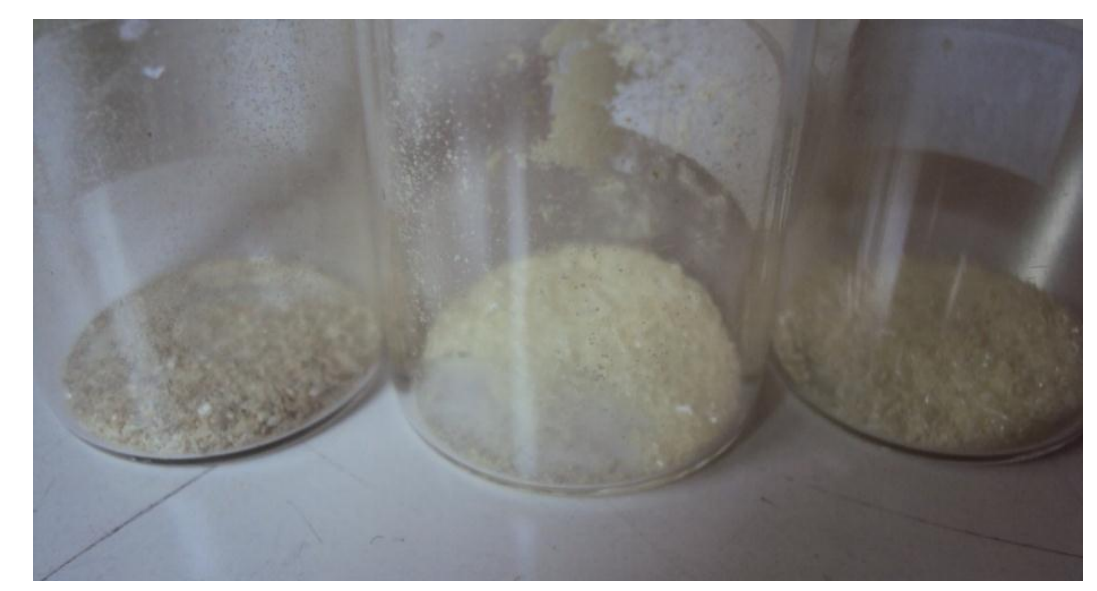

Figura 16: Amostras pulverizadas dos cristais de $\mathrm{TIBr}$ a serem utilizadas em difração de Raios X (DRX).

\subsubsection{ANÁLISE MORFOLÓGICA E VERIFICAÇÃO ESTEQUIOMÉTRICA: MICROSCOPIA ELETRÔNICA DE VARREDURA COM ELÉTRONS SECUNDÁRIOS (MEV-SE) E COM ESPECTROSCOPIA DE ENERGIA DISPERSIVA (MEV-EDS)}

Foi realizada análise morfológica dos cristais de $\mathrm{TIBr}$ por meio de microscopia eletrônica de varredura com elétrons secundários (MEV-SE) utilizando-se um microscópio eletrônico de varredura modelo LX 30, da Philips, conforme apresentado na Figura 17, e verificação estequiométrica por meio de microscopia eletrônica de varredura com espectroscopia de energia dispersiva (MEV-EDS) utilizando-se um microscópio eletrônico de varredura modelo TM3000, da Hitachi High Technologies, Figura 18 e Figura 19.

As amostras para a análise por MEV foram preparadas da seguinte forma:

a) as amostras do cristal de $\mathrm{TIBr}$ foram submetidas a pressão de $1,33.10^{-4} \mathrm{~Pa} \mathrm{e}$ temperatura de $90{ }^{\circ} \mathrm{C}$, durante 15 minutos, a fim de remover previamente toda água e voláteis da superfície. Estes poderiam comprometer os resultados finais, uma vez que a análise de MEV é realizada sob vácuo;

b) as amostras foram preparadas usando fita condutiva de carbono para montagem correta da fatia do cristal de $\mathrm{TIBr}$ no porta amostra (Figura 20); 
c) evaporar um filamento de carbono na superfície, utilizando uma evaporadora modelo SCD 040, da Balzers Union, Figura 21, para tornar o cristal condutivo. Esse item foi suprimido na análise por MEV-EDS.

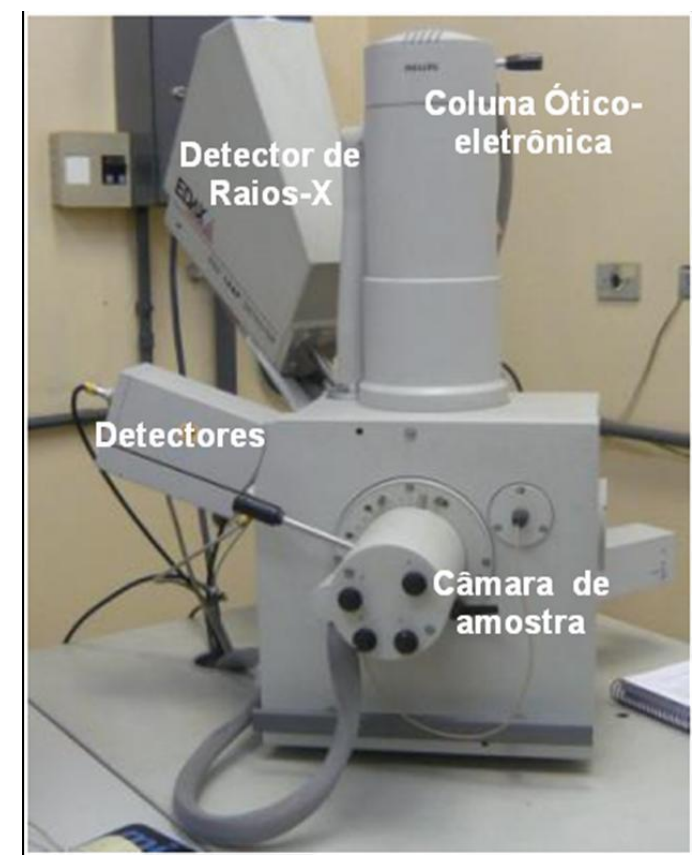

Figura 17: Microscópio eletrônico de varredura modelo LX 30, da Philips.

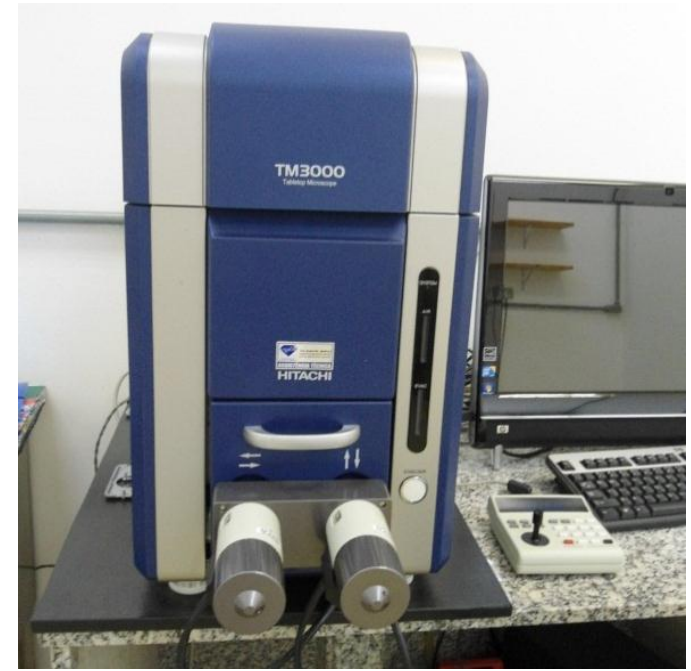

Figura 18: Microscópio eletrônico de varredura modelo TM3000, da Hitachi. 


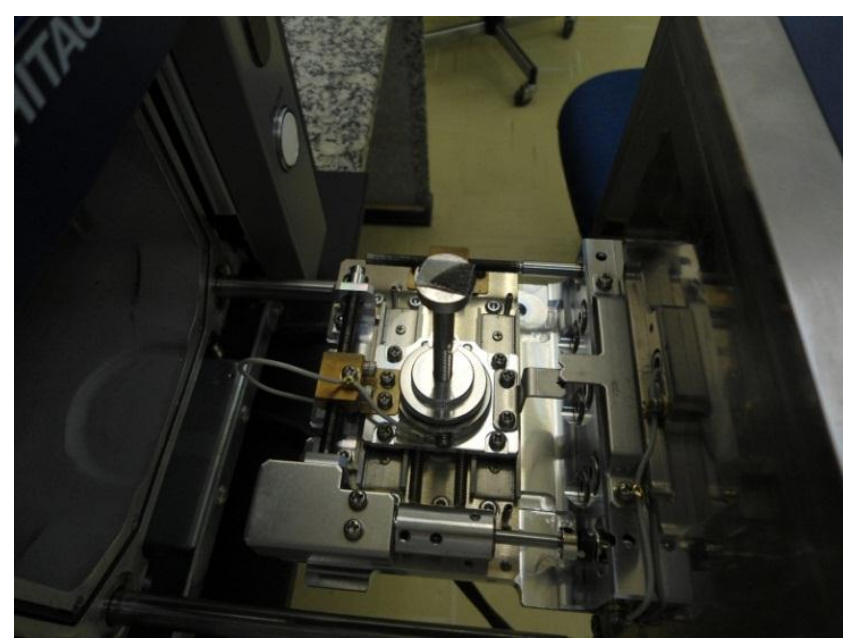

Figura 19: Amostra do cristal de TIBr posicionada no microscópio eletrônico de varredura TM3000, da Hitachi.

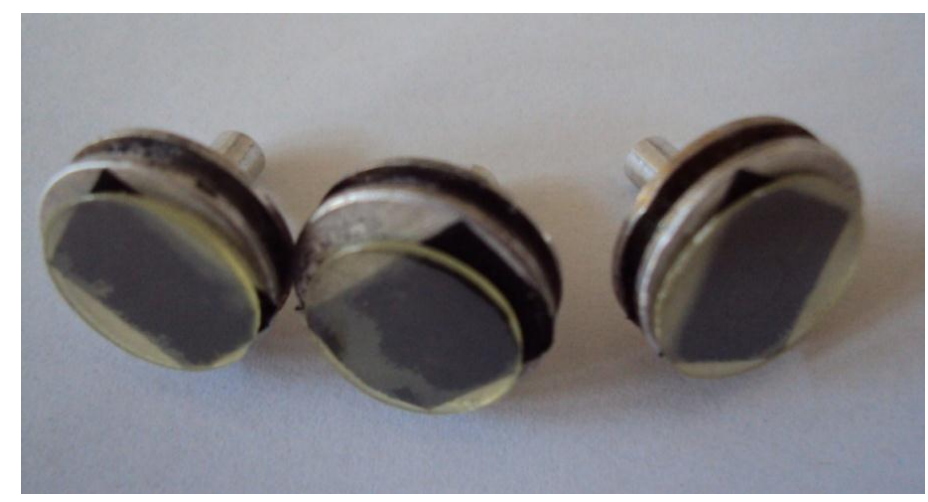

Figura 20: Cristais de TIBr fixos em porta amostras para análise de MEV-BSE.

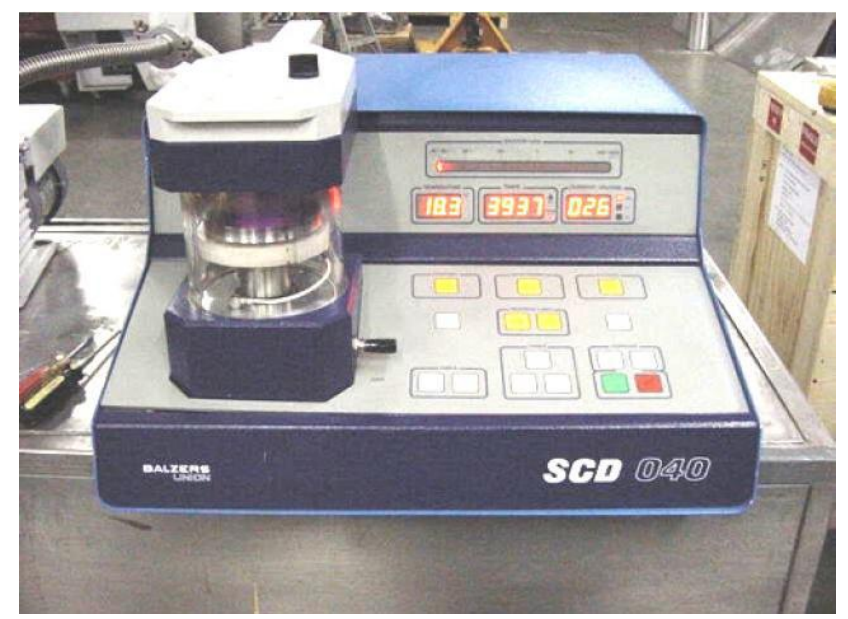

Figura 21: Evaporadora utilizada para evaporar um filamento de carbono na superfície do cristal para torná-lo condutivo. 


\subsubsection{PREPARAÇÃO DAS AMOSTRAS DE TIBr PARA ANÁLISES QUíMICA DAS IMPUREZAS E DO MODELO COMPARTIMENTAL.}

Para preparação das amostras para estudo da segregação das impurezas e proposição de um modelo compartimental, quatro amostras foram retiradas do cristal a cada crescimento. Para cada crescimento, o tubo de quartzo foi aberto e o cristal foi dividido em 3 regiões, como mostrado na Figura 22, sendo a região "Topo", a extremidade superior do cristal de $\sim 5 \mathrm{~mm}$ de espessura (compartimento $3 \mathrm{com}$ volume VC3 $=1571 \mathrm{~mm}^{3}$ ), para onde a maioria das impurezas migram, a qual foi amostrada para análise química. A região do meio, denominada "Meio", foi considerada a região nobre do cristal de $\sim 31 \mathrm{~mm}$ de espessura (compartimento 2 com volume VC2 $=4710 \mathrm{~mm}^{3}$ ), assumindo que existe uma boa uniformidade na concentração da região do meio do cristal. Amostras foram retiradas, da região chamada de "Meio", para análise química das impurezas e posterior preparação como detectores de radiação. A região chamada de "Ponta" corresponde a extremidade inferior do cristal de $\sim 20 \mathrm{~mm}$ de espessura, a qual tem o formato cônico (compartimento $1 \mathrm{com}$ volume VC1 $=1054 \mathrm{~mm}^{3}$ ). O compartimento quatro (C4) representa a quantidade acumulada de impurezas das duas fatias de $0.65 \mathrm{~mm}$ removidas da região de meio do cristal, para serem utilizadas como detector de radiação e para análise química. O compartimento cinco (C5) representa a quantidade acumulada de impurezas retiradas do topo do cristal $(5 \mathrm{~mm})$. 


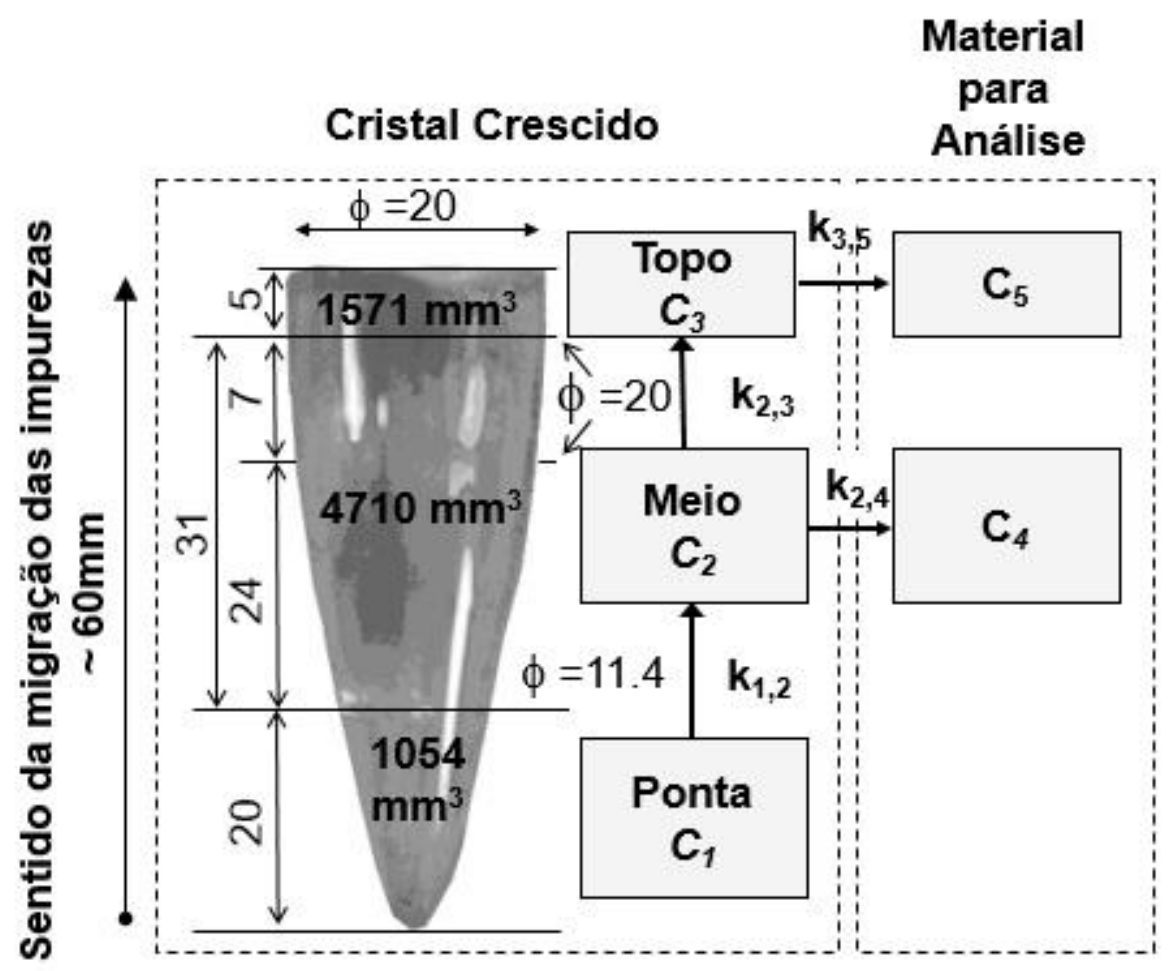

Figura 22: Modelo compartimental proposto para explicar a migração das impurezas no cristal de $\mathrm{TIBr}$.

\subsubsection{ANÁLISE QUANTITATIVA DAS IMPUREZAS PRESENTES POR ESPECTROMETRIA DE MASSAS COM FONTE DE PLASMA (ICP-MS)}

As amostras retiradas a cada crescimento, como descrito no item anterior (4.3.4.), foram analisadas por ICM-MS. Para a determinação das impurezas presentes, esta análise foi realizada utilizando um espectrômetro de massas Elan 6100, Perkin Elmer, USA, em colaboração com o Laboratório de Cristais lônicos, Filmes e Datação do IF/USP.

Em virtude da destacada característica de insolubilidade de $\mathrm{TIBr}$ [1,3,6,11,14,19,23,41,42,91,92] foram necessários estudos para estabelecer um procedimento adequado para abertura química das amostras, que é essencial para a análise química por ICP-MS. Experimentos foram realizados, variando solventes, concentrações de solventes e temperatura, simultaneamente, com o intuito de 
minimizar a possível introdução de outros elementos químicos na solução e reduzir o tempo de aquecimento. O procedimento que apresentou melhor resultado foi utilizado para as aberturas de todas as amostras deste trabalho, cuja descrição se encontra a seguir: amostras de $50 \mathrm{mg}$ (valor definido em função do limite de detecção do equipamento) dos cristais de $\mathrm{TIBr}$ foram adicionadas em frascos de teflon em $50 \mathrm{~mL}$ de ácido nítrico. Para a solubilização assistida do $\mathrm{TIBr}$ por microondas, nesta solução, os frascos de teflon foram aquecidos sob pressão por 20 minutos no forno digestor com microondas, modelo DGT 100 Plus, da Provecto Analítica. Este procedimento substituiu o processo utilizado nos trabalhos anteriores ( $50 \mathrm{~mL}$ de ácido nítrico, $2 \mathrm{~mL}$ de peróxido de hidrogênio, $3 \mathrm{~mL}$ de ácido clorídrico e 40 minutos de aquecimento, utilizando-se o mesmo forno de microondas).

As impurezas presentes nas amostras foram analisadas no espectrômetro de massas com plasma. No presente trabalho, foi realizada a análise quantitativa com o intuito de identificar e quantificar as impurezas presentes no $\mathrm{TIBr}$.

\subsubsection{ANÁLISE DE SEGREGAÇÃo DE IMPUREZAS PRESENTES (MODELO COMPARTIMENTAL)}

Para explicar a segregação das impurezas no cristal de $\mathrm{TIBr}$ em função do número de crescimentos Bridgman, foi proposto um modelo matemático utilizando a teoria da análise compartimental[ $[78,79,80]$.

O modelo compartimental, proposto para explicar a migração das impurezas como uma função da enésima repetição do crescimento Bridgman, é mostrado na Figura 22. Os parâmetros $k$ são os coeficientes de migração das impurezas da região i para a região $j$. Compartimento $C 5$ representa a quantidade acumulada de impurezas retiradas do topo do cristal $(5 \mathrm{~mm})$. Compartimento $\mathrm{C} 4$ representa a quantidade acumulada de impurezas das duas fatias de $0.65 \mathrm{~mm}$ removidas da região de meio do cristal, para serem utilizadas como detector de radiação e para análise química. A hipótese básica aplicada para formulação do modelo descrito na Figura 22 fundamenta-se em (i) o coeficiente de segregação $k>1$, ou seja, as 
impurezas medidas são mais solúveis na fração fundida do cristal; (ii) inicialmente, as concentrações das impurezas nas três regiões (compartimentos), 1 a 3 , são iguais aos sais utilizados como material de partida e as concentrações iniciais nos compartimentos 4 e 5 são ambas iguais a zero; (iii) o coeficiente de segregação $k_{i j}$ é uma constante, independentemente do número de repetições $x$, isto é, a quantidade de impurezas que migra da região $i$ para região $j$ é proporcional a sua concentração na região $i$ e, finalmente, (iv) $k_{1,2}=k_{2,3}$. Os coeficientes $k_{2,4}$ e $k_{3,5}$ dependem do volume do material fatiado do cristal e foram numericamente estimadas pelo processo algébrico de regressão não linear.

A Equação (8) foi utilizada como ponto de partida para o desenvolvimento do modelo matemático proposto para explicar e ajustar os dados da concentração de impurezas como função do número de repetições do crescimento do cristal. Assim, tem-se o núcleo deste modelo, ou seja, os compartimentos $\mathrm{C} 1, \mathrm{C} 2$ e $\mathrm{C} 3$, que pode ser definido, matematicamente, como o sistema de equações diferenciais de primeira ordem apresentado a seguir.

$$
\begin{gathered}
\frac{d C_{1}}{d x}=-k_{1,2} \cdot C_{1} \\
\frac{d C_{2}}{d x}=+k_{1,2} \cdot C_{1}-\left(k_{2,3}+k_{2,4}\right) \cdot C_{2} \\
\frac{d C_{3}}{d x}=+k_{3,5} \cdot C_{3}
\end{gathered}
$$

onde $C_{1,0}=C_{2,0}=C_{3,0}=$ concentração de impurezas no material de partida e $C_{4,0}=$ $C_{5,0}=0$, pois esses dois compartimentos só existem a partir do momento em que são retiradas as amostras. 
Reescreve-se o sistema de equações (9) em notação matricial e assume-se o argumento algébrico inicial $\sum_{i=1 ; i \neq j}^{N} k_{i, j}=k_{i, i}$, a fim de se conseguir a uniformidade nos índices dos elementos da matriz. Dessa forma, obtém-se:

$$
\left[\begin{array}{ccc}
-k_{1,1} & 0 & 0 \\
k_{1,2} & -k_{2,2} & 0 \\
0 & k_{2,3} & -k_{3,3}
\end{array}\right] \cdot\left[\begin{array}{l}
C_{1} \\
C_{2} \\
C_{3}
\end{array}\right]=\left[\begin{array}{l}
d C_{1} / d x \\
d C_{2} / d x \\
d C_{3} / d x
\end{array}\right]
$$

Dentre as técnicas utilizadas na resolução de equações diferenciais, a aplicação de transformadas integrais é bastante significativa e eficiente.

A transformada (integral) $f(\alpha)$ de uma função $F(t)$ é expressa na forma geral:

$$
f(\alpha)=\int_{a}^{b} F(t) \cdot K(\alpha, t) d t
$$

onde $f(\alpha)$ é a transformada da função $F(t)$ pelo núcleo $K(\alpha, t)$. Em outras palavras, tem-se o chamado mapeamento da função $F(t)$ no espaço (coordenadas) t para a função $f(\alpha)$, no espaço $\alpha$. Para um núcleo igual a $e^{-\alpha . t}$, tem-se a chamada transformada de Laplace:

$$
\mathcal{L}\{F(t)\}=f(\alpha)=\int_{0}^{\infty} F(t) e^{-\alpha t} d t
$$

Cuja transformada inversa é:

$$
\mathcal{L}^{-1}\{f(t)\}=F(\alpha)=\int_{0}^{\infty} f(t) e^{-\alpha t} d t
$$

A transformada de Laplace apresenta diversas propriedades e possibilidades úteis no desenvolvimento matemático, visando maior facilidade e obtenção de 
parâmetros para solução de problemas diversos. Assim, podem ser destacadas as seguintes propriedades e possibilidades: transformada inversa, transformada de derivadas, linearidade, transformada da função de Heaviside (função degrau), entre outras.

Aplicando a tranformada de Laplace [79-81] na equação (10) e invertendo a matriz:

$$
\left[\begin{array}{c}
\overline{C_{1}}(s) \\
\overline{C_{2}}(s) \\
\overline{C_{3}(s)}
\end{array}\right]=\frac{1}{\Delta} \cdot\left[\begin{array}{ccc}
\left(s+k_{2,2}\right) \cdot\left(s+k_{3,3}\right) & 0 & 0 \\
\mathrm{k}_{1,2} \cdot\left(\mathrm{s}+\mathrm{k}_{3,3}\right) & \left(s+k_{1,1}\right) \cdot\left(s+k_{3,3}\right) & 0 \\
k_{1,2} \cdot k_{2,3} & k_{2,3} \cdot\left(s+k_{1,1}\right) & \left(s+k_{1,1}\right) \cdot\left(s+k_{2,2}\right)
\end{array}\right] \cdot\left[\begin{array}{l}
C_{1,0} \\
C_{2,0} \\
C_{3,0}
\end{array}\right]
$$

onde, $\bar{C}_{i}(s)=\mathcal{L}\left\{\mathrm{C}_{\mathrm{i}}(\mathrm{x})\right\}$ é a transformação de Laplace de $\mathrm{C}_{\mathrm{i}}(\mathrm{x})$ pela mudança da variável $x$ para um espaço de coordenadas $s$ e $\Delta=\left(s+k_{1,1}\right) \cdot\left(s+k_{2,2}\right) \cdot\left(s+k_{3,3}\right)$.

Realizando-se a substituição e o produto das matrizes, obtém-se:

$$
\left[\begin{array}{c}
\overline{C_{1}}(s) \\
\overline{C_{2}}(s) \\
\overline{C_{3}}(s)
\end{array}\right]=\left[\begin{array}{c}
\frac{\left(s+k_{2,2}\right) \cdot\left(s+k_{3,3}\right)}{\left(s+k_{1,1}\right) \cdot\left(s+k_{2,2}\right) \cdot\left(s+k_{3,3}\right)} \cdot C_{1,0} \\
\frac{k_{1,2} \cdot\left(s+k_{3,3}\right) \cdot C_{1,0}+\left(s+k_{1,1}\right) \cdot\left(s+k_{3,3}\right) \cdot C_{2,0}}{\left(s+k_{11}\right) \cdot\left(s+k_{2,2}\right) \cdot\left(s+k_{3,3}\right)} \\
\frac{k_{1,2} \cdot k_{2,3} \cdot C_{1,0}+k_{2,3} \cdot\left(s+k_{1,1}\right) \cdot C_{2,0}+\left(s+k_{1,1}\right) \cdot\left(s+k_{2,2}\right) \cdot C_{3,0}}{\left(s+k_{11}\right) \cdot\left(s+k_{2,2}\right) \cdot\left(s+k_{3,3}\right)}
\end{array}\right]
$$

Aplicando-se a transformada de Laplace de forma inversa:

$C_{i}(x)=\mathcal{L}^{-1}\left\{C_{i}(s)=\frac{P_{i}(s)}{Q(s)}\right\}$, usando a propriedade da função degrau (algoritmo de Heaviside) [79-81], em que $Q(s)=\Delta=\left(s+k_{1,1}\right) \cdot\left(s+k_{2,2}\right) \cdot\left(s+k_{3,3}\right)$ e $P_{i}(s)$ consiste nos elementos do numerador da matriz-produto. Com isso, são obtidas as principais equações utilizadas nesse modelo: 


$$
\begin{gathered}
C_{1}(x)=C_{1,0} \cdot e^{-k_{1,1} \cdot x} \\
C_{2}(x)=\frac{k_{1,2} \cdot C_{1,0}}{k_{2,2}-k_{1,1}} \cdot e^{-k_{1,1} \cdot x}+\left(\frac{k_{1,2} \cdot C_{1,0}}{k_{1,1}-k_{2,2}}+C_{2,0}\right) \cdot e^{-k_{2,2} \cdot x} \\
C_{3}(x)=\frac{k_{1,2} \cdot k_{2,3} \cdot C_{1,0}}{\left(k_{2,2}-k_{1,1}\right) \cdot\left(k_{3,3}-k_{1,1}\right)} \cdot e^{-k_{1,1} \cdot x} \\
+\left(\frac{k_{1,2} \cdot k_{2,3} \cdot C_{2,0}}{\left(k_{1,1}-k_{2,2}\right) \cdot\left(k_{3,3}-k_{2,2}\right)}+\frac{k_{2,3} \cdot C_{2,0}}{k_{3,3}-k_{2,2}}\right) \cdot e^{-k_{2,2} \cdot x} \\
\left.+\frac{k_{1,2} \cdot k_{2,3} \cdot C_{3,0}}{\left(k_{1,1}-k_{3,3}\right) \cdot\left(k_{2,2}-k_{3,3}\right)}+\frac{k_{2,3} \cdot C_{2,0}}{k_{2,2}-k_{3,3}}+C_{3,0}\right) \cdot e^{-k_{3,3} \cdot x} \\
C_{5}(x)=k_{3,5} \cdot \int_{x=0}^{x} C_{3}(x) d x \\
C_{4}(x)=k_{2,4} \cdot \int_{x=0}^{x} C_{2}(x) d x
\end{gathered}
$$

As equações 16, 17, 18, 9 e 20 foram utilizadas para estimar numericamente os coeficientes de segregação das diferentes impurezas. Os coeficientes $k_{2,4}$ e $k_{3,5}$ dependem do volume do material fatiado do cristal e foram numericamente estimadas pelo processo algébrico de regressão não linear.

$\mathrm{Na}$ abordagem clássica, para determinar o cálculo do coeficiente de segregação K, algumas hipóteses idealizadas são assumidas [19]: (i) a concentração da impureza na matéria-prima é constante em toda a extensão da sua distribuição no cadinho; (ii) a secção transversal do lingote é uma constante; (iii) o coeficiente de segregação é constante ao longo do comprimento do lingote (compartimento); (iv) a concentração inicial em cada região I do lingote corresponde à soma de toda a pastilha, dividido pelo número de secções região; (v) o comprimento do lingote deve 
ser maior do que o comprimento da zona de fusão, a fim de arrastar impurezas com base nas diferenças de solubilidade de fase sólida-líquida. Se forem satisfeitas todas essas condições, então o modelo matemático previsível descrito na equação (21) pode ser usado para calcular a concentração $C_{i}$ após o crescimento do cristal pelo método de Bridgman.

$$
C_{i}=C_{0} \cdot\left[1-(1-k) \cdot e^{-k \cdot \frac{i}{l}}\right]
$$

onde: Ci é a concentração de impureza no compartimento I; $\mathrm{C}_{0}$ é a concentração inicial; k é o coeficiente de segregação e I é o comprimento da zona de fusão do compartimento.

Os cálculos realizados para obtenção dos coeficientes de segregação de impurezas nos cristais de $\mathrm{TIBr}$ a partir das equações 1, 2, 3, 4, 5 e 11 foram feitos com a utilização do software GNUPLOT, que consiste em um software extremamente versátil utilizado para construção de gráficos e operações matemáticas e estatísticas. Esse utilitário usa o método de Levenberg-Marquardt para ajuste de funções não lineares nos parâmetros e suas linhas de comando podem ser desenvolvidas em diferentes plataformas, tais como MS Windows, Linux, entre outras.

\subsubsection{CARACTERIZAÇÃO DO CRISTAL SEMICONDUTOR DE TIBr COMO DETECTOR DE RADIAÇÃO A TEMPERATURA AMBIENTE}

A montagem eletrônica utilizada para as medidas de radiação é mostrada na Figura23 e na Figura 24. Para a caracterização do cristal como detector, primeiramente a medida de corrente de fuga em função da tensão aplicada foi avaliada. As medidas de corrente de fuga foram realizadas utilizando o multímetro Keithey, modelo 619,uma fonte de alta tensão Ortec, modelo 459, e desconectando 
o pré-amplificador A250F. A partir dos valores obtidos dessa medida foi determinada a resistividade apresentada pelos detectores, empregando-se a equação 22.

$$
\rho=\frac{V \cdot A}{I_{d} \cdot l}
$$

Na qual $\rho$ é a resistividade no escuro, $V$ é a tensão aplicada em volts, $A$ é área do contato em $\mathrm{cm}^{2}$, Id é a corrente no escuro em ampére e l é a espessura da amostra em cm.

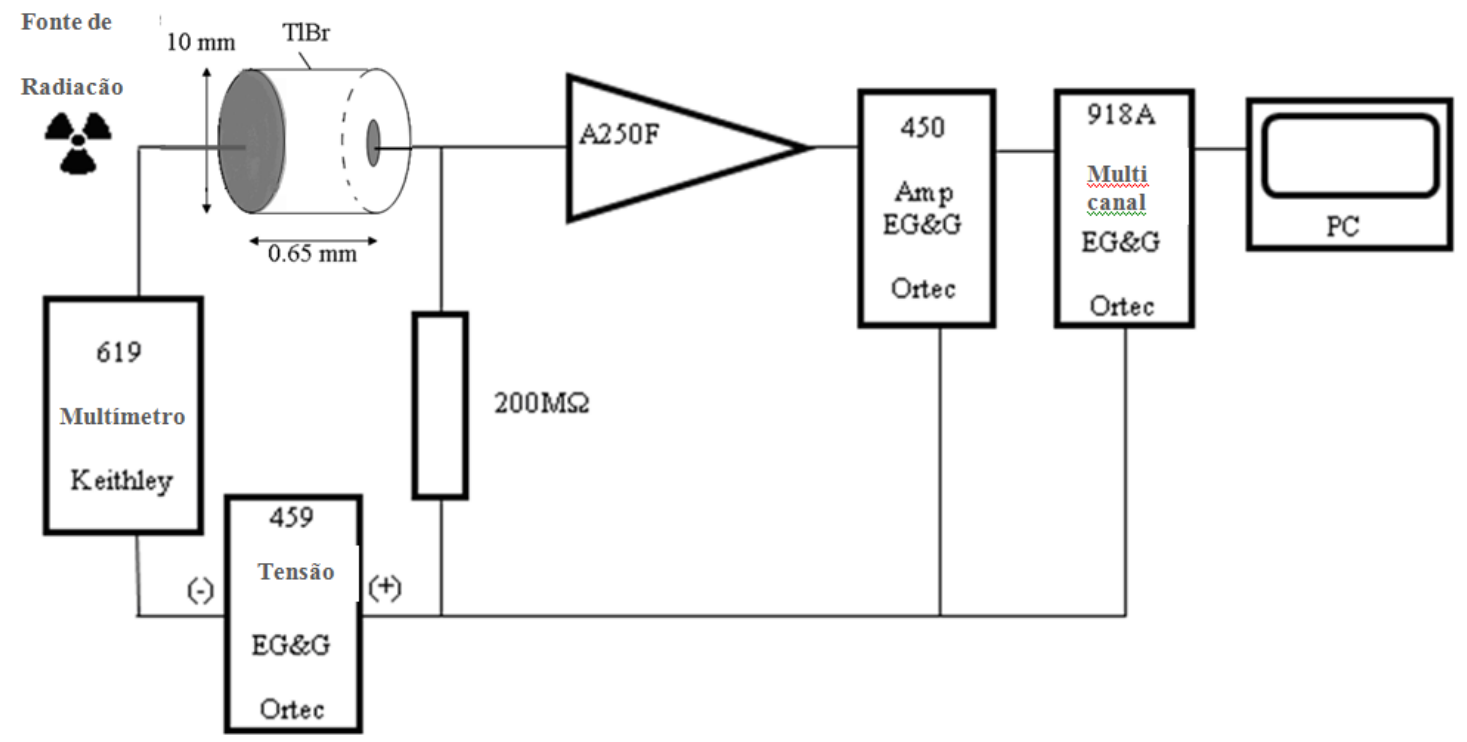

Figura23: Montagem eletrônica utilizada para as medidas de radiação e análise de dados 


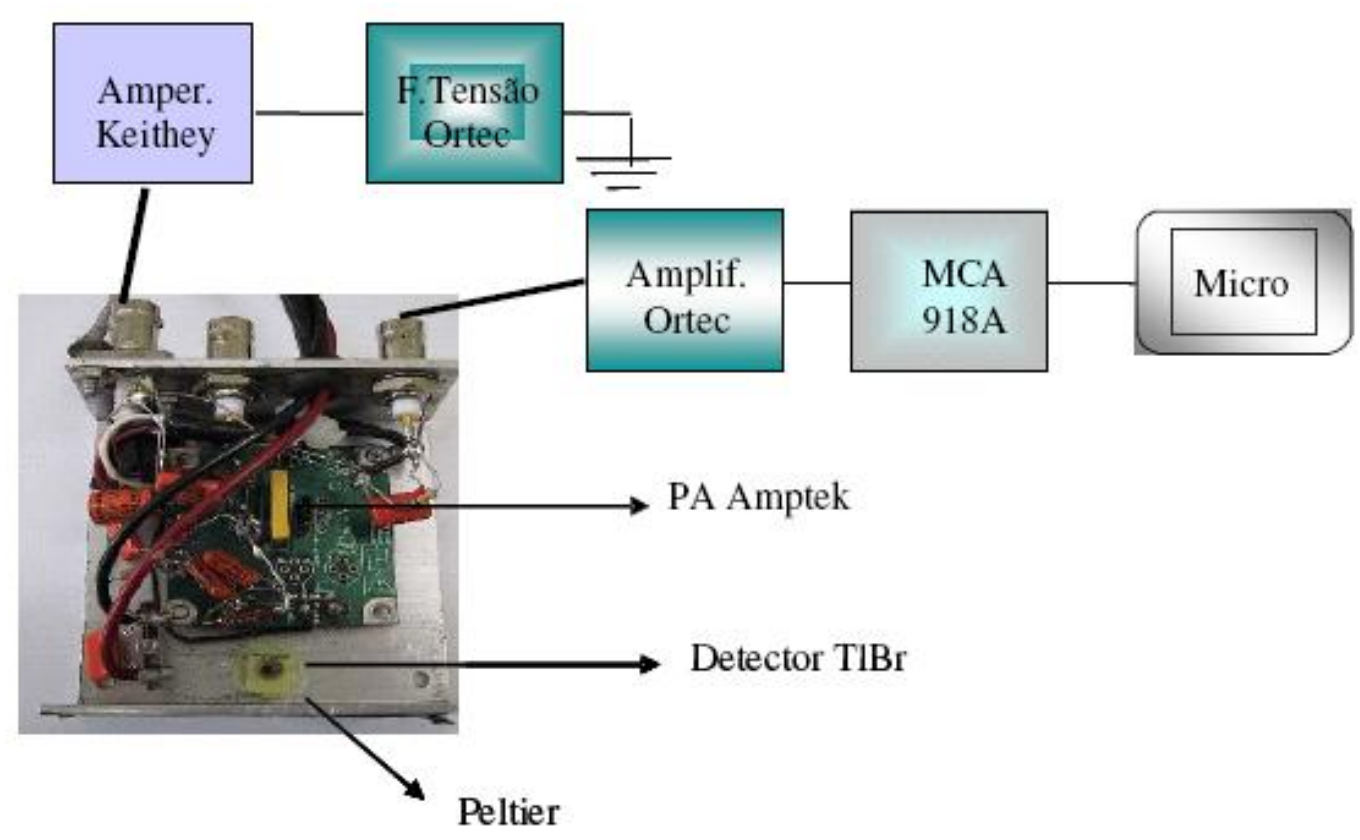

Figura 24: Representação da eletrônica associada ao detector semicondutor de $\mathrm{TIBr}$ para medidas de resposta à incidência de radiação gama.

O desempenho do detector referente à coleta de cargas foi avaliado mediante análise das medidas de altura de pulso, utilizando raios gama provenientes das fontes de ${ }^{241} \mathrm{Am}(59 \mathrm{keV})$ e ${ }^{133} \mathrm{Ba}(81 \mathrm{keV})$. Para medidas de altura de pulso, o sinal do pré-amplificador sensível à carga $A$ 250F, da Amptek, foi conectado ao amplificador 450 EG\&G, da Ortec, e ao analisador multicanal 918A EG\&G, da Ortec.

Para medidas de radiação gama foram utilizadas fontes seladas de ${ }^{241} \mathrm{Am}$ (59 $\mathrm{keV}) \mathrm{e}{ }^{133} \mathrm{Ba}(81 \mathrm{keV})$ para a excitação de cristal. A tensão utilizada foi de $400 \mathrm{~V}$ e o tempo de contagem espectral foi de $3000 \mathrm{~s}$, à temperatura ambiente de $24 \stackrel{\circ}{\circ} \mathrm{C}$.

O tempo de estabilidade do detector é avaliado pela verificação da mudança temporal da posição do pico e da resolução energética. 


\section{RESULTADOS E DISCUSSÃO}

\subsection{PURIFICAÇÃO E CRESCIMENTO DOS CRISTAIS}

\subsubsection{LEVANTAMENTO DO PERFIL TÉRMICO DO FORNO UTILIZADO NO MÉTODO DE BRIDGMAN}

A Figura11 (metodologia) ilustra o forno vertical utilizado para purificação e crescimento de cristais de $\mathrm{TIBr}$ pelo método de Bridgman. A purificação foi realizada por meio de repetições do crescimento por Bridgman, denominado Bridgman Repetido. A Figura 25 mostra a curva característica obtida do perfil de temperatura do forno. Esse procedimento foi necessário para se verificar a simetria do gradiente de temperatura antes e depois da região de temperatura máxima do forno. É a partir dessa região que se inicia o crescimento do cristal. $O$ forno foi programado para atingir a temperatura máxima de $560^{\circ} \mathrm{C}$.

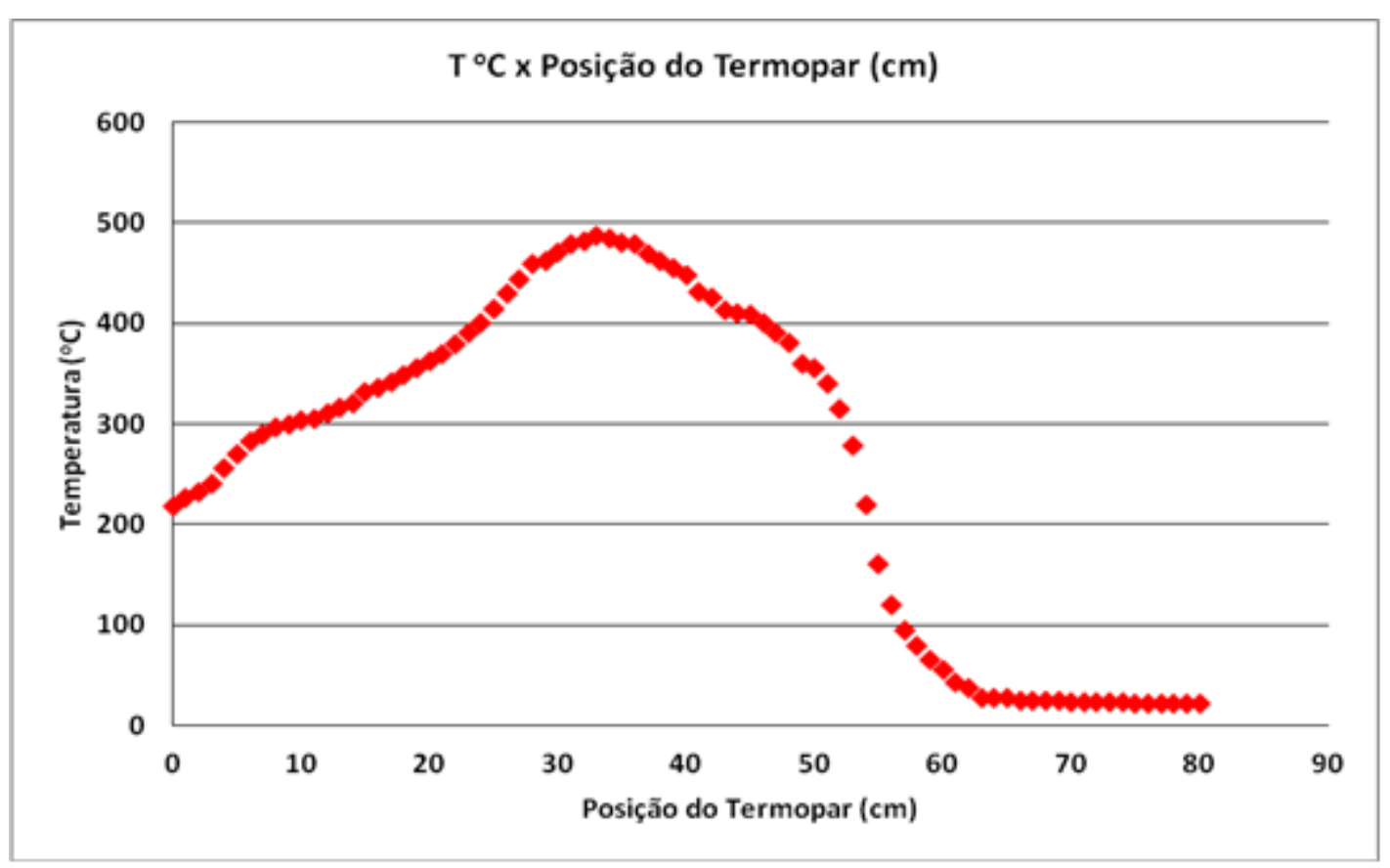

Figura 25: Curva característica do forno vertical de crescimento de cristais: variação da temperatura $\left({ }^{\circ} \mathrm{C}\right)$ x posição do termopar $(\mathrm{cm})$ no interior do forno de crescimento. 
A curva característica de perfil de temperatura do forno (Figura 25) apresentou comportamento de acordo com o esperado, especialmente nos valores de temperaturas entre $400^{\circ} \mathrm{C}$ e $500^{\circ} \mathrm{C}$, em que apresentou simetria em torno do valor máximo obtido. $O$ forno utilizado apresenta a borda inferior aberta, além da borda superior (pela qual é introduzido o cadinho contendo o sal de $\mathrm{TIBr}$ ), possibilitando perdas térmicas que resultam em temperaturas máximas obtidas (entre $400^{\circ} \mathrm{C}$ e $500^{\circ} \mathrm{C}$ ) inferiores as que foram programadas $\left(560^{\circ} \mathrm{C}\right)$. O termopar, bem como o tubo de quartzo (cadinho) contendo o sal de $\mathrm{TIBr}$, não podem encostar nas paredes no interior do mesmo, fato que pode comprometer a estrutura cristalina do cristal crescido e sua termodinâmica de formação, mas deve ficar sempre centralizado, evitando gradientes de temperatura indesejados ou eventuais impactos mecânicos. O controle do processo de descida do tubo de quartzo no interior do forno, de modo a minimizar possíveis oscilações, consiste em um processo fundamental na obtenção de uma estrutura cristalina adequada.

\subsubsection{TRATAMENTO QUÍMICO E DESGASEIFICAÇÃO DOS CADINHOS E DO} SAL DE TIBr

A Figura 26 apresenta os resultados do tratamento químico (retirada de possíveis impurezas) e térmico (desgaseificação) dos cadinhos de quartzo e do sal utilizados. A Figura 26 (a) mostra que o tratamento foi eficiente, visto que o cristal crescido se desprendeu facilmente dos mesmos ao serem retirados. Este é um parâmetro importante a ser avaliado, pois o oxigênio presente em possível resquício de umidade no interior do cadinho pode reagir com o silício presente na constituição do cadinho de quartzo, formando ligação TI-O-Si, o que causa a aderência do cristal nas paredes do cadinho. Este evento pode atribuir danos estruturais e mecânicos aos cristais crescidos e prejudicar a dinâmica de transporte de portadores de carga, comprometendo sua performance final como detector de radiação. A Figura 26 (b) mostra um exemplo de um cristal aderido ao tubo. Fatores como excesso de impurezas no material de partida e/ou presença de oxigênio no cadinho devido à umidade no tubo, podem justificar a adesão apresentada na Figura 26 (b). 


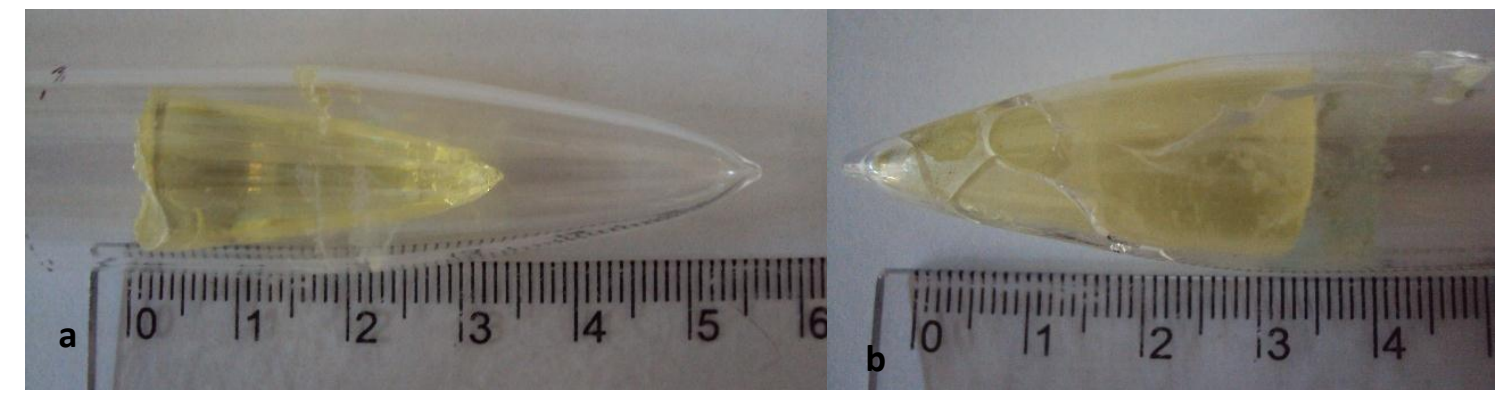

Figura 26: Cristais de $\mathrm{TIBr}$ crescidos pelo método de Bridgman desprendidos no interior do tubo de quartzo (a) e aderido no tubo (b)

As etapas de crescimento e purificação dos cristais pelo método de Bridgman não devem sofrer interferências externas durante o processo de crescimento. Assim, quando ocorre uma ruptura do cadinho de quartzo ou aderência do cristal no interior do mesmo, durante um processo de crescimento, não é possível o reaproveitamento e continuidade dos processos utilizando-se o mesmo cristal, uma vez que, após a ruptura do cadinho, podem ocorrer diferentes agravantes, tais como: introdução de impurezas diversas do ambiente, vazamento e perda de material, oscilações e variações bruscas de temperatura. Logo, deve-se reiniciar outra sequência de crescimentos e purificações com uma nova quantidade de sal comercial de $\mathrm{TIBr}$, para que todas as condições experimentais sejam mantidas. Foram realizadas cinco tentativas de obtenção de cristais de $\mathrm{TIBr}$ submetidos a três processos de crescimentos. Cada uma destas cinco tentativas sofreu alguma interferência imprevista (como, por exemplo, trincas dos cadinhos, aderência dos cristais, queda no fornecimento de energia elétrica, falha no motor de passo controlador de descida dos cadinhos no interior do forno, falha no forno de desgaseificação, ocasionando a fusão parcial do cristal). Após as cinco tentativas, os procedimentos foram ajustados e realizados de forma bem sucedida.

A Figura 27 e a Figura 28 (a) mostram exemplos de aderência dos cristais de $\mathrm{TIBr}$ as paredes dos cadinhos e ruptura dos mesmos, em diferentes etapas dos processos de crescimento e purificação. A Figura 28 (b) mostra um exemplo de cristal de $\mathrm{TIBr}$ que não sofreu aderência ao cadinho de quartzo durante o processo de crescimento. A Figura 29 mostra o detalhe de um cadinho de quartzo que sofreu ruptura durante o processo de crescimento de cristal de $\mathrm{TIBr}$. 


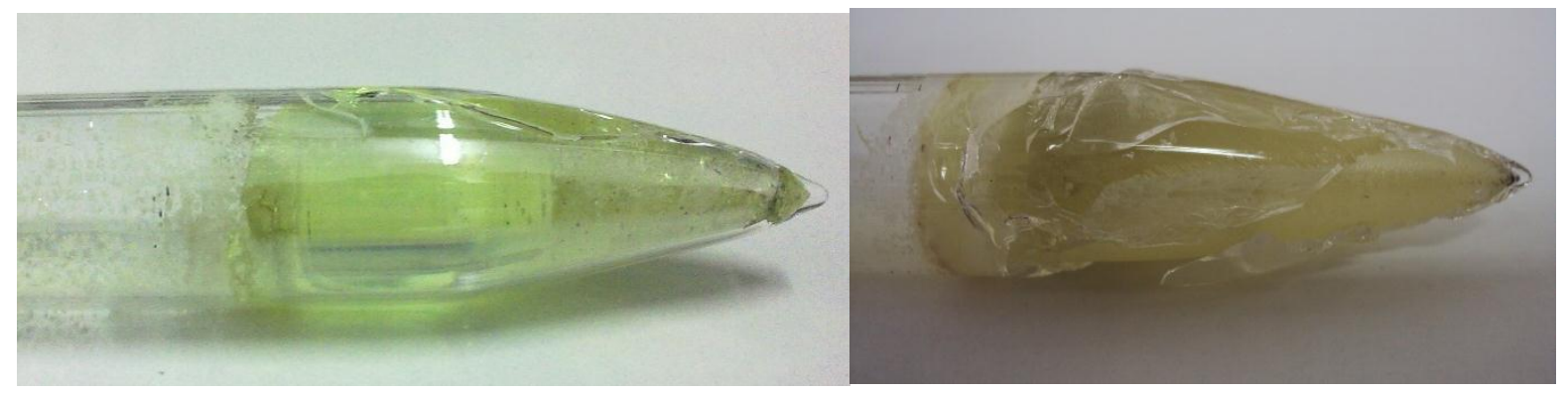

Figura 27: Diferentes cristais de TIBr com aderência aos cadinhos de quartzo.

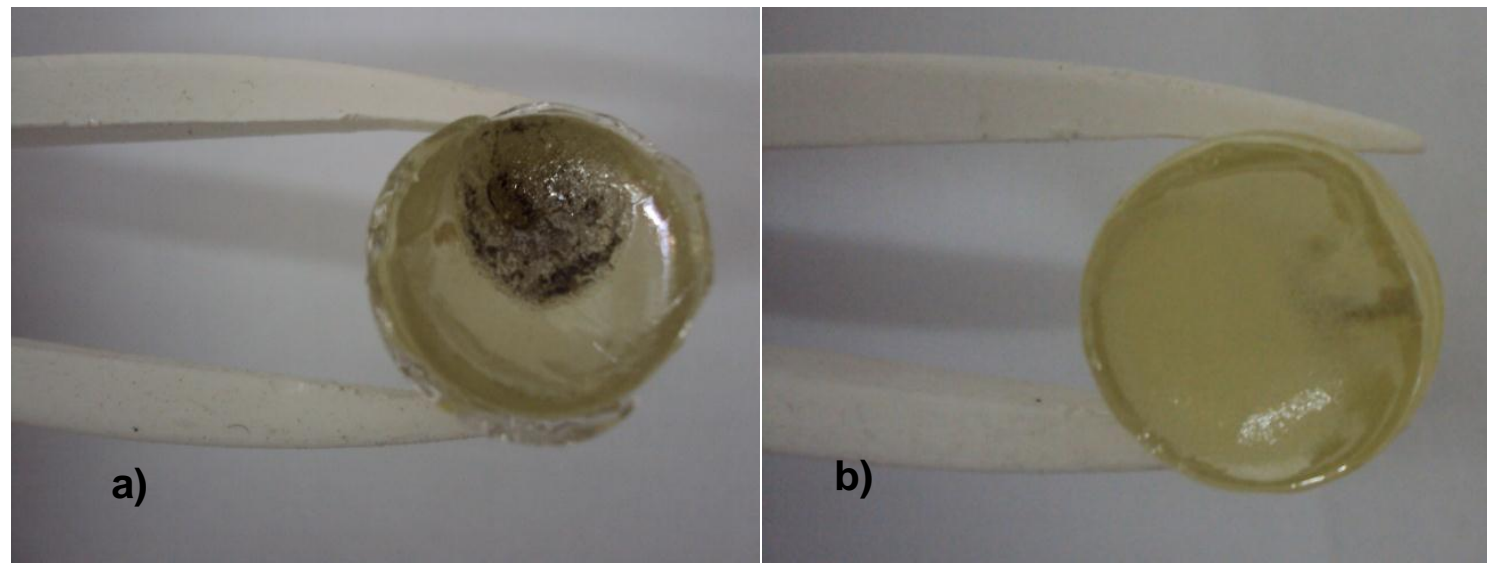

Figura 28: (a) Exemplo de cristal de TIBr que sofreu aderência ao cadinho de quartzo; (b) Exemplo de cristal de TIBr que não sofreu aderência ao cadinho de quartzo

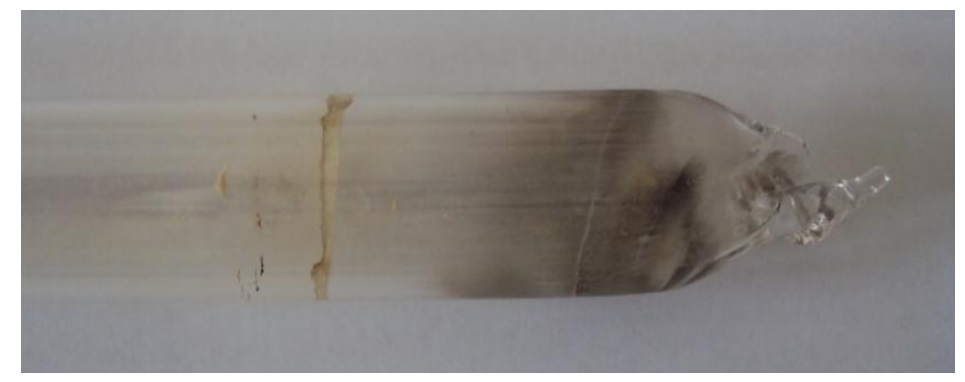

Figura 29: Detalhe de cadinho de quartzo que sofreu ruptura durante o processo de crescimento de cristal de $\mathrm{TIBr}$. 


\subsubsection{CRESCIMENTO DE CRISTAIS DE TIBr PELO MÉTODO DE BRIDGMAN REPETIDAS VEZES PARA PURIFICAÇÃO}

Cristais de $\mathrm{TIBr}$ foram obtidos e apresentaram coloração transparente já no primeiro crescimento, como mostrados na Figura 30 (a). Como pode ser observado desta figura, os cristais submetidos a um único processo de crescimento apresentaram coloração levemente opaca, em comparação aos cristais purificados duas ou três vezes. Os cristais crescidos duas e três vezes apresentaram gradativamente uma cor amarela brilhante forte ao longo de todo o comprimento, como pode ser observado na Figura 30 (b) e na Figura 30 (c).

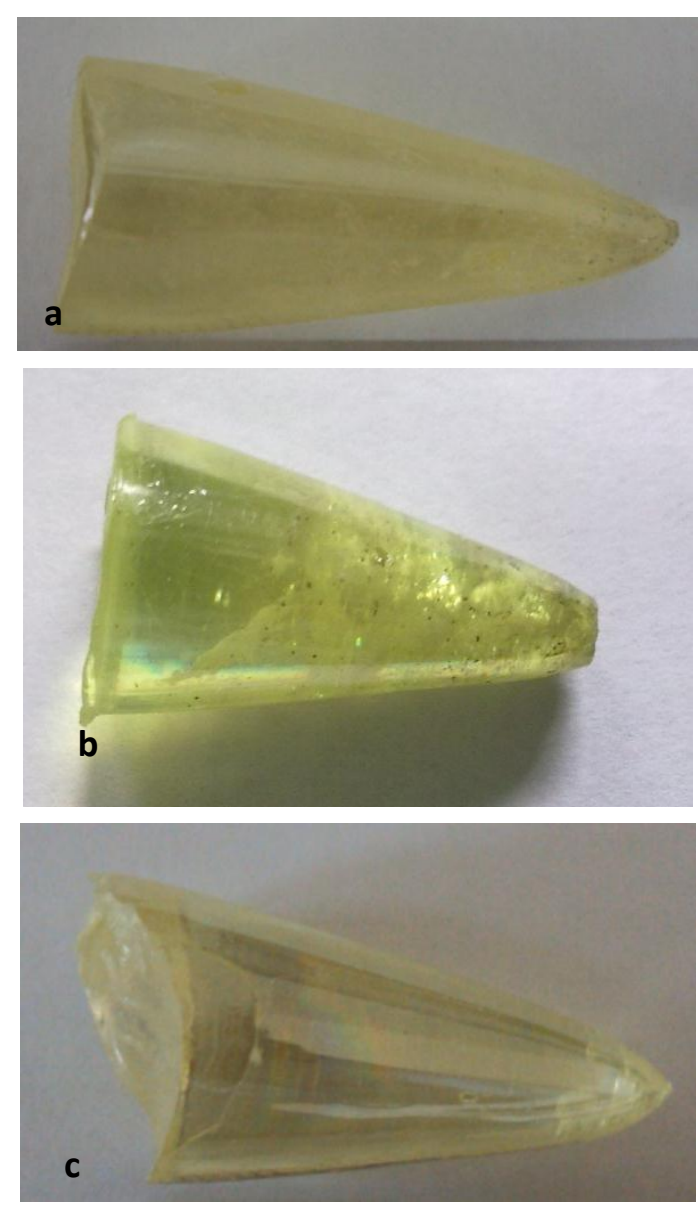

Figura 30: Cristais de $\mathrm{TIBr}$ crescidos pelo método de Bridgman: (a) submetido a um crescimento, (b) submetido a dois crescimentos e (c) submetido a três crescimentos. 


\subsection{TRATAMENTO DAS SUPERFÍCIES}

\subsubsection{CORTE DOS CRISTAIS DE TIBr E POLIMENTO DAS AMOSTRAS}

As Figuras 31 (a) e (b) mostram as fatias cortadas dos cristais de $\mathrm{TIBr}$, a partir da parte central do cristal crescido. Pode-se notar a transparência e cristalinidade da cor característica do material. As fatias foram cortadas usando uma serra com disco de corte de borda diamantada e lubrificada com etileno glicol. O processo foi feito lentamente durante o intervalo de 40 min para cada amostra. A espessura de cada fatia é de $0,65 \mathrm{~mm}$. O polimento foi feito utilizando os abrasivos mencionados no item 3 (Materiais Usados).
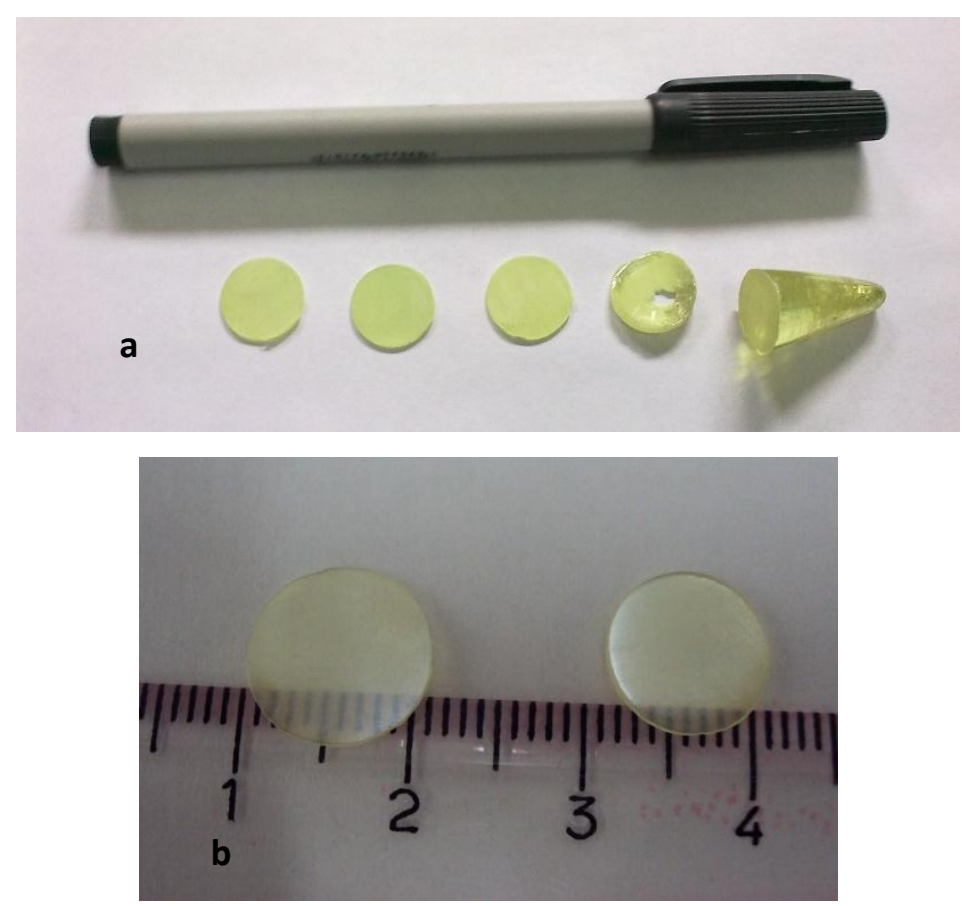

Figura 31: Detalhe das fatias cortadas do cristal de $\mathrm{TIBr}$, sendo antes do polimento (a) e depois do polimento(b). 


\subsection{CARACTERIZAÇÃo FíSICA E QUÍMICA E DE DETECÇÃO À RADIAÇÃo DOS CRISTAIS}

\subsubsection{ANÁLISE DA ESTRUTURA CRISTALINA: DIFRAÇÃO DE RAIOS X (DRX);}

A Figura 32 (a) e (b) e a Figura 33 (a) e (b)ilustram os espectros de resposta da análise de difração de Raios-X, obtidos do sal de $\mathrm{TIBr}$ e das superfícies dos cristais de $\mathrm{TIBr}$ crescidos uma, duas e trêsvezes, respectivamente. Os espectros obtidos para todas as amostras foram similares; não foram observadas diferenças significativas nas estruturas dos cristais obtidos sem purificação e purificados, apenas variações das intensidades dos picos de difração, devido às probabilidades de interações. Com isso, tem-se que as diferentes concentrações de diferentes impurezas não interferiram na estrutura cristalina. Os difratogramas indicam que os cristais estão orientados preferencialmente nos planos (110) e (211) com estrutura semelhante ao modelo cúbico cristalino do $\mathrm{TIBr}$. Este resultado está de acordo com a literatura[1,2,3,10,12]. 


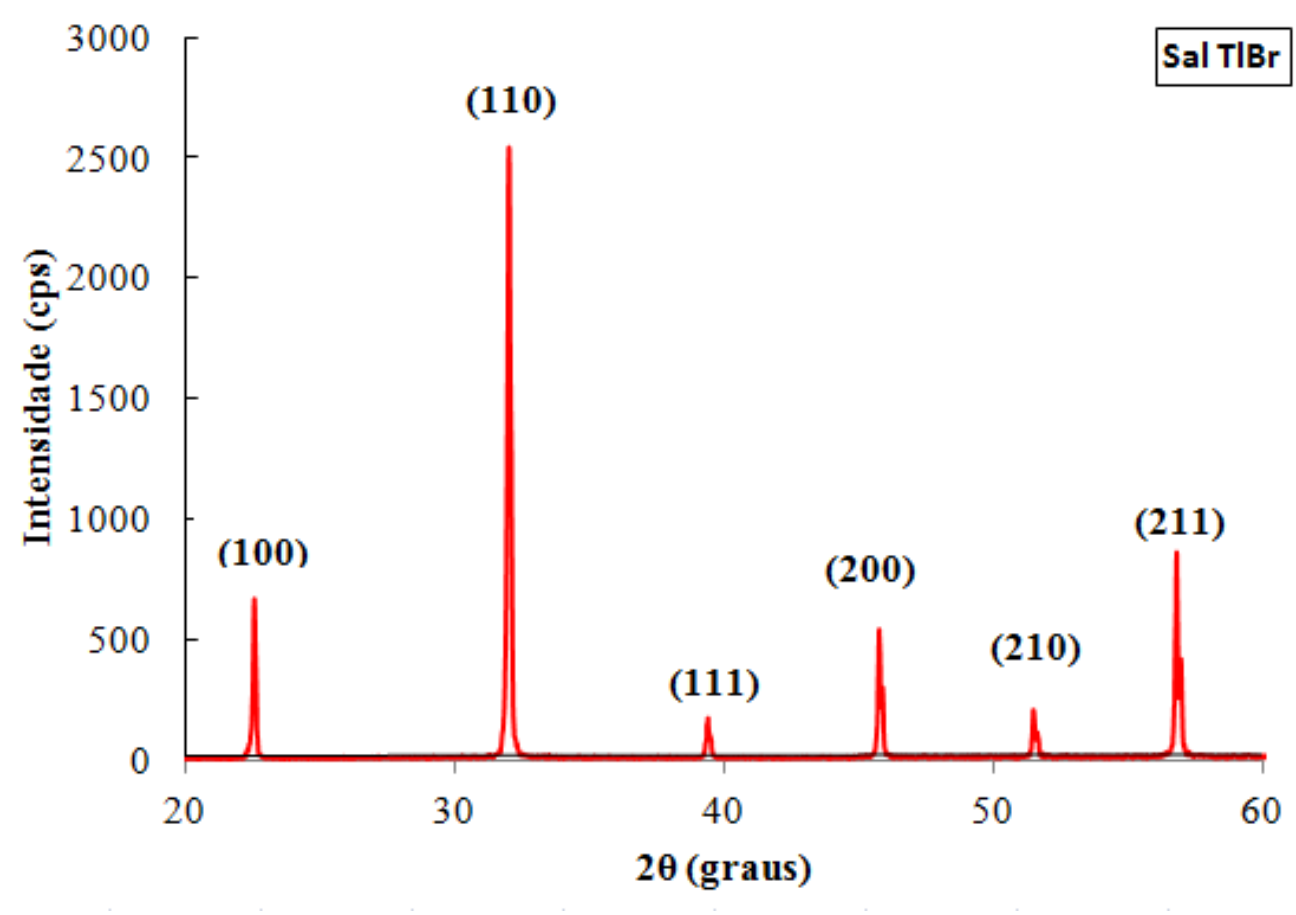

a)

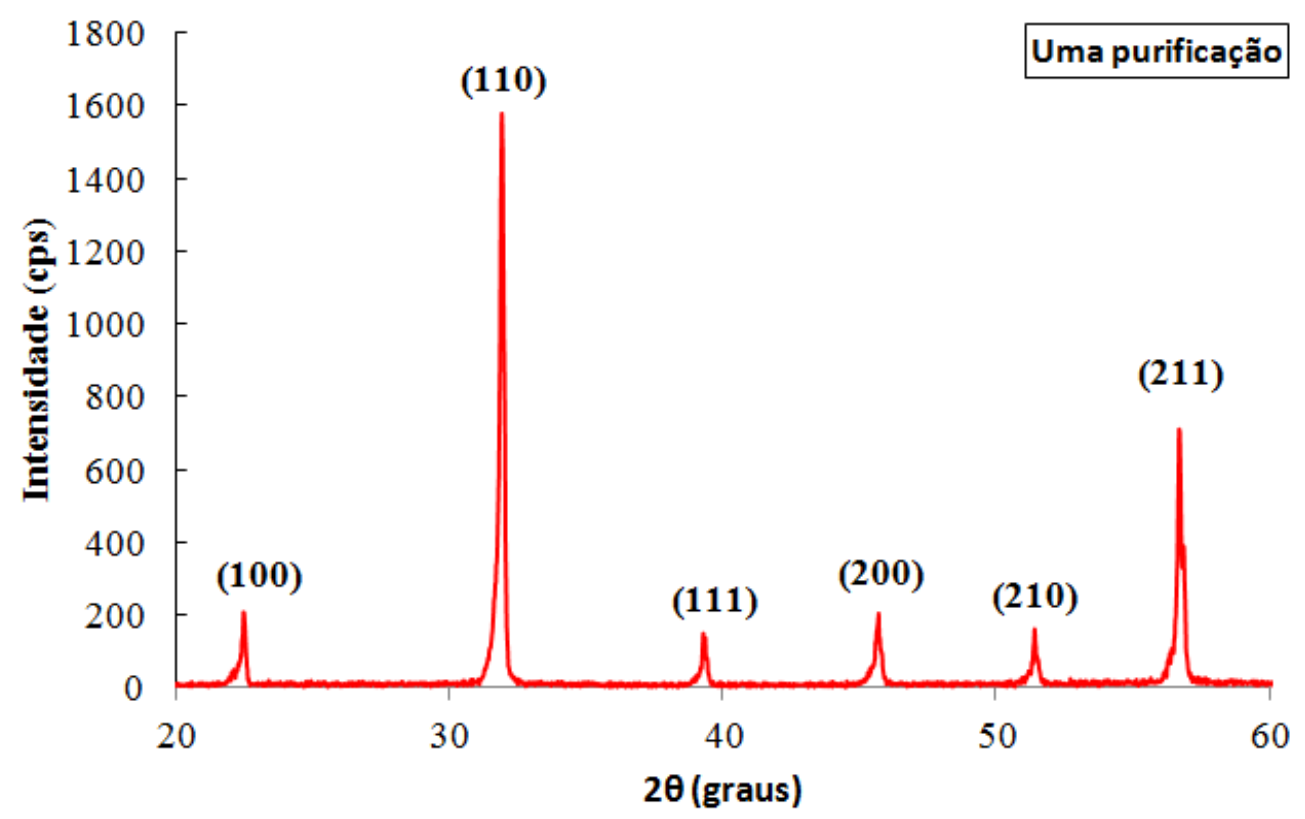

b)

Figura 32: Difratograma típico do sal comercial de $\operatorname{TIBr}(\mathrm{a})$; difratograma do cristal de TIBr submetido a uma purificação (b). 


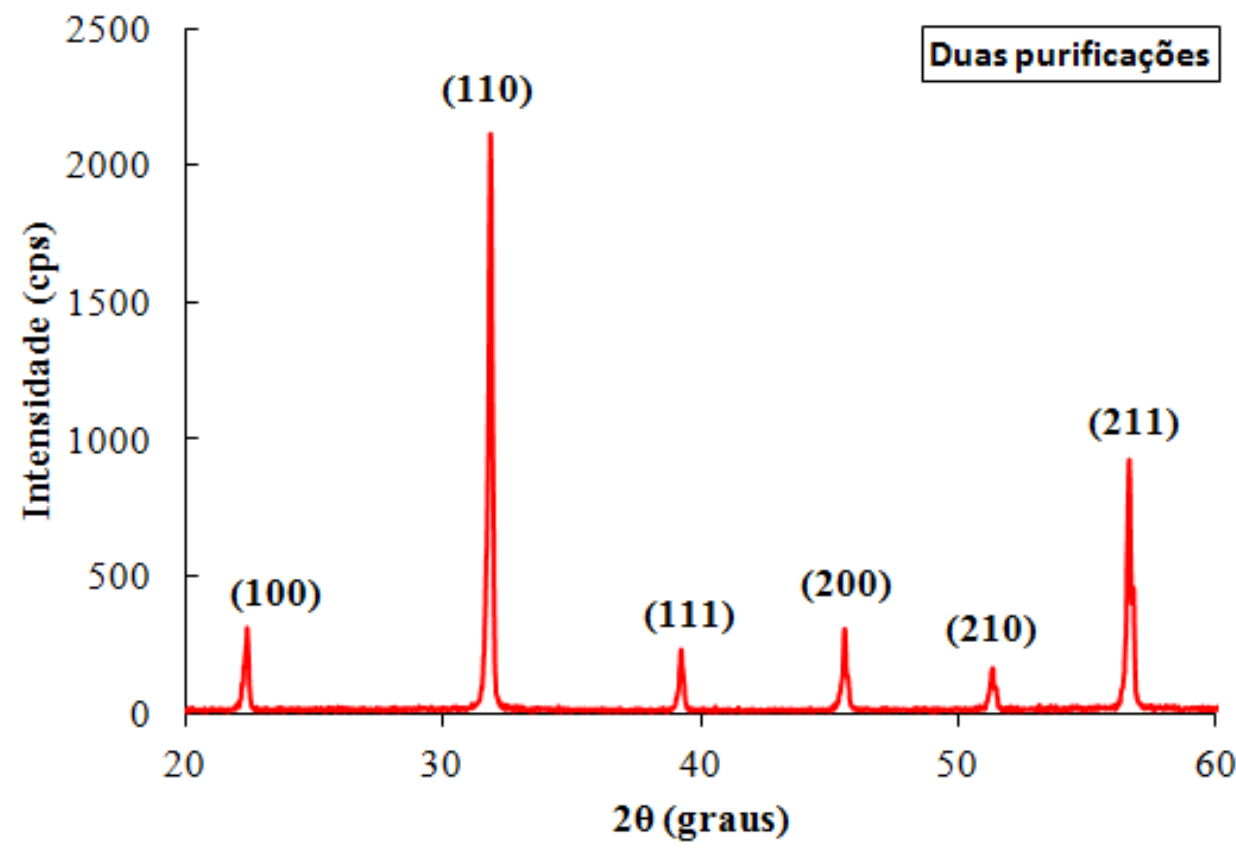

c)

Três purificações

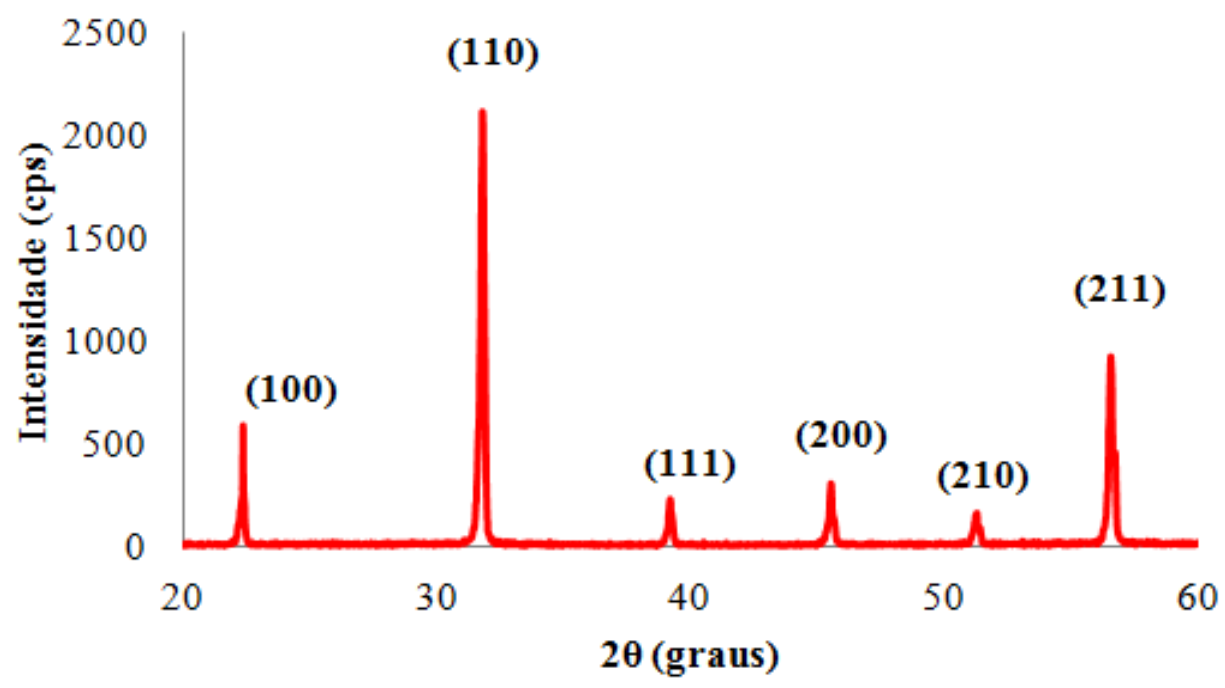

d)

Figura 33: Difratograma do cristal de TIBr crescido a partir do sal comercial: a) submetido a duas purificações e b) submetido a três purificações. 


\subsubsection{ANÁLISE MORFOLÓGICA E VERIFICAÇÃO ESTEQUIOMÉTRICA: MICROSCOPIA ELETRÔNICA DE VARREDURA COM ELÉTRONS SECUNDÁRIOS (MEV-SE) E COM ESPECTROSCOPIA DE ENERGIA DISPERSIVA (MEV-EDS);}

As Figuras 34, 35 e 36 apresentam as micrografias realizadas com MEV-SE em fatias cortadas dos cristais de $\mathrm{TIBr}$ após primeiro, segundo e terceiro crescimentos, respectivamente, com diferentes ampliações. Pode ser observada que as fatias dos cristais crescidos apresentam uma superfície bastante uniforme e que a rugosidade diminui em função do número de crescimento. No entanto, as possíveis incrustações de resíduos (impurezas diversas) tornam-se mais evidente devido à uniformidade da superfície, como pode ser observado nas diferentes ampliações para os três crescimentos.
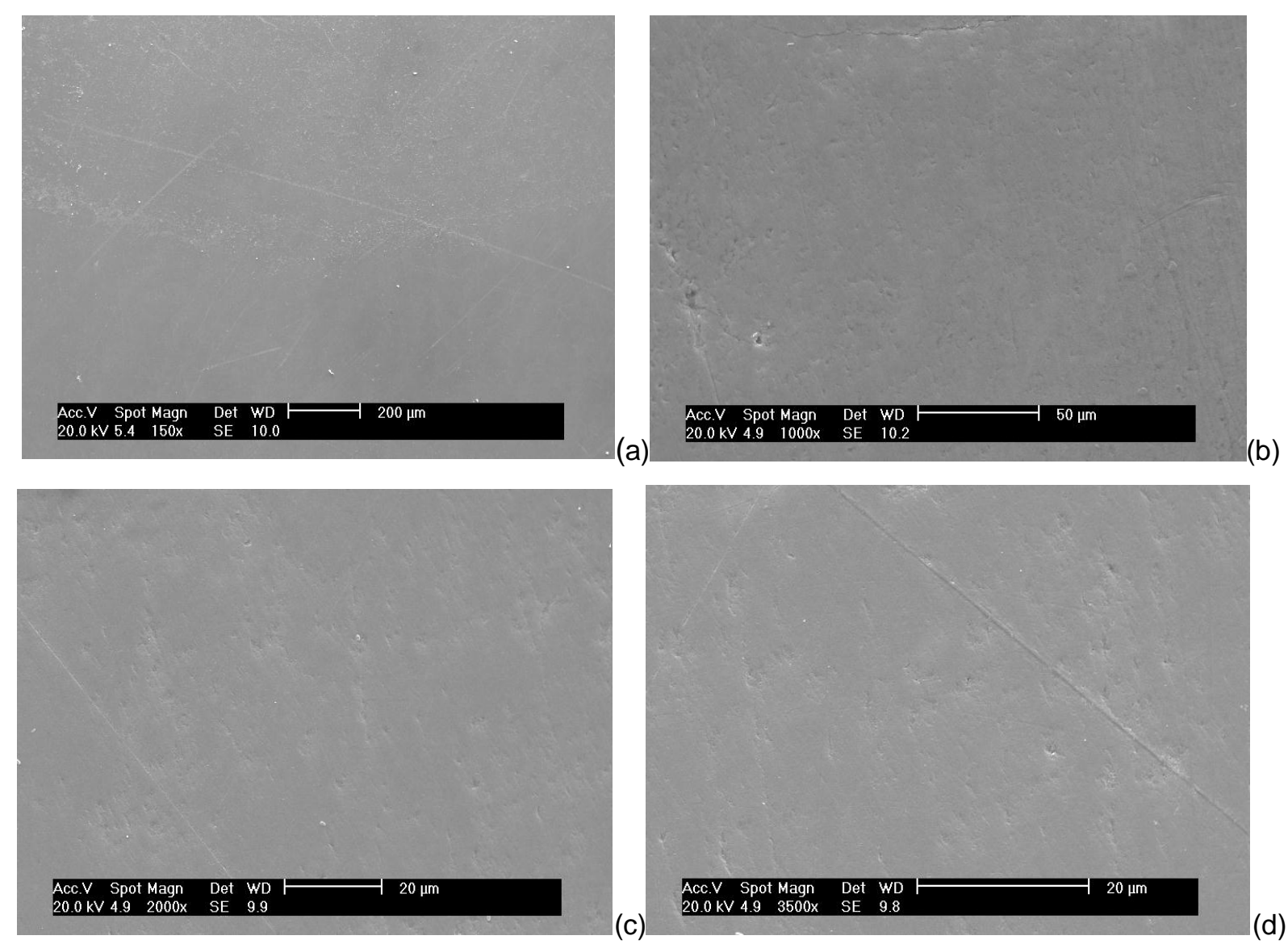

Figura 34: Micrografia das fatias do cristal obtido com um crescimento ampliada 150 vezes (a), 1000 vezes (b), 2000 vezes (c) e 3500 vezes (d). 

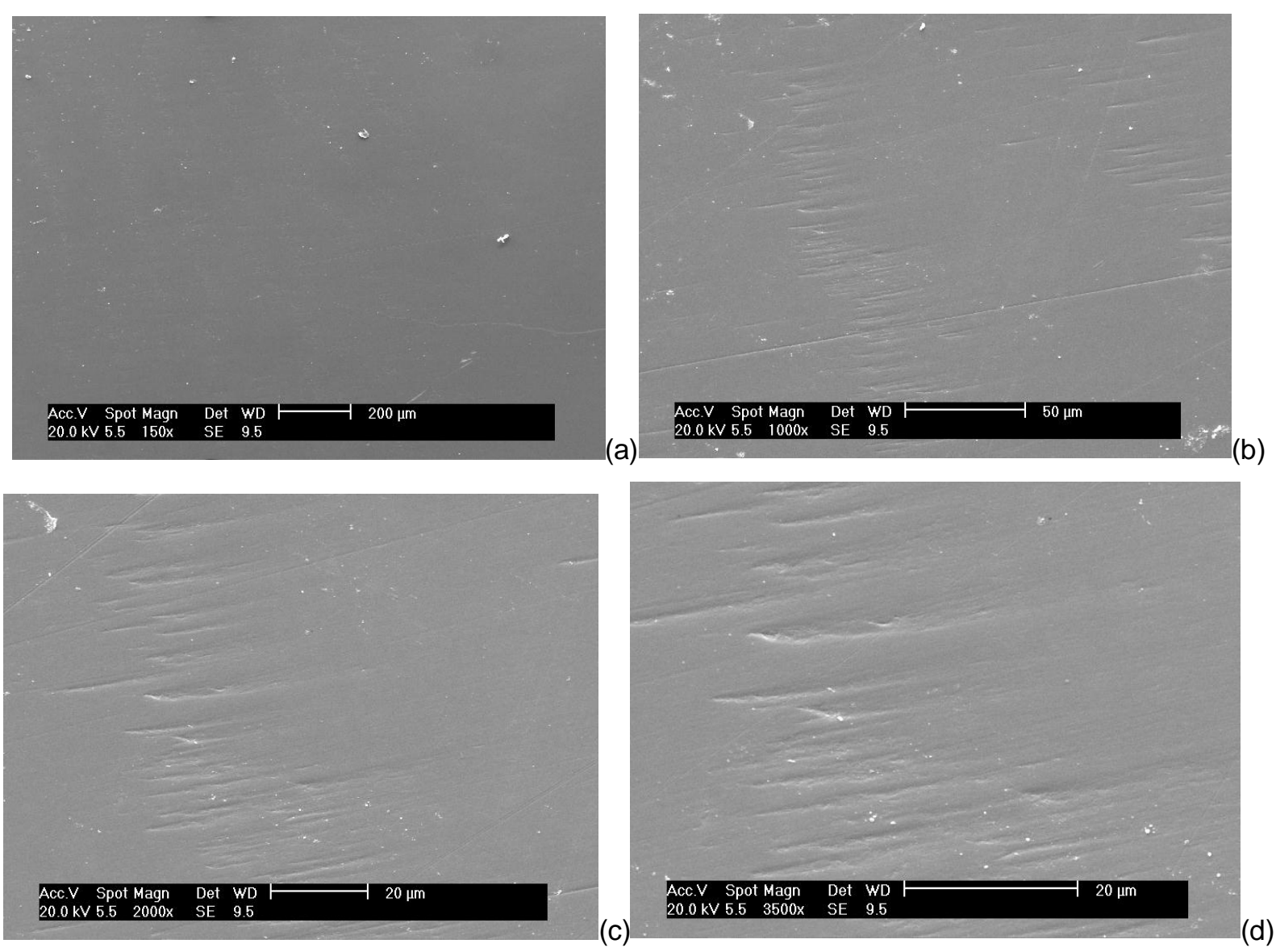

Figura 35: Micrografia das fatias do cristal obtido com dois crescimentos ampliada 150 vezes (a), 1000 vezes (b), 2000 vezes (c) e 3500 vezes (d). 

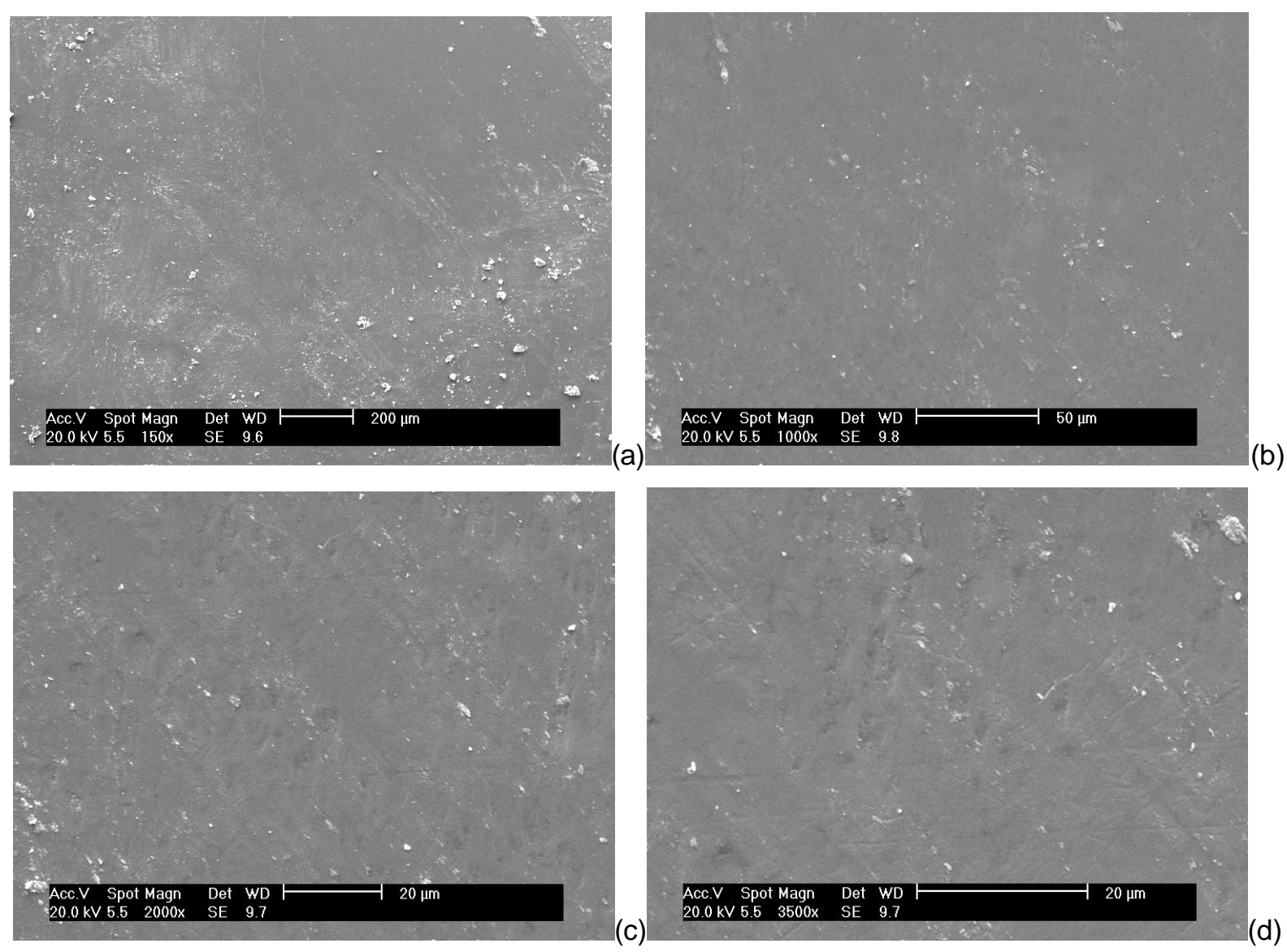

Figura 36: Micrografia das fatias do cristal obtido com três crescimentos ampliada 150 vezes (a), 1000 vezes (b), 2000 vezes (c) e 3500 vezes (d).

Adicionalmente, a técnica de MEV-EDS fornece uma varredura semiquantitativa dos elementos presentes na superfície do cristal, bem como a estequiometria do $\mathrm{TIBr}$. Os resultados de estequiometria apresentados na Tabela 2 são de três amostras representativas dos cristais purificados uma, duas e três vezes e a Figura 37 ilustra um exemplo típico de espectro da composição elementar da superfície dos cristais obtido por MEV-EDS. Como pode ser observado nestes resultados, a estequiometria do $\mathrm{TIBr}$ foi mantida para todos os cristais, independentemente do número de purificações. Por exemplo, no cristal 3 da Tabela 2, pode se inferir que a porcentagem atômica de $\mathrm{TI}$ foi $50,73 \%$ e de $\mathrm{Br}$ foi de $49,27 \%$, ou seja manteve-se a estequiometria adequada, de um átomo de TI para um átomo de $\mathrm{Br}$. 
Tabela 2: Composição elementar da superfície do cristal obtido por três repetições do processo de crescimento dos cristais obtidos.

\begin{tabular}{|c|c|c|c|c|}
\hline \multirow{2}{*}{ Crescimento } & Elemento & \% massa & \% atômica & $\begin{array}{c}\text { Desvio } \\
\text { Padrão }\end{array}$ \\
\hline \multirow{2}{*}{1} & $\mathrm{Br}$ & 30,54 & 52,93 & 1,17 \\
\cline { 2 - 5 } & $\mathrm{TI}$ & 69,46 & 47,07 & 0,96 \\
\hline \multirow{2}{*}{2} & $\mathrm{Br}$ & 30,1 & 52,42 & 1,13 \\
\cline { 2 - 5 } & $\mathrm{TI}$ & 69,9 & 47,58 & 0,92 \\
\hline \multirow{2}{*}{3} & $\mathrm{Br}$ & 27,52 & 49,27 & 1,84 \\
\cline { 2 - 5 } & $\mathrm{TI}$ & 72,48 & 50,73 & 1,38 \\
\hline
\end{tabular}

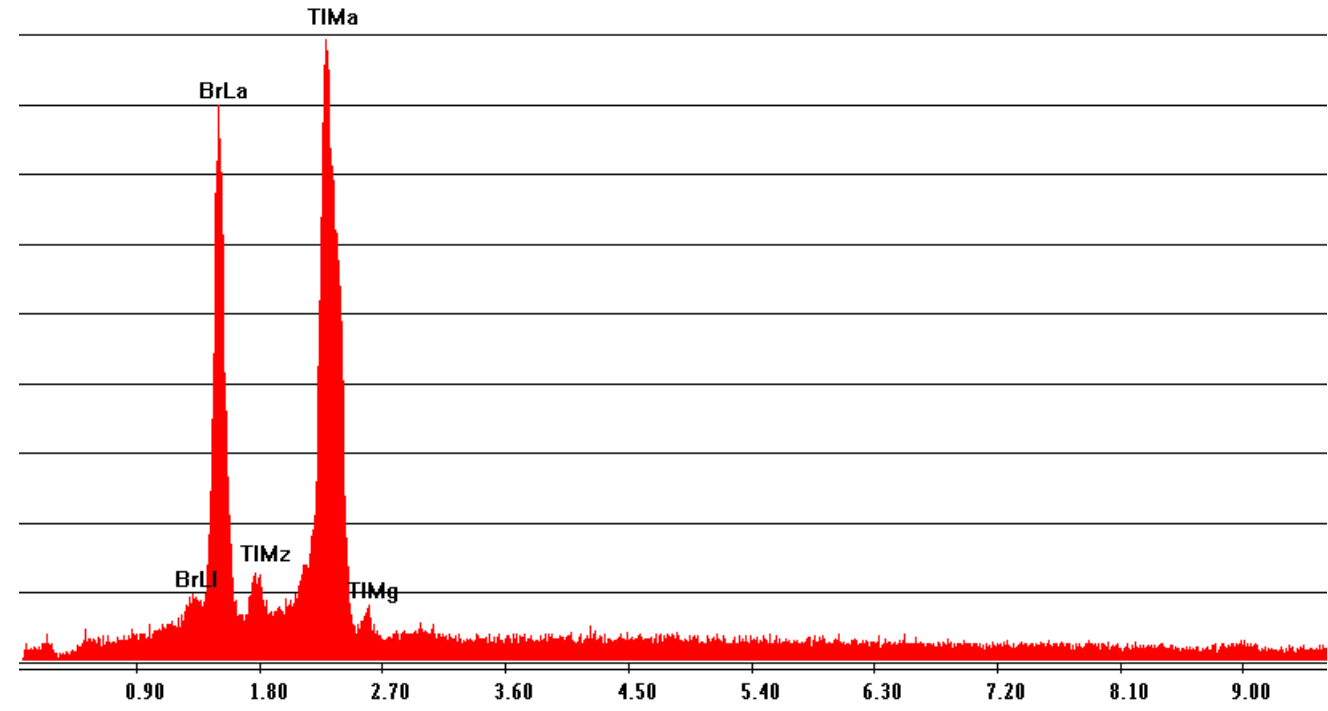

Figura 37: Espectro da composição elementar da superfície dos cristais, obtido por MEV-EDS. 


\subsubsection{ANÁLISE QUANTITATIVA DAS IMPUREZAS PRESENTES POR ESPECTROMETRIA DE MASSA COM FONTE DE PLASMA (ICP-MS)}

A Tabela 3 resume os valores da concentração dos seis íons mensurados por meio da técnica de ICP/MS, para as diferentes partes dos cristais, bem como no material de partida (sal de $\mathrm{TIBr}$ ). Pode-se notar, conforme a Tabela 3, que alguns valores estão constantes e abaixo do limite de detecção para a técnica utilizada (aprox. 0,02). As oscilações nos valores de concentrações obtidas para alguns elementos, como $\circ \mathrm{Fe}$, por exemplo, podem ser justificadas pelo movimento aleatório (browniano) intra e inter-regional dos mesmos, devido a fatores cinéticos e termodinâmicos, bem como pela possível contaminação durante algumas das fases de todo o processo de crescimento e purificação dos cristais.

Tabela 3: Concentrações (em ppm) das principais impurezas medidas por ICP/MS para diferentes partes de cada um dos cristais crescidos, bem como a concentração no material de partida (sal de $\mathrm{TIBr}$ ).

\begin{tabular}{|c|c|c|c|c|c|c|c|c|c|}
\hline \multicolumn{5}{|c|}{$\mathbf{A l}$} & \multicolumn{5}{|c|}{$\mathrm{Ti}$} \\
\hline Sal & Crescimento & 1 & 2 & 3 & Sal & Crescimento & 1 & 2 & 3 \\
\hline 1,49169 & Ponta & 0,00150 & 0,00150 & 0,00150 & 0,10996 & Ponta & 0,02546 & 0,00787 & 0,00075 \\
\hline 1,49169 & Meio & 0,00150 & 0,00150 & 0,00150 & 0,10996 & Meio & 0,01782 & 0,00689 & 0,00150 \\
\hline 1,49169 & Topo & 0,00150 & 0,00150 & 0,00150 & 0,10996 & Topo & 0,00075 & 0,02673 & 0,00075 \\
\hline \multicolumn{5}{|c|}{ V } & \multicolumn{5}{|c|}{$\mathrm{Fe}$} \\
\hline Sal & \multicolumn{2}{|l|}{ Crescimento } & \multicolumn{2}{|l|}{2} & Sal & \multicolumn{2}{|l|}{ Crescimento } & \multirow[b]{2}{*}{0,05603} & 3 \\
\hline 1,27557 & Ponta & 0,58232 & 0,53266 & 0,43718 & 0,92320 & Ponta & 0,07673 & & 0,00060 \\
\hline 1,27557 & Meio & 0,55557 & 0,52989 & 0,47254 & 0,92320 & Meio & 0,07673 & 0,00060 & 0,00060 \\
\hline 1,27557 & Topo & 0,45901 & 0,64594 & 0,45445 & 0,92320 & Topo & 0,00060 & 0,44529 & 0,00060 \\
\hline \multicolumn{5}{|c|}{ As } & \multicolumn{5}{|c|}{$\mathrm{Zr}$} \\
\hline Sal & Crescimento & \multicolumn{2}{|r|}{2} & 3 & Sal & Crescimento & 1 & 2 & 3 \\
\hline 0,52750 & Ponta & 0,16415 & 0,15313 & 0,13149 & 0,56119 & Ponta & 0,00005 & 0,00005 & 0,00005 \\
\hline 0,52750 & Meio & 0,15589 & 0,15431 & 0,13700 & 0,56119 & Meio & 0,01250 & 0,00005 & 0,00005 \\
\hline 0,52750 & Topo & 0,13464 & 0,17202 & 0,14959 & 0,56119 & Topo & 0,00005 & 0,00005 & 0,00005 \\
\hline
\end{tabular}




\subsubsection{ANÁLISE DE SEGREGAÇÃO DE IMPUREZAS PRESENTES (MODELO COMPARTIMENTAL)}

Os valores dos coeficientes de segregação de impurezas obtidos a partir das equações 16, 17, 18, 19 e 20 e do modelo apresentado na Figura 22 são sumarizados na Tabela 4, juntamente com os valores dos erros dos mesmos, calculados por meio de regressão assintótica.

Assim como as concentrações das diferentes impurezas estão sujeitas a fatores cinéticos e termodinâmicos, os valores dos coeficientes de migração das impurezas também estão sujeitos a tais fatores, bem como a fatores probabilísticos (movimentos aleatórios), justificando seus valores com suas respectivas incertezas. Em um aspecto geral, tem-se que cada uma das etapas de crescimento e purificação dos cristais, retirada de amostras para análise, procedimentos de análises diversas, dentre outros fatores experimentais, contribui de forma significativa para os resultados das análises finais, bem como para o desempenho do material aplicado como detector de radiação. 
Tabela 4: Coeficientes de segregação de impurezas para as diferentes regiões dos cristais juntamente com suas incertezas (erros de regressão assintótica).

\begin{tabular}{|c|c|c|}
\hline Impurezas & $\begin{array}{c}\text { Coeficiente de } \\
\text { segregação }\end{array}$ & Valores \\
\hline \multirow[b]{3}{*}{ Al } & $k_{1,2}=k_{2,3}$ & $0.43 \pm 0.12$ \\
\hline & $k_{2,4}$ & $0.047 \pm 0.023$ \\
\hline & $\mathbf{k}_{3,5}$ & $0.13 \pm 0.07$ \\
\hline \multirow[b]{3}{*}{ Ti } & $k_{1,2}=k_{2,3}$ & $0.31 \pm 0.09$ \\
\hline & $k_{2,4}$ & $0.0055 \pm 0.0463$ \\
\hline & $k_{3,5}$ & $0.322 \pm 0.086$ \\
\hline \multirow[b]{3}{*}{$\mathbf{V}$} & $k_{1,2}=k_{2,3}$ & $0.36 \pm 0.01$ \\
\hline & $k_{2,4}$ & $0.077 \pm 0.013$ \\
\hline & $\mathbf{k}_{3,5}$ & $0.29 \pm 0.01$ \\
\hline \multirow[b]{3}{*}{$\mathrm{Fe}$} & $k_{1,2}=k_{2,3}$ & $0.18 \pm 0.09$ \\
\hline & $k_{2,4}$ & $0.0075 \pm 0.0352$ \\
\hline & $\mathbf{k}_{3,5}$ & $0.508 \pm 0.097$ \\
\hline \multirow[b]{3}{*}{ As } & $k_{1,2}=k_{2,3}$ & $0.21 \pm 0.51$ \\
\hline & $k_{2,4}$ & $0.004 \pm 0.200$ \\
\hline & $k_{3,5}$ & $0.12 \pm 0.45$ \\
\hline \multirow[b]{3}{*}{$\mathrm{Zr}$} & $k_{1,2}=k_{2,3}$ & $0.651 \pm 0.21$ \\
\hline & $\mathbf{k}_{\mathbf{2 , 4}}$ & $0.003 \pm 0.210$ \\
\hline & $k_{3,5}$ & $0.23 \pm 0.15$ \\
\hline
\end{tabular}

O modelo apresentado na Figura 22 mostrou ser útil como uma ferramenta para propósito de análise de controle de qualidade. Os parâmetros $k_{i, j}$, que são associados a eficiência da migração das impurezas, podem ser uma importante ferramenta auxiliar para projetar, otimizar e explicar os resultados e processos envolvidos na purificação do sal de partida para crescimento de cristais diversos. Por exemplo, para entender o aumento na concentração de impurezas na região "Meio" do cristal no segundo crescimento Bridgman (Figura 22). Ainda que pareça uma contradição, pois essa tende a ser a região de maior pureza, esta ocorrência pode ser prevista e quantificada pela análise compartimental apresentada. $\mathrm{O}$ modelo 
proposto (Figura 22) possibilita a compreensão deste efeito, uma vez que pode ser utilizado para prever que as impurezas localizadas na região anterior migram para a região subseqüente, contribuindo para o aumento da sua concentração. Assim, o parâmetro $k_{i, j}$ é de grande valia para representar a eficácia da técnica de purificação, especificar regiões de interesse e traçar relações entre parâmetros cinéticos e termodinâmicos gerais e locais. Portanto, pode-se prever e analisar o número de purificações necessário para se atingir determinada concentração de impurezas a partir de um estado inicial, como mostrado na Figura 38. Nessa figura, pode-se observar o número de processos de purificação necessário para que a concentração de impurezas sofra uma redução de $90 \%$, por exemplo. Não é observado na literatura um percentual aceitável de redução de impurezas para o $\mathrm{TIBr}$.

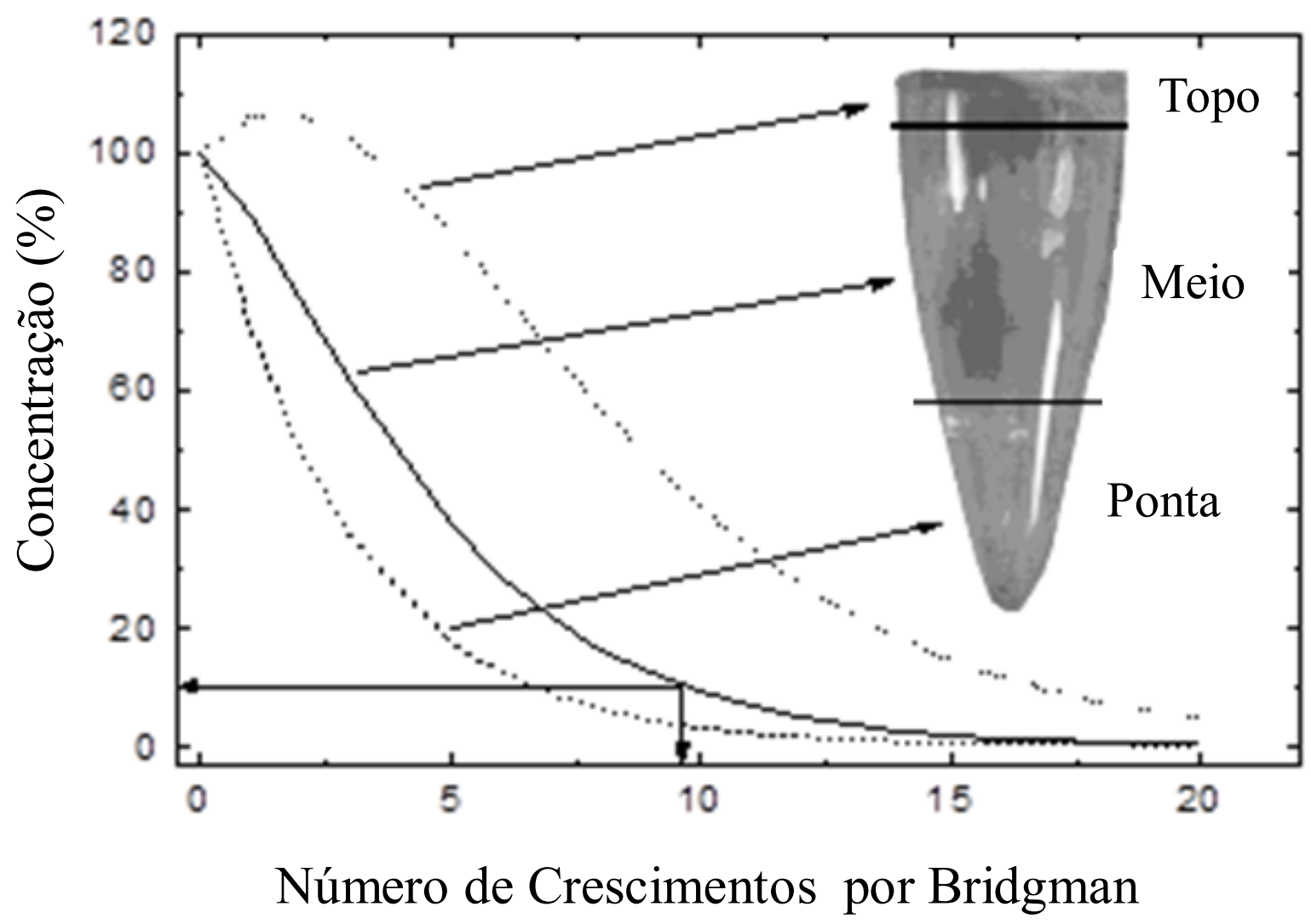

Figura 38: Concentração prevista em função do número de repetições do processo de crescimento Bridgman (purificações) para as diferentes regiões do cristal (compartimentos). 


\subsubsection{CARACTERIZAÇÃO DO CRISTAL SEMICONDUTOR DE TIBr COMO DETECTOR DE RADIAÇÃO A TEMPERATURA AMBIENTE}

A Figura 39 ilustra os espectros de altura de pulso obtidos para o cristal crescido duas vezes e a Figura 40, para o cristal crescido três vezes, pelo método de Bridgman repetido. As fontes de radiação gama de ${ }^{241} \mathrm{Am}$ (energia de 59,5keV) e ${ }^{133} \mathrm{Ba}$ (energia de $81 \mathrm{keV}$ ) foram utilizadas para a excitação de cristal. A tensão utilizada foi $400 \mathrm{~V}$ e tempo de contagem para obtenção do espectro de $3000 \mathrm{~s}$. Foram utilizadas duas amostras de cada cristal para a incidência de radiação das fontes: amostras 3 e 4 retiradas do cristal crescido duas vezes e amostras 5 e 6 retiradas do cristal crescido três vezes.

Os espectros obtidos para o cristal crescido duas vezes apresentaram picos em posições diferentes para cada uma de suas amostras (amostras 3 e 4) devido a pequenas variações de condições experimentais, tais como: diferenças de espessura das amostras, devido ao processo de polimento, e de superfície dos contatos elétricos; variação da distância fonte-detector (tal distância deve ser a menor possível). O mesmo evento ocorreu para o cristal crescido três vezes (amostras 5 e 6). Com relação à espessura máxima possível associada ao desempenho das amostras como detectores, deve-se considerar, dentre outros fatores, o produto de mobilidade dos portadores de carga por seu tempo de vida $(\mu \tau)$, que é relacionado com a eficiência de coleta de cargas, indispensável para boa resolução energética. Estudos sobre tais parâmetros devem ser realizados por outros trabalhos futuros. 


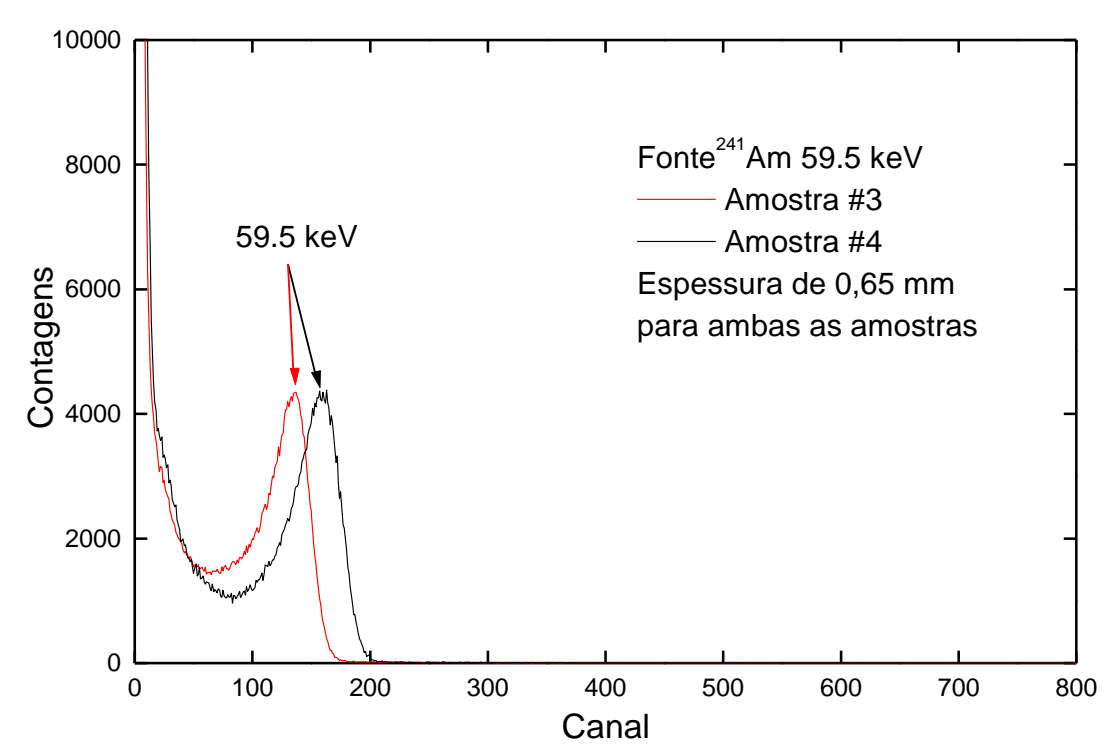

a)

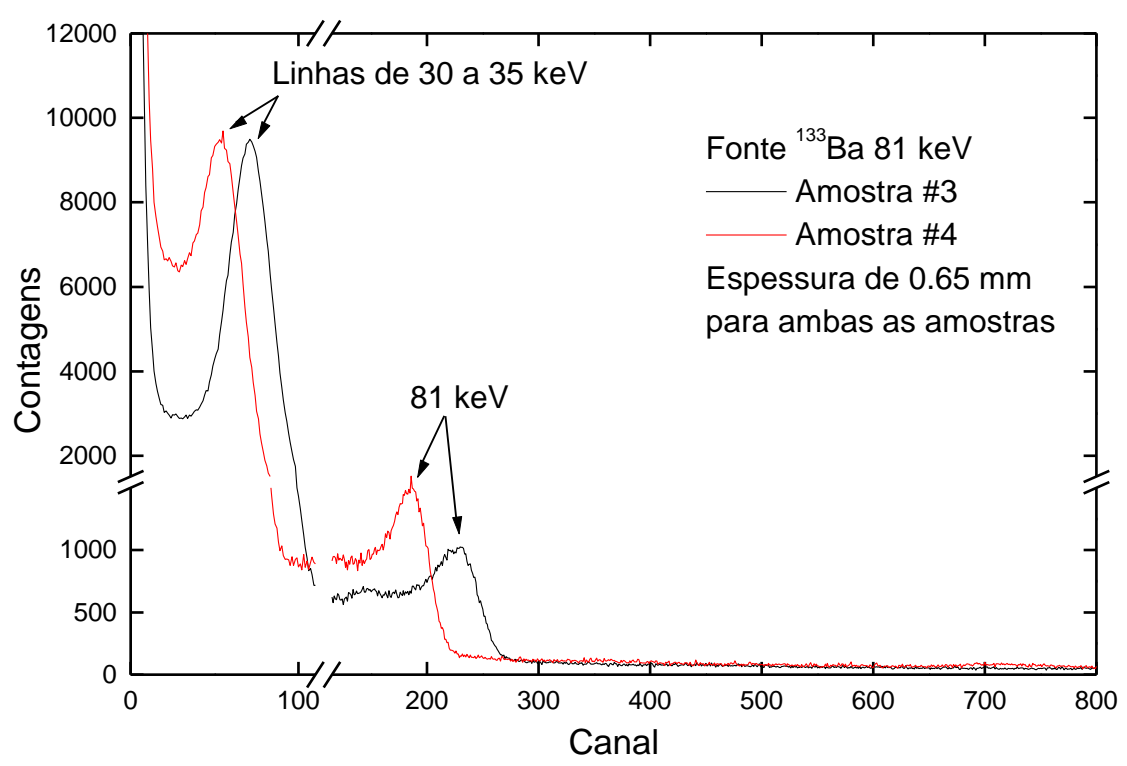

b)

Figura 39: Espectros obtidos para as amostras do cristal de $\mathrm{TIBr}$ submetido a dois crescimentos para as fontes de ${ }^{241} \mathrm{Am}$ (a) e ${ }^{133} \mathrm{Ba}(\mathrm{b})$. 


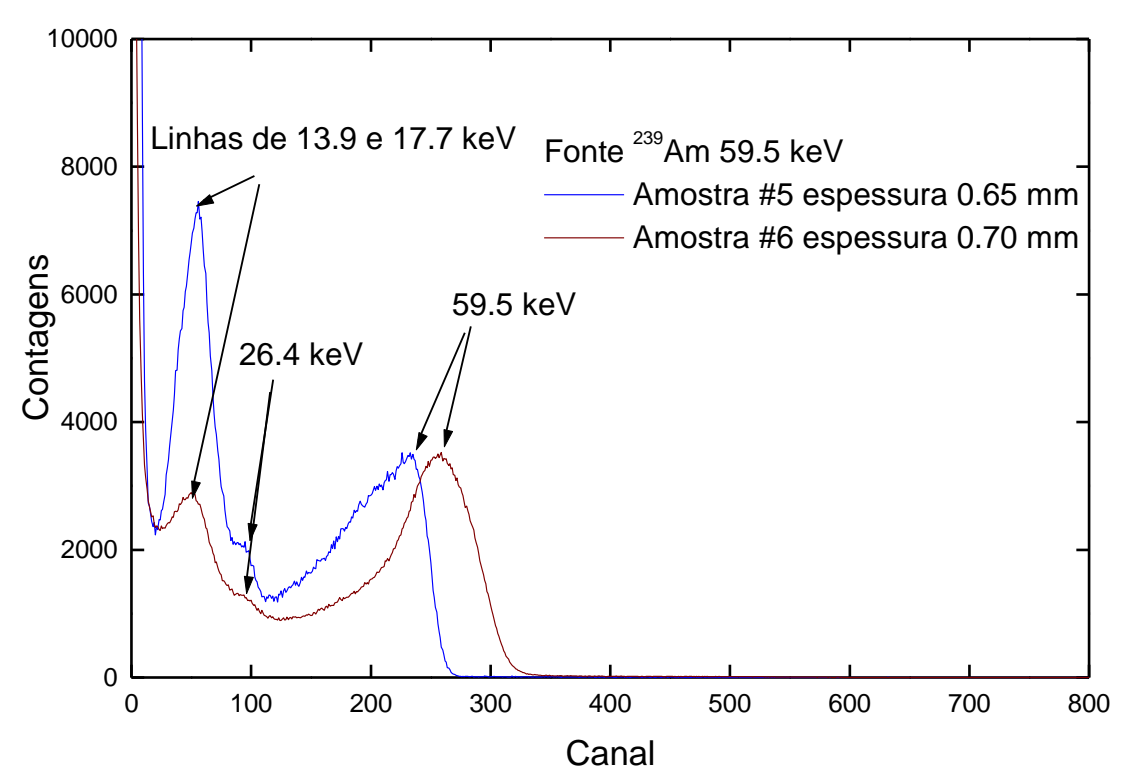

a)

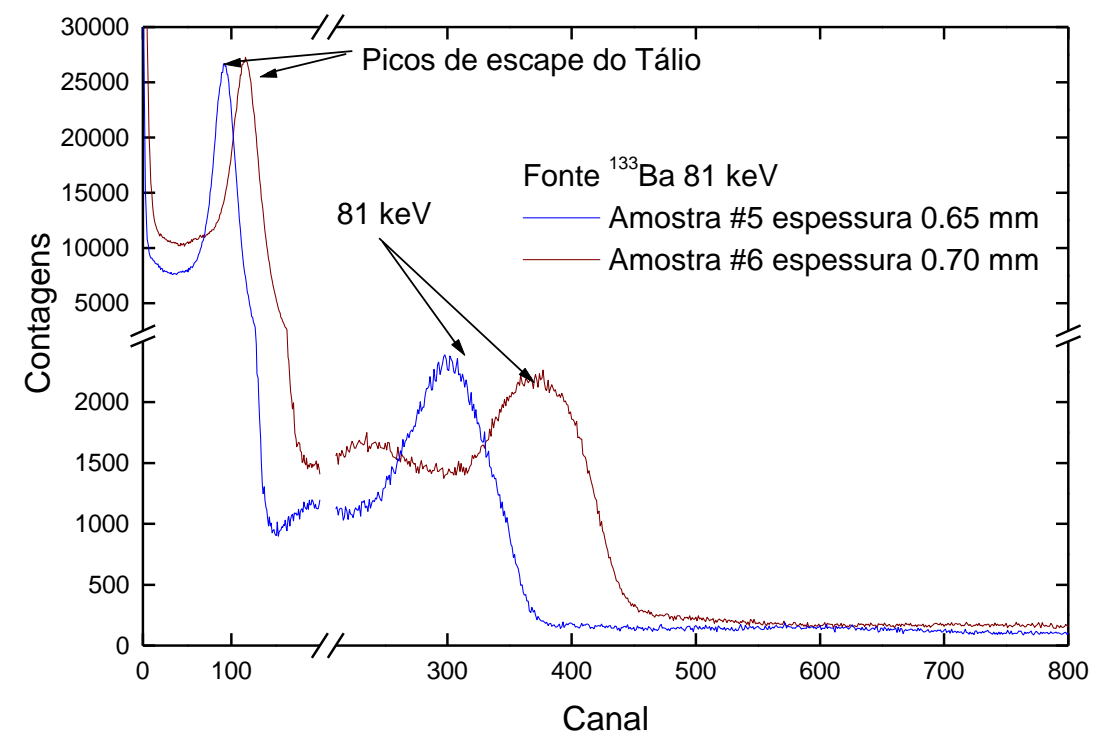

b)

Figura 40: Espectros obtidos para as amostras do cristal de $\mathrm{TIBr}$ submetido a três crescimentos para as fontes de ${ }^{241} \mathrm{Am}$ (a) $\mathrm{e}^{133} \mathrm{Ba}(\mathrm{b})$. 
Para o cristal de $\mathrm{TIBr}$ crescido apenas uma vez, foi possível observar a resposta da radiação apenas no modo de corrente. Para esses detectores, o modo de pulso não foi observado devido a uma baixa resposta à radiação e um sinal de ruído elevado. Nas Figuras 39(b) e 40(b) podem ser vistos os picos de escape (28 $\mathrm{keV}$ ) do tálio e na Figura 40(a) pode ser visto um fotopico de uma das múltiplas linhas do ${ }^{241} \mathrm{Am}$, mas sem resolução suficiente para se observar cada uma delas separadamente.

Embora apresentem diferentes parâmetros tecnológicos a serem otimizados para serem reproduzidos comercialmente em larga escala com objetivo de atuarem como detectores de radiação a temperatura ambiente, os cristais de $\mathrm{TIBr}$ desenvolvidos neste trabalho apresentam resultados significativos em termos de resolução energética, conforme Figura 39, Figura 40 e Tabela 5. Considerando-se diferentes características, tais como elevado custo, necessidade de refrigeração, condições laboratoriais restritas, uso de eletrônica específica, eficiência em coleta de cargas e resolução energética, o $\mathrm{TIBr}$, se comparado a materiais tradicionalmente utilizados, como Si e HGe (germânio hiperpuro), constitui um material bastante promissor. As resoluções energéticas obtidas com os cristais detectores de $\mathrm{TIBr}$ neste trabalho contribuem para essa perspectiva.

A Tabela 5 sumariza os resultados da resistividade e resolução de energia para os cristais produzidos neste trabalho. As amostras obtidas a partir do Crist al do primeiro crescimento foram denominadas S1 e S2; as amostras obtidas a partir do cristal de segundo crescimento foram denominadas $\mathrm{S} 3$ e $\mathrm{S4}$, e as do terceiro crescimento, S5 e S6. 
Tabela 5: Valores de resistividade, resolução energética e altura de pulso obtidos para as amostras de cristais semicondutores de $\mathrm{TIBr}$ submetidos ao primeiro, segundo e terceiro crescimentos pelo método de Bridgman.

\begin{tabular}{|c|c|c|c|c|c|c|}
\hline Crescimento & \multicolumn{2}{|c|}{ Primeiro } & \multicolumn{2}{|c|}{ Segundo } & \multicolumn{2}{|c|}{ Terceiro } \\
\hline Amostra & S1 & S2 & S3 & S4 & S5 & S6 \\
\hline $\begin{array}{c}\text { Espessura } \\
(\mathrm{mm})\end{array}$ & 0.55 & 0.7 & 0.65 & 0.65 & 0.65 & 0.7 \\
\hline $\begin{array}{c}\text { Resistividade } \\
\left(10^{10} \Omega \mathrm{cm}\right)\end{array}$ & 0.46 & 1.8 & 5.7 & 3.8 & 5.2 & 8.3 \\
\hline $\begin{array}{l}\text { Resolução } \\
\text { Energética }\end{array}$ & $\begin{array}{l}\text { Sem } \\
\text { foto } \\
\text { pico }\end{array}$ & $\begin{array}{l}\text { Sem } \\
\text { foto } \\
\text { pico }\end{array}$ & $\begin{array}{c}28 \mathrm{keV} 34 \% \\
59.5 \mathrm{keV} 23 \% \\
81 \mathrm{keV} 16 \%\end{array}$ & $\begin{array}{c}28 \mathrm{keV} 38 \% \\
59.5 \mathrm{keV} 25 \% \\
81 \mathrm{keV} 17 \%\end{array}$ & $\begin{array}{c}28 \mathrm{keV} 38 \% \\
59.5 \mathrm{keV} 35 \% \\
81 \mathrm{keV} 22 \%\end{array}$ & $\begin{array}{c}28 \mathrm{keV} 27 \% \\
59.5 \mathrm{keV} 35 \% \\
81 \mathrm{keV} 18 \%\end{array}$ \\
\hline $\begin{array}{l}\text { Altura de } \\
\text { Pulso } \\
\text { (canais) }\end{array}$ & & & $\begin{array}{c}28 \mathrm{keV}(71) \\
59.5 \mathrm{keV}(161) \\
81 \mathrm{keV}(227)\end{array}$ & $\begin{array}{c}28 \mathrm{keV}(50) \\
59.5 \mathrm{keV}(135) \\
81 \mathrm{keV}(186)\end{array}$ & $\begin{array}{c}28 \mathrm{keV}(109) \\
59.5 \mathrm{keV}(233) \\
81 \mathrm{keV}(322)\end{array}$ & $\begin{array}{c}28 \mathrm{keV}(116) \\
59.5 \mathrm{keV}(255) \\
81 \mathrm{keV}(376)\end{array}$ \\
\hline
\end{tabular}

Não foi observada diferença significativa nos valores de resistividade e resolução de energia do cristal crescido duas vezes e no crescido três vezes, mas a altura de pulso foi melhorada no terceiro crescimento provavelmente devido a uma melhor coleta de cargas, permitindo observar melhor as linhas de baixas energias do ${ }^{241} \mathrm{Am}$ (Figura 39a). Estes detectores mostraram bom desempenho como detectores de radiação gama, à temperatura ambiente. No entanto, para obter uma melhor resolução energética é necessário melhorar a coleta de cargas [14,19,42,49,91]; para atingir esta meta, mais purificações devem ser realizadas a fim de reduzir as impurezas e reduzir os processos de armadilhamento de cargas. A presença de impurezas e possível formação de defeitos pontuais na estrutura cristalina constituem um tema extremamente importante no estudo para desenvolvimento de semicondutores, especialmente naqueles aplicados como detectores de radiação. Essa importância se deve ao fato de originarem falhas pontuais, planares ou mesmo volumétricas na estrutura e na superfície cristalina, comprometendo o desempenho dos materiais quanto ao transporte de carga e energia. Pode-se definir uma superfície ou interface como uma região do sistema, ou, nesse caso específico, um material, em que há uma mudança abrupta nas suas propriedades em função da distância. Dentre as propriedades que representam mudanças abruptas, podem ser citadas: estrutura cristalina, densidade, orientação cristalina, composição química, etc. 
A polarização é ainda um fator que tem limitado o uso do cristal $\operatorname{TIBr}[43,44,46$ 48]. Esse fenômeno é descrito na literatura [43,44,46-48], como uma redução gradual da corrente do detector e de uma progressiva redução da altura do pulso ao longo do tempo. Neste trabalho, a redução nos valores de altura de pulso não foi observada por um período de medição contínua de 10 horas. Para as amostras do terceiro crescimento, observou-se que, depois de algumas horas sem aplicação de tensão, a corrente inicial do detector sempre retorna à condição inicial. Este resultado pode ser explicado devido à melhor estrutura do cristal que permite taxas de utilização de armadilhas de portadores de carga sem aplicação de tensão. Os detectores do terceiro crescimento têm sido utilizados por três meses, nessa condição, sem mostrar a redução da altura do pulso. Estudos futuros podem ser realizados para entender melhor esse fenômeno, considerando, inclusive, a probabilidade de ocupação no transporte de cargas.

A Figura 41 apresenta o espectro de energia do cristal de $\mathrm{TIBr}$ purificado por refino zonal com 50 passos, em um trabalho de doutorado realizado no CTR/IPEN [4], para fins de comparação. A Tabela 6 sumariza os valores de resistividade e resolução energética dos detectores de radiação confeccionados com cristais de $\mathrm{TIBr}$ purificados por refino zonal com 50 passos [4] e aqueles submetidos a três purificações por método de Bridgman Repetido. Como pode ser visto nessa Tabela, os valores obtidos pelas duas técnicas foram comparáveis, sendo que o método de purificação por Bridgman repetido representa melhores resultados. A partir do cristal crescido pelo método de Bridgman repetido foi possível observar os picos de escape do Tálio (utilizando-se a fonte de ${ }^{133} \mathrm{Ba}$ ) e as linhas de baixa energia de 13,9 keV e 17,7 keV (utilizando-se a fonte ${ }^{239} \mathrm{Am}$ ), além dos picos de $81 \mathrm{keV}$ e de $59,5 \mathrm{keV}$ das fontes de ${ }^{133} \mathrm{Ba} \mathrm{e}{ }^{239} \mathrm{Am}$, respectivamente, conforme Figura 40 . Muitos fatores podem influenciar na escolha da técnica a ser utilizada (Bridgman repetido ou refino zonal), dentre eles quantidade de material de partida, geometria dos cadinhos, fornos disponíveis e tempo para conclusão dos crescimentos $[1,3,4,6,11,12,19,22,33,91,97]$. 


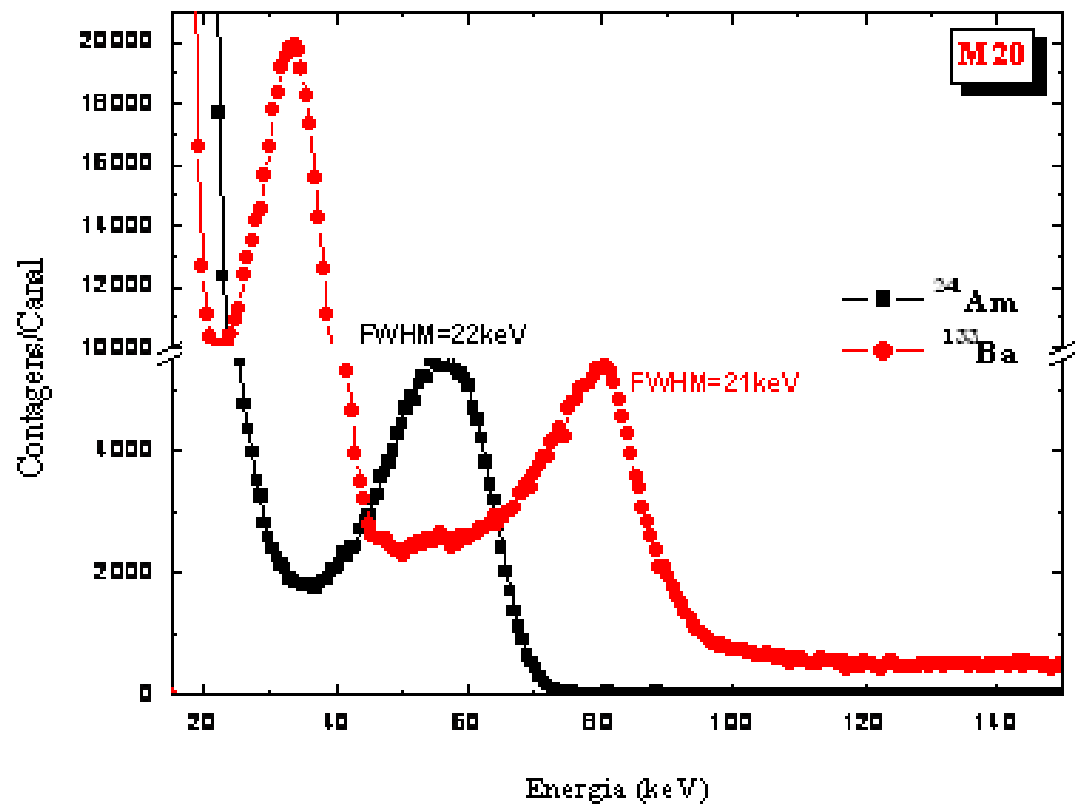

Figura 41: espectro de energia do cristal de $\mathrm{TIBr}$ purificado por refino zonal com 50 passos [4].

Tabela 6: Valores de resistividade, energia e resolução energética obtidos para os métodos de Bridgman e refino zonal [4].

\begin{tabular}{|c|c|c|c|c|}
\hline Cristal & $\begin{array}{c}\text { Método de } \\
\text { Purificação }\end{array}$ & Resistividade( $\Omega$ ) & Energia & Resolução \\
\hline 1 & Bridgman & $8,3 \times 10^{10}$ & $59,5 \mathrm{keV}$ & $35 \%$ \\
& & & $81,0 \mathrm{keV}$ & $18 \%$ \\
\hline 2 & Refino Zonal & $4,0 \times 10^{10}$ & $59,5 \mathrm{keV}$ & $37 \%$ \\
& & & $81,0 \mathrm{keV}$ & $25 \%$ \\
\hline
\end{tabular}

Estes resultados demonstram a importância da pureza do cristal de $\mathrm{TIBr}$ para sua aplicação como detector de radiação. A resolução e eficiência do detector são influenciadas pelo armadilhamento dos portadores de cargas devido a impurezas presentes no cristal. Isso sugere que purificações adicionais são efetivas para melhorar a resolução de um detector. 


\section{CONCLUSÕES}

O método de Bridgman Repetido mostrou ser eficiente para crescimento e purificação dos cristais de TIBr.

Foi observada uma melhora significativa na cristalinidade e transparência do cristal obtido no terceiro crescimento comparado ao do segundo e primeiro crescimento. Estes resultados demonstram a eficiência de purificação da técnica de Bridgman repetido.

Os cristais obtidos no terceiro crescimento apresentaram transparência e coloração característica (amarelo transparente) de $\mathrm{TIBr}$.

Estruturas semelhantes ao modelo cúbico cristalino do $\mathrm{TIBr}$ foram encontrados para os cristais desenvolvidos. O nível de impureza presente nos cristais estudados não interferiu nas suas estruturas cristalinas. Os difratogramas apresentados indicam que os cristais são, preferencialmente, orientados no sentido (110) e (211). Estes resultados estão de acordo com a literatura[1,4,6,7,10,12-14].

Uma boa morfologia com uniformidades nas camadas foi observada na superfície dos cristais crescidos. As incrustações de elementos distintos ao cristal ficaram mais evidentes nas superfícies de cristais obtidos no terceiro crescimento devido à superfície mais uniforme em função da pureza do cristal.

Pela análise de MEV- SE foi comprovada a estequiometria adequada de TIBrnos cristais desenvolvidos.

O modelo compartimental definido a partir de equações diferenciais pode ser usado para calcular o coeficiente de segregação das impurezas, que pode ser extremamente útil em análises microestruturais e de fenômenos de transporte na estrutura dos cristais. Pode-se, ainda, prever e analisar a taxa de diminuição da concentração de impurezas nas diferentes regiões do cristal (compartimentos) em função do número de repetições do processo de purificação. 
Para os cristais de $\mathrm{TIBr}$ crescidos duas e três vezes foram observados fotopicos definidos nos seus espectros de altura de pulso. No entanto, para o cristal de $\mathrm{TIBr}$ crescido apenas uma vez, foi possível observar a resposta da radiação apenas no modo de corrente. Para esses detectores, o modo de pulso não foi observado devido a uma baixa resposta de radiação e um sinal de ruído elevado.

Não foi observada diferença significativa nos valores de resistividade $\mathrm{e}$ resolução de energia do cristal crescido duas vezes e no crescido três vezes. A altura de pulso foi melhorada no terceiro crescimento, provavelmente devido a uma melhor coleta de cargas, permitindo observar melhor as linhas espectrais de baixa energia do ${ }^{241} \mathrm{Am}$.

\section{SUGESTÕES DE TRABALHOS FUTUROS}

A pesquisa de cristais semicondutores de $\mathrm{TIBr}$ aplicados como detectores de radiação a temperatura ambiente ainda apresenta muitos parâmetros a serem otimizados para garantir uma performance adequada à longo prazo direcionada a obtenção de detectores comerciais. Dentre as muitas possibilidades de trabalhos de pesquisa, tanto teóricos quanto experimentais, podem ser citados:

- Modernização dos sistemas de automação utilizados nos fornos de crescimento de cristais, com o objetivo de minimizar possíveis oscilações e otimizar o controle térmico;

- Estudo de diagramas de equilíbrio de fases associado aos processos de segregação de impurezas presentes e a processos de purificação;

- Estudo das relações entre espessura dos cristais, resolução energética e eficiência de coleta de cargas. 


\section{REFERÊNCIAS BIBLIOGRÁFICAS}

1. MCGREGOR, D.S.; HERMON H.Room-temperature compound semiconductor radiation Detectors.Nucl. Instr and Meth. Phys. Res., v.A395, p.101-124, 1997.

2. KNOLL, G.F. Radiation Detection and Measurement. $3^{\circ}$ ed. New York, N.Y.: John Wiley \& sons, 2009.

3. OLIVEIRA, I.B. Desenvolvimento e caracterização do detector semicondutor de $\mathbf{P b l}_{2}$. São Paulo: 2001. Dissertação (Mestrado) IPEN/CNEN - USP.

4. OLIVEIRA, I.B. Desenvolvimento de cristal semicondutor de $\mathrm{TIBr}$ para aplicação como detector de radiação. São Paulo, 2006. Tese (Doutoramento) - IPEN/CNEN - USP.

5. HITOMI, K.; SHOJI, T.; et al. Radiation Damage Effects by $25 \mathrm{MeV}$ Protons and thermal anneleing effects on thalium bromide nuclear radiation detectors. IEEE Trans. Nuc. Sci., vol.46, p. 213-217, 1999.

6. SCHLESINGER, T.E.; JAMES, R.B.Semiconductors for Room Temperature Nuclear Detector Applications, Semiconductors and Semimetals,vol.43, cap.12, San Diego: Academic Press, 1995.

7. SHAH, K.S.; OLSCHNER, F.; et al. Characterization of thallium bromide nuclear detectors. Nucl. Instr. and Meth. Phys. Res., vol.A299, p.57-59, 1990.

8. BARBOSA, L.B. Preparação e propriedades elétricas e ópticas de cristais de $\mathbf{P b l}_{2}$. São Paulo: 1999. Dissertação (Mestrado) - Instituto de Física de São Carlos, USP. 
9. HITOMI, K.; KIKUCHI, Y.; SHOJI, T.; ISHII, K. Improvement of energy resolutions in $\mathrm{TIBr}$ detectors. Nucl. Instr and Meth. Phys. Res., vol.A607, p.112-115, 2009.

10. ELSHAZLY, E.S.; TEPPER, G.; BURGER, A. Charge trapping in detector grade thallium bromide and cadmium zinc telluride: Measurement and theory. Nucl. Instr and Meth. Phys. Res., vol.A620, p.279-284, 2010.

11. KOZLOV, V.; HEIKKILA, M.; KOSTAMO, P.; LIPSANEN, H.; LESKELA, M. TIBr purification and single crystal growth for the detector applications. Nucl. Instr and Meth. Phys. Res., vol.A633, p.s72-s74, 2011.

12. MADELUNG, O. Semiconductors: Data Handbook. 3ํㅡ. Ed., Spriger, U.S.A, caps. 1, 21 e 23, 1999.

13. SELLIN, P. Recent advances in compound semiconductor radiation detectors. Nucl. Instr. and Meth. Phys. Res., vol. A513, pp.332-339, 2003.

14. OlIVEIRA, I.B.; COSTA, F.E.; CHUBACI, J.F.D.; HAMADA, M.M. Purification and preparation of $\mathrm{TIBr}$ crystals for room temperature radiation detector applications. IEEE. Trans. Nucl. Sci., vol.51, pp. 1224-1228, June 2004.

15. KOUZNETSOV, M.S.; LISITSKY, I.S.; ZATOLOKA, S.I.; GOSTILO, V.V. Development of the technology for growing $\mathrm{TIBr}$ detector crystals. Nucl. Instr. and Meth. Phys. Res., vol. A531, pp.174-180, 2004.

16. PONPON, J.P.; AMANN, M. Etching of mercuric iodide in cation iodide solutions. Applied Surface Science, vol.252, pp.6313-6322, 2006.

17. AHORANTA, J.; UUNILA, M.; HUOVELIN, J.; ANDERSSON, H.; VAINIO, R.; VIRTANEN, A.; KETTUNEN H. Radiation hardness studies of CdTe and Hgl2 for the SIXS particle detector on-board the BepiColombo spacecraft. Nucl. Instr. And Meth. Phys. Res., vol. A605, pp. 344-3491, 2009. 
18. COSTA, F.E., Desenvolvimento de Sondas Cirúrgicas Radioguiadas com Semicondutores de TIBr e com Cristais Cintiladores de CsI(TI). São Paulo: 2006. Tese (Doutoramento), IPEN/CNEN - USP.

19. SANTOS, R.A.; MESQUITA, C.H.; COSTA, F.E.; MARTINS, J.F.T.; HAMADA, M.M. Dependence of the Radiation Response on the $\mathrm{TIBr}$ Crystal Purity. Symposium on Radiation Measurements and Applications. University of Michigan, Ann Arbor, Michigan, U.S.A.,2010.

20. VOSS, L.F., CONWAY, A.M. E col. Surface processing of $\mathrm{TIBr}$ for improved gamma spectroscopy.IEEE Trans. Nuc. Sci., R05-27 p. 3746-3748, 2010.

21. MARTINS, J.F.T. Desenvolvimento Do Cristal Semicondutor De lodeto De Mercúrio Para Aplicação Como Detector De Radiação. São Paulo: 2011. Dissertação (Mestrado) - IPEN/CNEN - USP.

22. PFANN, W.G. Zone Melting. New York, John Wiley, 1958.

23. HITOMI, K.; ONODERA, T.; SHOJI, T. Influence of zone purification process on tlbr crystals for radiation detector fabrication. Nucl. Instr. and Meth. Phys. Res., vol. A579, pp.153-156, 2007.

24. HITOMI, K.; MURAYAMA, T.; SOJI, T.; SUEHIRO, T.; HIRATATE, Y. Improved spectrometric characteristics of thallium bromide nuclear radiation detectors. Nucl. Instr. and Meth. Phys. Res., vol.A 428, pp. 372-378, 1999.

25. HOFSTADTER, R. Thallium Halide Crystal Counter, Physical Review Letters, vo. $71,1120,1947$.

26. LEFKOWITZ, I.; LOWNDES, R. P. E YOFFE, A. D. Direct observation of excitons in some thallous halide single crystals. J. Phys. Chem. Solids., vol. 26, pp. 1171-1175, 1965. 
27. MORSE, G.E. e LAWSON, A. W. The temperature and pressure dependence of the elastic constants of thallium bromide.J. Phys. Chem. Solids. vol. 28, pp. 939-950, 1967.

28. OVERHOF, H. e TREUSCH, J. The energy bands of thallous chloride and bromide. Solid State Communications, vol. 9, pp.53-56, 1971.

29. KAPATA, J. e SKUDLARSKI, K. Resolving of the mass spectra of double salt system with the common cation. Internationul Journal of Mass Spectrometry and Ion Physics, vol.47, pp. 257-260, 1983.

30. SKUDLARSKI, K. e KAPALA, J. Thermodynamics of the sublimation of thallium halides investigated by the mass-spectrometric method. J. Chem. Thermodynamic, vol.16, pp. 91-100, 1984.

31. RAHMAN, I.U.; FISHER, W.A.; HOFSTADTER, R.; JING, S. Behavior of thallium bromide conduction counters. Nucl. Instr. and Meth. Phys. Res., vol. A 261, pp. 427-439, 1987.

32. LUCA, L.; GIORGIANNI, U.; PERILLO, P.; SAITTA, G. Spectroscopic studies of complex ion centres in thallium bromide solutions. J. Phys. Chem. Solids vol. 49, no. 4, pp. 363-368, 1988.

33. HITOMI, K.; MUROI, O.; MATSUMOTO, M.; HIRABUKI, R.; SHOJI T.; SUEHIRO, T.; HIRATATE, Y. Recent progress in thallium bromide detectors for $\mathrm{X}$ - and gama-ray spectroscopy. Nucl. Instr. and Meth. Phys. Res., vol. A458, pp. 365-369, 2001.

34. GOSTILO, V.; OWENS, A.; BAVDAZ, M.; LISJUTIN, I.; PEACOCK, A.; SIPILA, $\mathrm{H}$; ZATOLOKA, S. A comparison of the X-ray performance of $\mathrm{TIBr}$ crystals grown by the Bridgeman-Stockbarger and travelling molten zone methods. Nucl. Instr. and Meth. Phys. Res., vol. A509, pp. 47-51, 2003. 
35. ZHOU, D.; QUAN, L.; CHEN, X.; YU, S.; WANG, C.; ZHENG, Z. A Novel Method to Grow Thallium Bromide Single Crystal and Crystal. Crystal Growth \& Design, vol. 9, No. 10, pp. 4298-4300, 2009.

36. TADA, T.; HITOMI, K.; TANAKA, T.; WU, Y.; YUNKIM, S.; YAMAZAKI, H.; ISHII $\mathrm{K}$. Digital pulse processing and electronic noise analysis for improving energy resolutions in planar $\mathrm{TIBr}$ detectors. Nucl. Instr. and Meth. Phys. Res., vol.A638, pp. 92-95, 2011.

37. KOSTAMO, P.; SHOROHOV, M.; GOSTILO, V.; SIPILA, H.; KOZLOV, V.; LISITSKY, I.; KUZNETSOV, M.; LANKINEN, A.; DANILEWSKY, A.N.; LIPSANEN, H.; LESKELA, M. Characterization of $\mathrm{TIBr}$ for X-ray and g-ray detector applications. Nucl. Instr. and Meth. Phys. Res., vol. A607, pp. 129131, 2009.

38. KOZLOV, V.; ANDERSSON, H.; GOSTILO, V.; KEMELL, M.; KOSTAMO, P.; KOUZNETSOV, M.S.; LESKELA, M.; LIPSANEN, H.; LISITSKY, I.S.; SHOROHOV, M.; SIPILA, H. Improvements and problems of BridgmanStockbarger method for fabrication of $\mathrm{TIBr}$ single crystal detectors. Nucl. Instr. and Meth. Phys. Res., vol. A 607, pp.126-128, 2009.

39. HITOMI, K.; KIKUCHI, Y.; SHOJI, T.; ISHII, K. Improvement of energy resolutions in TIBr detectors. Nucl. Instr. and Meth. Phys. Res., vol.A607, pp. 112-115, 2009.

40. KAZUKAUSKAS, V.; ZIMINSKIJ, A.; VAITKUS, J. V.; GOSTILO, V.; SHOROHOV, M. Photoelectrical properties of $\mathrm{TIBr}$ related to ionic transport and presence of defects. Nucl. Instr. and Meth. Phys. Res., vol.A607, pp. 123-125, 2009.

41. GAZIZOV, I.M.; ZALETIN, V.M. The Sensitivity of Pure and Doped $\mathrm{TIBr}$ Crystals. IEEE Trans. Nuc. Sci.,R05-4 pp. 3704-3708, 2010. 
42. SANTOS, R.A.; MESQUITA, C.H.; COSTA, F.E.; MARTINS, J.F.T.; COTRIN, M.E.B.; HAMADA, M.M. Influence of the TIBr crystal impurities on the detector performance. VIII Encontro da Sociedade Brasileira de Crescimento de Cristais, São Carlos, Brasil, 2010.

43. KOZLOV, V.; KEMELL, M.; VEHKAMAKI, M.; LESKELA, M. Degradation effects in $\mathrm{TIBr}$ single crystals under prolonged bias voltage. Nucl. Instr. and Meth. Phys. Res., vol.A 576, pp.10-14, 2007.

44. HITOMI, K., SHOJI, T., NIIZEKI, Y. A method for suppressing polarization phenomena in $\mathrm{TIBr}$ detectors. Nucl. Instr. and Meth. Phys. Res., vol.A585, pp. 102-104, 2008.

45. GAZIZOV, I. M. The Vacancy-Cluster Mechanism of Photocurrent Degradation in $\mathrm{TIBr}$ Detectors under y-irradiation. IEEE Trans. Nuc. Sci.,R05-7 pp. 3709$3715,2010$.

46. KOZOREZOV, A.; GOSTILO, V.; OWENS, A.; QUARATI, F.; SHOROHOV, M.; WEBB, M. A. E WIGMORE, J. K. Polarization effects in thallium bromide $x$-ray detectors. Journal of Applied Physics, vol. 108, 064507, pp. 1-10, 2010.

47. DÖNMEZ, B.; THRALL, C.L.; HE,Z., CIRIGNANO, L.J.; KIM, H. e SHAH, K.S.. Investigation of Polarization Effect with $\mathrm{TIBr}$ Detectors at Different Operating Temperatures. IEEE Trans. Nuc. Sci.,R05-43 pp. 3773-3775, 2010.

48. ONODERA, T.; HITOMI, K.; SOJI, T. Spectroscopic performance and long-term stability of Thalium bromide radiation detectors. Nucl. Instr. and Meth. Phys. Res., vol. A568, pp. 433-436, 2006.

49. COSTA, F.E.; RELA, P.R.; OLIVEIRA, I. B.; PEREIRA, M.C.C.; HAMADA, M.M. Surgical Gamma Probe with $\mathrm{TIBr}$ Detector Semiconductor for Identification of Sentinel Lymph Node. IEEE. Trans. Nucl. Sci., vol. 53, pp. 1403-1407, 2006. 
50. HITOMI, K.; ONODERA, T.; SHOJI, T.; HE, Z. Pixellated TIBr detectors with the depth sensing technique. Nucl. Instr. And Meth. Phys. Res., vol. A578, pp.235-238, 2007.

51. VIEIRA, C.L.; COSTA, F.E.; HAMADA, M.M. Effect of etching on the TIBr crystal surface and its radiation response. International Nuclear Atlantic Conference, INAC, Santos, Brasil, 2007.

52. KIIM, H.; CHURILOV, A.; CIAMPI, G.; CIRIGNANO, L.; HIGGINS, W.; KIM, S.; OLSCHNER,F.Continued development of thallium bromide and related compounds for gamma-ray spectrometers. Nucl. Instr. and Meth. Phys. Res., vol. A629, pp.192-196, 2011.

53. HITOMI, K.; MATSUMOTO, M.; e coll. Characterization of thallium bromide crystals for radiation detector applications. Journal Crystal Growth, vol.225, p. 129-133, 2001.

54. HITOMI, K; MUROI, O.; e col. Thalium bromide photodetectors for scintillation detection. Nucl. Instr. and Meth. Phys. Res., vol.A448, p.571-575, 2000.

55. FARRELL, R.; OLSCHNER, F.; e col. Advances in semiconductor photodetectors for scintillators. Nucl. Instr. and Meth. Phys. Res., vol.A387, p.194-198, 1997.

56. GRIGORJEVA, L.; MILLERS, D. The model of recombination process in TIBr. Nucl. Instr. and Meth. Phys. Res., vol.B191, pp.131-134, 2002.

57. GRIGORJEVA, L.; MILLERS, D.; SHOROHOV, M.; LISITSKII, I.S.; KUZNETSOV, M.S.; ZATOLOKA, S.; GOSTILO, V. Optical investigations of $\mathrm{TIBr}$ detector crystals. Nucl. Instr. and Meth. Phys. Res., vol. A 531, pp.197$201,2004$. 
58. VAITKUS, J.; GOSTILO, V.; JASINSKAITE, R.; MEKYS, A.; OWENS, A.; ZATOLOKA, S.; ZINDULIS, A. Investigation of degradation of electrical and photoelectrical properties in TIBr crystals. Nucl. Instr. and Meth. Phys. Res., vol.A 531, pp.192-196, 2004.

59. GOSTILO, V.; GRYAZNOV, D.; LISJUTIN I. Technological limitations and processing-generated defects at the development of pixel and strip arrays. Nucl. Instr. and Meth. Phys. Res., vol.A 487, pp.13-18, 2002.

60. OWENS, A.; BAVDAZ, M.; BRAMMERTZ, G.; GOSTILO, V.; HAACK, N.; KOZOREZOV, A.; LISJUTIN, I.; PEACOCK, A.; ZATOLOKA S. Hard X-ray spectroscopy using a small-format $\mathrm{TIBr}$ array. Nucl. Instr. and Meth. Phys. Res., vol.A 497, pp.359-369, 2003.

61. ONODERA, T.; HITOMI, K.; SHOJI, T.; HIRATATE, Y. Pixellated thallium bromide detectors for gamma-ray spectroscopy and imaging. Nucl. Instr. and Meth. Phys. Res., vol.A 525, pp.199-204, 2004.

62. HZWSOW, D. C.; e STEVZWSOW, J. R. Optical Constants of T1C1 and T1Br with a Comparison of the Kramers - Kronig and "Two-Angle" Methods of Data Analysis. Physical Review, vol.59, no 3, 1967.

63. BERKOWITZ, J.; e WALTER, T. A.Photoionization of HighTemperature Vapors IV. TIF, TICI, and TIBr. J. Chem. Physics., vol. 49, no 3, pp.1184 - 1189, 1698.

64. BROTHERS, A. D. e LYNCH, D. W. Optical Properties of AgCl, AgBr, T1C1, and $\mathrm{T} 1 \mathrm{Br}$ under Hydrostatic Pressure. Physical Review, vol. 180, № 3, pp. 911918, 1969.

65. GRIFFINI, E.; LONGHI, P.; MUSSINI, T. e RONDININI, S. Standard potentials for the (thallium amalgam + aqueous thallous bromide) electrode from 283.15 to $343.15 \mathrm{~K}$ and for the (thallium + aqueous thallous bromide) electrode from 288.15 to $308.15 \mathrm{~K}$, and thermodynamic solubility product of aqueous thallous 
bromide from 283.15 to 343.15 K. J. Chem. Thermodynamics, vol. 13, pp. 843-848, 1981.

66. WANG, J.X.; ROBINSON, I.K.; ADZIC R.R. Formation of well-ordered surface compounds by coadsorption of thallium and bromide on the $\mathrm{Au}(111)$ electrode surface. Surface Science no-412/413, pp. 374-383, 1998.

67. SECCO, E.A.; SECCO, R. A. Cation conductivity in mixed thallium halides. Solid State lonics, vol.118, pp. 37-42, 1999.

68. DestefanO, N.; MULATO, M. Influence of multi-depositions on the final properties of thermally evaporated TIBr films. Nucl. Instr. and Meth. Phys. Res., vol.A624, pp. 114-117, 2010.

69. AMRANE, N.;BENKRAOUDA, M.;HAMED, F. Ab Initio Calculations of Optical Properties of TIBr and TICI Radiation Detectors. J. of Cond. Matter Phys., vol. 1, pp. 63-69, 2011.

70. YUN, S.; LIM, C.H.; KIM, H.K.; TANGUAY, J.; CUNNINGHAM, I.A. Finding the best photoconductor for digital mammography detectors. Nucl. Instr. and Meth. Phys. Res., vol.A652, pp. 829-833, 2011.

71. CULLITY, B. D. Elements of x-ray diffraction. 3a Ed. Massachusetts, Addison-wesley publishing company, inc., 1956.

72. MILLMAN, J.; HALKIAS, C.C. Eletrônica: Dispositivos e Circuitos. $1^{\circ} \mathrm{Ed}$. McGraw-Hill do Brasil, 1981.

73. KITTEL, C. Introdução à Física do Estado Sólido.8aㅡ Ed. Brasil, LTC, 2006.

74. GARCIA, A. Solidificação - fundamentos e aplicações. 1ำ Ed. Editora Unicamp, Brasil, 2001. 
75. BUCKLEY, H.E. Crystal Growth. 1a Ed. New York, John Willey, 1950.

76. HOFFMANN, E. e STROOBANT V.Mass Spectrometry-Principles and Applications. 3a Ed. New York, John Willey, 2007.

77. GOLDSTEIN, J.I.; NEWBURY, D.E.; et. al. Scanning Electron Microscopy and X-ray microanalysis. Springer, 2007.

78. BERMAN, M. The formulation and testing of models, Ann NY Acad. Sci., pp.182-94, 1963.

79. BEVINGTON, P.R. Data Reduction and Error Analisys for The Physical Sciences, McGraw-Hill, New York, U.S.A, pp. 204 - 246, 1969.

80. GOULDEN, C.H. Methods of statistical analysis. 2Ed. New York, John Wiley, 1956.

81. ABRAMOWITZ,M. \& I.A. STEGUN, Laplace Transforms, ch.29, Handbook of Mathematical Functions with Formulas, Graphs and Mathematical Tables, $9^{\text {th }}$ printing, New York, Dover, 1972, pp. 1019 - 1030.

82. BRIDGMAN, P.W. The Thermodynamics of electrical phenomena in metals and a condensed collection of thermodynamic formulas, Dover Publications Inc., New York, U.S.A., 1961.

83. THRALL, C. L., KAYE, W. R., HE Z., KIM H., CIRIGNANO, L. e SHAH, K., Transient Behavior in TIBr Gamma-Ray Detectors and Its Analysis Using 3-D Position Sensing. IEEE. Trans. Nucl. Sci., vol. 60, pp. 1162-1167, 2013.

84. HITOMI, K., TADA, S., ONODERA, T., SHOJI, T., KIM, S.Y., XU, Y. e ISHII, K., Timing Performance of $\mathrm{TIBr}$ Detectors. IEEE. Trans. Nucl. Sci., vol. 60, pp. 2883-2887, 2013. 
85. SMITH III, H., M., ZHOU, Y., CIAMPI G., KIM, H., CIRIGNANO, L., J., SHAH, K., S., HALLER, E., E. E CHRZAN, D., C., First principles and experimental study of the electronic structure and phase stability of bulk thallium bromide. Applied Physics Letters, no. 103, 091901, 2013.

86. KIM, H., CIRIGNANO, L., KARGAR, A., CHURILOV, A., CIAMPI, G., OGORODNIK, Y., HIGGINS, W., KIM, S., OLSCHNER, F. e SHAH, K., Long Term Stability of Thallium Bromide Gamma-Ray Spectrometers. IEEE. Trans. Nucl. Sci., vol.60, pp. 1219-1224, 2013.

87. KUHN, M., BISHOP, S.R., CIAMPI, G., TULLER, H.L., HIGGINS, W., SHAH, K.S., Ionic conduction in $\mathrm{TIBr}$ - Impact of Te acceptor dopant exsolution. Solid State lonics, no. 241, pp.30-35, 2013.

88. CONWAY, A., VOSS, L., F., NELSON, A., J., BECK, P., R., LAURENCE T., A., GRAFF, R. T., NIKOLIC, R., J., PAYNE, S., A., KIM, H., CIRIGNANO, L., J. e $\mathrm{SHAH}, \mathrm{K}$., Fabrication Methodology of Enhanced Stability Room Temperature TIBr Gamma Detectors. IEEE Trans. Nucl. Sci., vol. 60, pp.1231-1236, 2013.

89. KIM, K., H., KIM, E., KIM, H., TAPPERO, R., BOLOTNIKOV, A., E., CAMARDA G., S., HOSSAIN, A., CIRIGNANO, L., e JAMES,R., B., Electro-migration of impurities in TIBr. Journal of Applied Physics, 114, 133701, 2013.

90. HITOMI,K.; TADA,T.;ONODERA, T.;KIM, S.;XU, Y.; SHOJI, T.;ISHII, K. TIBr Capacitive Frisch Grid Detectors. IEEE Trans. Nucl. Sci., vol. 60, pp. 11561161, 2013.

91. SANTOS, R.A.Otimização da metodologia de preparação do cristal de Brometo de Tálio para sua aplicação como detector de radiação. São Paulo: 2012. Dissertação (Mestrado) - IPEN/CNEN - USP. 
92. ZHENG, Z.; MENG, F.; GONG, S.; QUAN, L.; WANG, J.; ZHOU, D., An effective method for thallium bromide purification and research on crystal properties, Nucl. Instr. and Meth. Phys. Res., vol.A 676, pp. 26-31, 2012.

93. PHILLIPS,D., J.;BLAINE, K., E.;CIRIGNANO,L., J.;CIAMPI,G.; HAEGEL,N., M. Cathodoluminescence and Spatial Variation in Mobility-Lifetime Product in Bulk Doped Thallium Bromide, IEEE Trans. Nucl. Sci. VOL. 59, NO. 5, pp. 26082613, 2012.

94. TOSHIYUKI ONODERA, KEITARO HITOMI, CHIKARA ONODERA, TADAYOSHI SHOJI, AND KATSUMI MOCHIZUKI,Characterization of $\mathrm{TIBr}_{x} \mathrm{Cl}_{1-x}$ Crystals for Radiation Detectors, IEEE Trans. Nucl. Sci. VOL. 59, NO. 4, pp. 1559-1562, 2012.

95. BURCIN DONMEZ, ZHONG HE, HADONG KIM, LEONARD J.CIRIGNANO, KANAI S.SHAH, Collection of holes in thick $\mathrm{TIBr}$ detectors at low temperature, Nucl. Instr. and Meth. Phys. Res., vol.A 689, pp. 7-11, 2012.

96. DU,M.,H.First-principles study of impurities in $\mathrm{TIBr}$, Journal of Applied Physics, no. 073519, 2012.

97. KIM, H.;KARGAR, A.;CIRIGNANO,L.;CHURILOV,A.;CIAMPI,G.; HIGGINS,W.;OLSCHNER, F.;SHAH,K. Recent Progress in Thallium Bromide Gamma-Ray Spectrometer Development, IEEE Trans. Nucl. Sci., VOL. 59, NO. 1, pp. 243-248, 2012.

98. T. SEINO,I. TAKAHASHI, T. ISHITSU, K. YOKOI, AND K. KOBASHI, IEEE Trans. Nucl. Sci., R08-2, pp. 4222-4225, 2012.

99. HITOMI,K.; SHOJI,T.;ISHII,K. Advances inTIBr detector development, Journal of Crystal Growth, 371, 2013. 
100. ZHENG, Z.; YU, Y.; GONG, S.; FU, Q.; ZHOU, D.; On thermal conditions and properties of thallium bromide single crystals grown by the Electro Dynamic Gradient method, Journal of Crystal Growth, 371, pp.90-93, 2013.

101. ZHENG, Z.; YU Y.; ZHOU D.; GONG S.; FU Q. Research on annealing and properties of $\mathrm{TIBr}$ crystals for radiation detector use, Nucl. Instr. and Meth. Phys. Res., vol. A 741, pp. 104-107, 2014.

102. HITOMI, K.;ONODERA, T.;YUNKIM,S.; SHOJI,T.;ISHII, K. Characterization of pixelated $\mathrm{TIBr}$ detectors with TI electrodes, Nucl. Instr. and Meth. Phys. Res., vol.A 747, pp. 7-12, 2014.

103. SMITH, III,H., M. NANCY M. HAEGEL, DAVID J. PHILLIPS, LEONARD CIRIGNANO, GUIDO CIAMPI, HADONG KIM, DARYL C. CHRZAN, EUGENE E. HALLER, Electrical and Optical Studies of Deep Levels in Nominally Undoped Thallium Bromide, IEEE Trans. Nucl. Sci., vol. 61, NO. 1, pp. 689694, 2014.

104. HANSSON, C., C., T.; OWENS, A.; J., BIEZEN, V., D. X-ray, Y-ray and nêutron detector development for future space instrumentation, Acta Astronautica, no. 93, pp. 121-128, 2014.

105. WILL KOEHLER, ZHONG HE, CRYSTAL THRALL, SEAN O'NEAL, HADONG KIM, LEONARD CIRIGNANO, KANAI SHAH, Quantitative Investigation of Room-Temperature Breakdown Effects in Pixelated $\mathrm{TIBr}$ Detectors, IEEE Trans. Nucl. Sci., VOL. 61, no. 5, pp. 2573-2578,2014.

106. KORSAKOV, A.; ZHUKOVA, L.; KORSAKOVA, E.; ZHARIKOV, E. Structure modeling and growing $\mathrm{AgCl}_{\mathrm{x}} \mathrm{Br}_{1 \_\mathrm{x}}, \mathrm{Ag}_{1 \_\mathrm{x}} \mathrm{Tl}_{\mathrm{x}} \mathrm{Br}_{1 \_\mathrm{x}} \mathrm{I}_{\mathrm{x}}$, and $\mathrm{Ag}_{1} \mathrm{TTl}_{\mathrm{x}} \mathrm{Cl}_{\mathrm{y}} \mathrm{I}_{\mathrm{z}} \mathrm{Br}_{1 \_y} \mathrm{z}$ crystals for infrared fiber optics, Journal of Crystal Growth, no. 386, pp.94-99, 2014. 
107. RAY, A.; SMITH, III, H., M., HAEGEL, N., M. Temperature dependence of the indirect bandgap in thallium bromide from cathodoluminescence spectroscopy, Journal of Applied Physics no. 115 - 163709, 2014.

108. YOON, DO-K.;JUNG,J., Y.;HAN, S., M.; T., S. Statistical analysis for discrimination of prompt gamma ray peak induced by high energy neutron: Monte Carlo simulation study, Jounalof Radioanalitica Nuclear Chemistry, pp. 859-866, 2015.

109. LANG P., F.; SMITH, B., C. An equation to calculate internuclear distances of covalent, ionic and metallic lattices, Royal Society of Chemistry, no.17, pp.3355-3369, 2015.

110. DATTA A.; BECLA, P.; MOTAKEF, S, Characterization of Stress in Thallium Bromide Devices, IEEE Trans. Nucl. Sci., VOL. 62, NO. 2, pp. 437-442, 2015.

111. DATTA A.; BECLA, P.; MOTAKEF, S. Visualization of $\mathrm{TIBr}$ ionic transport mechanism by the Accelerated Device Degradation technique, Nucl. Instr. and Meth. Phys. Res., no. A784, pp. 37-43, 2015. 